\title{
Zur Verbreitung einiger in Finnland südlichen Pilze, besonders in der südwestlichen Eichenzone
}

\author{
Pavo Kallio
}

\begin{abstract}
Veröffentlichungen des Botanischen Institutes der Universität Turku, Nr 28
\end{abstract}
Der pflanzengeographisch als Eichenzone bezeichnete südliche (südwestliche) Küstenstreifen Finnlands (vgl. Hult 1896; NorRLIN 1910; JALAS 1957) ist zunächst nach der Gefässpflanzenflora und der Vegetation begrenzt worden. Die Pilze sind in Finnland kaum in erwähnenswertem Umfang für diesbezügliche Untersuchungen herangezogen worden, und doch sind die Pilze eine Gruppe, innerhalb welcher die Verbreitungsverhältnisse sich oft nicht wenig empfindlich an bestimmte Züge in der Phanerogamenvegetation anpassen (vgl. PIR K 1944), zugleich aber viele edaphische und klimatische Umstände widerspiegeln. Gleiches gilt für den ganzen Norden, wo die Pilzfloristik insgemein stark vernachlässigt worden ist (vgl. NANNFELDT 1959).

Verfasser hat im Zuge seiner Unterrichtstätigkeit an der Universität Turku während vieler Jahre in den Umgebungen der Stadt Makromyceten gesammelt, in letzter Zeit um zielbewusst ein Bild von der Pilzflora der Eichenstandorte $\mathrm{zu}$ erhalten.

Meinem Freund Professor Dr. Risto Tuomikoski danke ich für reichliches Angabematerial, liebenswürdigen Beistand und ergiebige Besprechungen. Herr Herbert Edelmann übernahm freundlich die Úbertragung des Manuskripts ins Deutsche.

\section{HISTORISCHES}

Es gibt bei uns nur verhältnismässig wenige pilzfloristisch untersuchte Punkte - auch diese fast durchgehends in Südfinnland gelegen - mit deren Hilfe man versucht hat, sich einen allgemeinen Begriff von der Verbreitung der Grosspilze zu bilden. Ein solcher ist vor allem Tammela in der Provinz EteläHäme (EH. Karsten 1868), der langjährige Wohnort des berühmtesten finnischen Mykologen P. A. Karsten (siehe Hintikka 1950). Von anderen von Karsten mykologisch untersuchten Gebieten verdient in diesem Zusammenhang besonders die Gegend von Turku erwähnt zu werden. Ruissalo (bei Karsten in der schwedischen Schreibform Runsala) ist dabei ein in seinen Arbeiten zumal in Verbindung mit südlichen Arten oft sich wiederholender Name. In seiner akademischen Abhandlung (1859, p. 7) schätzt er sich glücklich, zu den von ihm am eingehendsten untersuchten Gegenden »auch Finnlands an Pilzen reichsten Ort, die Insel Runsala rechnen zu können, die in ihren Eichen- und Haselbeständen unsere raresten Pilze, wie z.B. Fistulina hepatica, Daedalea quercina und Polyporus frondosus, hervorbringt». Später haben hier Dr. Lauri E. Kari und Stud.rer.nat. Matti Laurila Pilze gesammelt, ersterer grösstenteils Mikromyceten, letzterer Makromyceten. Die Sammelergebnisse von LAURILA (1939) sind wegen des allzu frühzeitigen Todes des Autors nur zum Teil an die Öffentlichkeit gelangt.

In der Gegend von Viipuri liegt ein von Karstens Schüler ThesLefF (1919) untersuchtes Gebiet, aus dem man ein Bild von 
der pilzfloristischen Natur u.a. der Eichenbestände im östlichen Teil Ostfennoskandiens gewinnt.

Im Schärenhof von Turku, im Gebiet von Varsinais-Suomi (V), Korppoo-Houtskari, unternahm EKLUND $(1943,1944)$ auch mykofloristische Einsammlungen, und auch wenn in bezug auf die Artbestimmungen insonderheit wegen Mangels an Literatur auch Schwierigkeiten bestanden haben mögen, geben uns seine diesbezüglichen Arbeiten immerhin die ersten Hinweise auf die Beschaffenheit dieses Inselgebietes gerade vom Standpunkt der Pilzfloristik und Pilzökologie. Von hier aus besteht ein Anschluss einerseits nach der Gegend von Turku und zweitens nach Ahvenanmaa (A) hin, das in bezug auf seine Pilzflora gleichfalls nicht ganz unbekannt ist, denn hier haben u.a. FREY (1944), Malmström (1943), Stenlid (1947) und v. Schulmann (1960) Grosspilze gesammelt. Die auf das Eichengebiet bei Uusimaa (U), Porvoo bezüglichen Angaben stammen durchgehends von den Sammelbelegen und Mitteilungen Wolmar Nybergs.

Gebiete, in denen fleissiger als anderswo gesammelt worden ist und von wo einige kleine Mitteilungen sowohl in der Literatur als auch Sammelbelege im Botanischen Museum der Universität Helsinki vorliegen, sind ferner die Umgebungen der Hauptstadt und das Gebiet von Tvärminne, wo sich die zoologische Station der Universität Helsinki befindet. Von Schulmann (op.c.) hat ausser auf Ahvenanmaa an verschiedenen Punkten in Südfinnland gesammelt: V. Parainen, Lohja und Karkkila; U. Tammisaari und Elimäki; EH. Lammi; ES. Punkaharju; PK. Parikkala; PS. Lapinlahti. Bei Karsten schliesslich finden sich Angaben u.a. aus der Gegend von Vaasa sowie (1867) aus Ostlappland. Kleine Erwähnungen über die Pilze machen noch Kallio (1959) für Utsjoki und Tuomikoski (1961) für Inari (beide in Inari-Lappland).

Vor allem wegen der schwachen Kenntnis der Grosspilze und bei vielen Arten auch wegen des schwachen Dokumentarwertes der Museumsbelege ist es nicht möglich gewesen, die grosse Schar von biologisch grundgeschulten Liebhabersammlern auszunutzen, deren Einsatz z.B. bei der kartographischen Erschliessung der Phanerogamenflora Finnlands von ausschlaggebender Bedeutung gewesen ist. Nur wenn es sich um irgendeine äusserst leicht kenntliche, auffällige Art handelt, ist bezüglich der Pilze auf eine solche Hilfe zu rechnen. Ein ausgezeichnetes Beispiel bietet Phallus impudicus, über dessen hiesige Verbreitung schon mehrere auf den neuesten Stand ergänzte Kartendarstellungen erschienen sind, in denen der südwestliche Verbreitungscharakter dieses Pilzes in Finnland deutlich hervortritt (THESLEFF 1895; Hintikka 1933; Luther 1947; Laine 1955).

Vorwiegend auf Grund der Literatur, von Belegen in Museen sowie von eigenen Beobachtungen haben es vor allem RAUTAVAARA (1947) und Tuomikoski $(1953,1959)$ unternommen, die Verbreitung der Arten im ganzen Lande übersichtlich darzustellen, mehr als ein Halbjahrhundert nach den ersten diesbezüglichen Äusserungen Karstens.

Manche finnische Mykologen haben in verschiedenen Zusammenhängen die speziellen Probleme namentlich unserer südlichen Pilzflora hervorgehoben und die Existenz eines südwestlichen mykofloristischen Gebietes erkannt (vgl. schon KARste N 1859, p. 7; Hintikka 1931). Besonders EkLUND (1943 b, p. 3) ersah, bei Erörterung der Verbreitung der von der Eiche abhängigen Pilze, die "südliche Frage» in der mykologischen Erforschung des Schärenhofes von Turku, und auch schon Thesleff streift gewissermassen das Thema in seiner Untersuchung vom Jahre 1919. Tuomikos ki (1953) weist in seiner Arbeit über die Gattung Lactarius gleichfalls des öfteren auf das südlichste Finnland hin, anderseits aber auch auf die sich bis nach Lappland erstreckende Verbreitung zahlreicher Arten. Gleiches ergibt sich aus seiner Arbeit von 1959.

\section{DAS UNTERSUCHUNGSGEBIET}

Als eigentliche Untersuchungspunkte wurden auf dem Festland und im innersten Schärenhof von Varsinais-Suomi (V) besonders in der Umgebung der Stadt Turku 13 für das Gebiet typische Ackerhügel und Hainreste mit Eichen sowie trockene (Hang-) Wiesen mit vielen südlichen Gefässpflanzen (z.B. Luzula campestris, Filipendula vulgaris und an- 


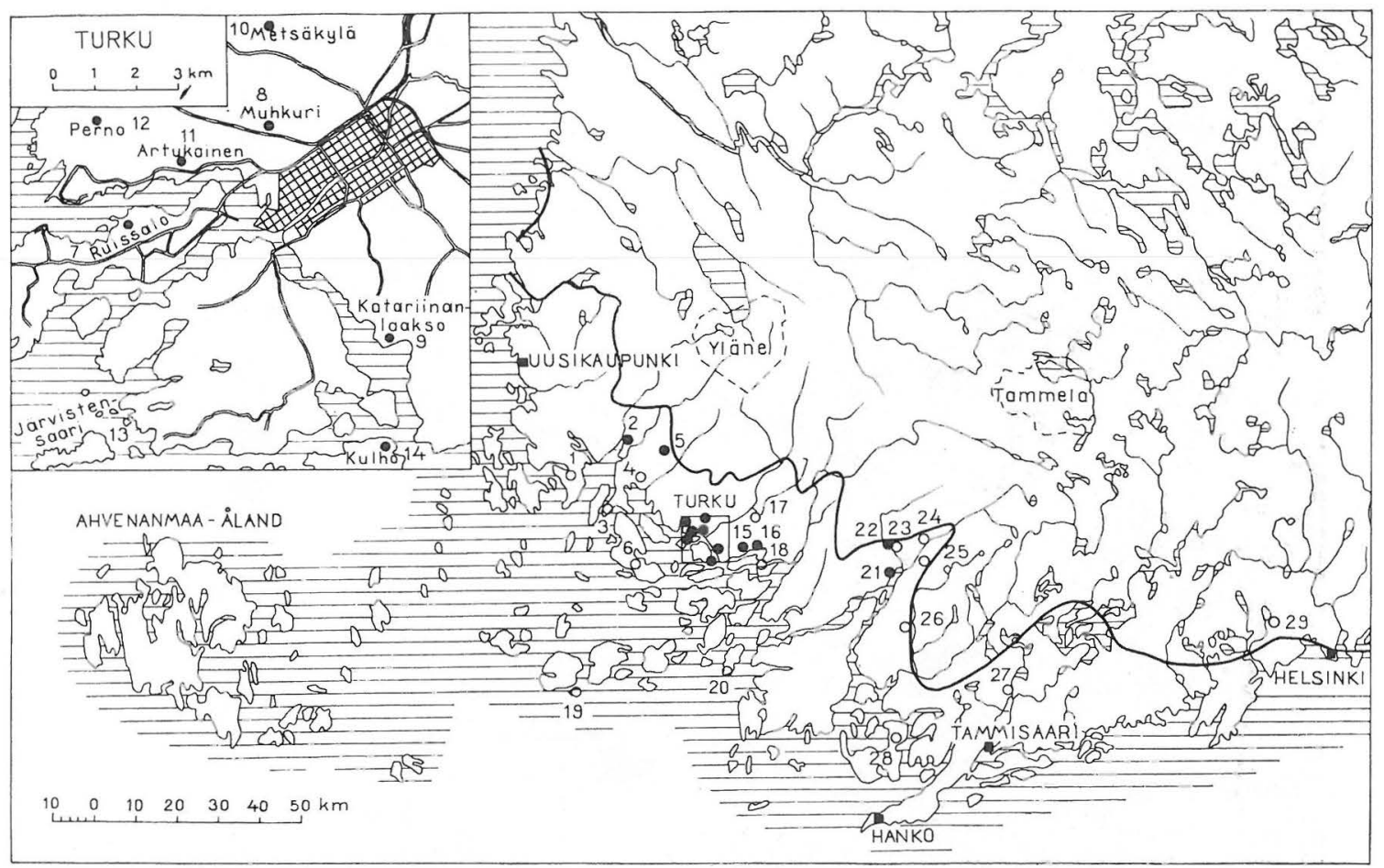

Abb. 1. - Die Untersuchungspunkte. 1. Taivassalo, Ketarsalmi - 2. Mietoinen, Saari - 3. Askainen, Lempisaari - 4. Lemu, Ohensaari - 5. Nousiainen, Linnamäki - 6. Rymättylä, Kepuinen - 7. Turku, Ruissalo - 8. Muhkuri 9. Katariinanlaakso - 10. Metsäkylä - 11. Artukainen — 12. Raisio, Perno - 13. Kakskerta, Järvistensaari - 14. Kakskerta, Kulho - 15. Kaarina, Karpanmäki - 16. Piikkiö, Tuorla - 17. Lieto, Kunnanmäki - 18. Piikkiö, Jauhosaari - 19. Korppoo (Korpo), Lohm - 20. Parainen (Pargas), Attu - 21. Halikko, Vaisakko - 22. Halikko, Pihko - 23. Halikko, Nummi - 24. Uskela, Veitakkala, - 25. Uskela. Tupuri - 26. Perniö, Ylikylä - 27. Pohja, Fiskari — 28. Bromary, Fram näs, - Die Grenze der Eichenzone ist nach Jalas (1957) bezeichnet.

dere aus derselben Verbreitungsgruppe) gewählt (Karte 1). Es ergibt sich daraus eine Begrenzung, die bei der Deutung der Ergebnisse berücksichtigt werden muss. Die Untersuchung bezweckt demnach nicht eine Klärung der Pilzflora der Eichenzone im allgemeinen, sondern lediglich die Herausfindung des mykofloristischen Gepräges eines namentlich für diese Zone kennzeichnenden Standortskomplexes. Gerade hier dürfte nämlich der Zug zu finden sein, der den Pilzbestand des Gebietes am deutslichsten von dem der anderen Vegetationsregionen Finnlands trennt. Es ist wahrscheinlich, dass anderseits z.B. die Pilzflora der dürftigen Kiefernbestände der Felserhebungen das Beispiel eines verbindenden Typs darstellen könnte, der sich im Untersuchungsgebiet vielleicht nur schwach vom Pilzbestand der entsprechenden Standorte z.B. im südlichen Satakunta unterscheidet. Man hat aber zu bedenken, dass sogar im nördlichsten Finnland, auf der birkenreichen, von CladinaArten, Empetrum und Vaccinium vitis-idaea geprägten Kiefernheide von Kevo in Utsjoki $\left(69^{\circ} 45^{\prime}\right.$ n. Br. $)$, die Pilzflora trotz des geographischen Unterschiedes von fast zehn Breitengraden sehr ähnlich derjenigen ist, der man auf der trockenen Kiefernheide (mit Calluna vulgaris, Vaccinium vitis-idaea und vielen Cladina-Arten) von Kankainen in Masku nicht weit von Turku begegnet. Polyporus perennis, Laccaria laccata (und L. proxima), Tricholoma flavovirens, Armillariella mellea, Omphalina ericetorum, Collybia dryophila, Marasmius androsaceus, Amanita muscaria, Cystoderma amianthinum, Naematoloma capnoides, Cortinarius armillatus, C. cinnamomeus, Rozites caperata, Gomphidius viscidus, Suillus luteus, Xerocomus subtomentosus, Boletus edulis, Leccinum scabrum, $L$. testaceo-scabrum, Russula decolorans, $R$. aeruginea, Lactarius rufus, L. mammosus und L. trivialis 


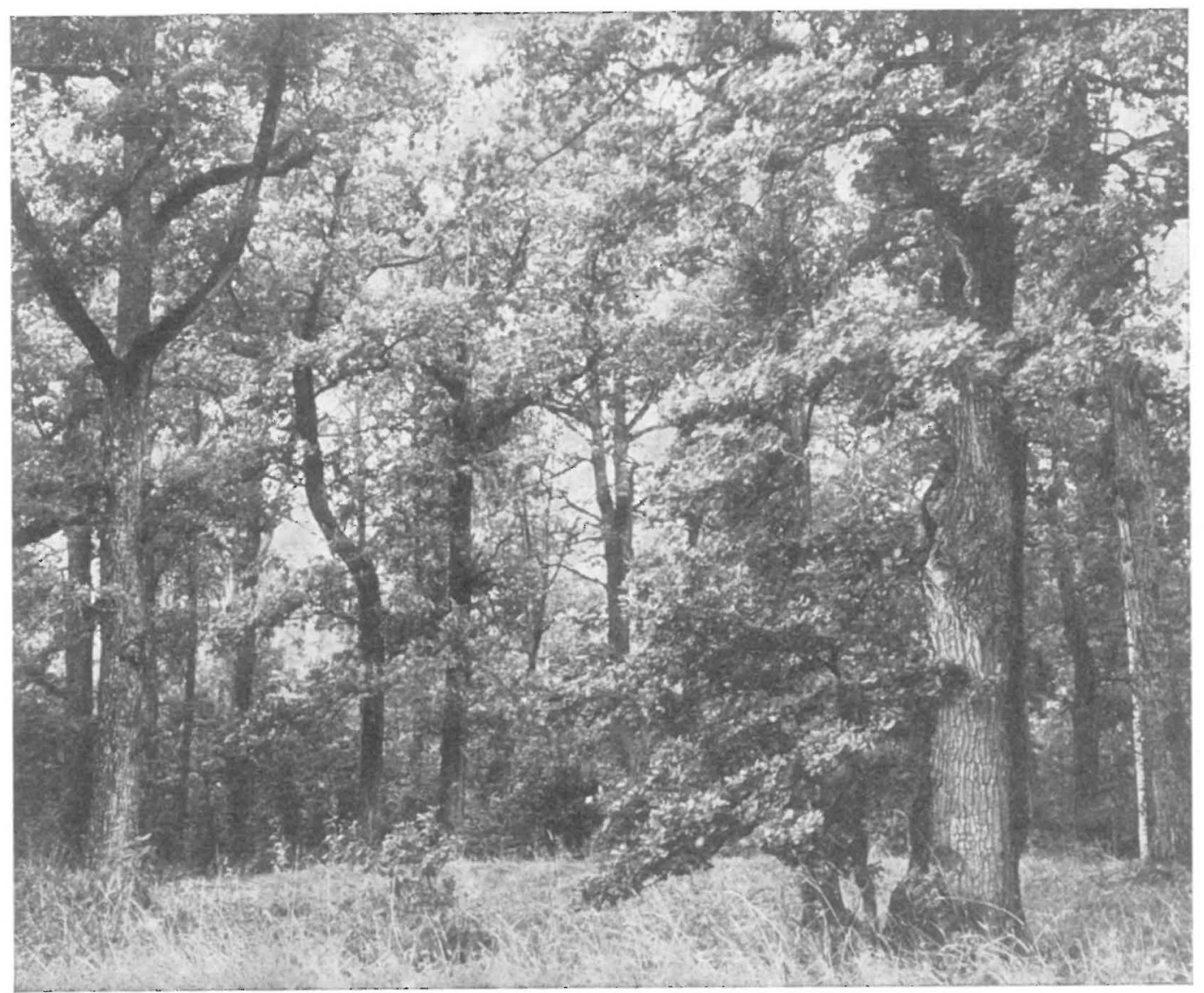

Abb. 2. - Lichter Eichenwald in Ruissalo. Aufn. Matti Uusi-Honko.

stehen an beiden Orten unter den Grosspilzen an wichtiger Stelle. Auch einige "Seltenheiten», wie z.B. Armillaria Goliath (Fr.) Lundell und Tricholoma pessundatum, sind gemeinsam.

Obgleich die Untersuchungspunkte durchgehends Eichenstandorte darstellen, handelt es sich nicht um die Pilzflora der Eichenwälder. Einige untersuchte Punkte bestehen lediglich aus einigen Eichen, umgeben von typischer »Halbkulturwiese», oft auch aus vereinzelten Eichen am Rande von Kiefernwald, usw.

Die folgenden Untersuchungspunkte (Karte 1, Punkte) sind also so gewählt, dass sie a $\mathrm{ch}$ Eichen (einsame Bäume oder Waldungen) enthalten.

Turku, Ruissalo (Nr. 7 auf Karte 1). - Eine etwa $10 \mathrm{~km}^{2}$ grosse, vom Festland nur durch einen schmalen Wasserstreifen getrennte längliche Insel im
Stadtgebiet von Turku. Das Gelände ist uneben, die höchsten Felsenhügel sind etwa $40 \mathrm{~m}$ hoch. Der karge Granit dominiert, dazu gibt es auch etwas Amphibolit. Die niedriggelegenen Punkte sind von Tonsedimenten bedeckt und grossenteils bebaut. Der Einfluss des Menschen in diesem heute vor allem als Rekreationsort für die Städter dienenden Gebiet ist schwächer, als es die stadtnahe Lage erwarten liesse. Eine 8 ha grosse Hainfläche steht unter dem Naturschutz, und so kann Ruissalo in mehr als einer Hinsicht als ein ziemlich idealischer Ort für mykofloristische Untersuchungen betrachtet werden. Die Vegetation (JAHnsson 1929) und Flora (LindgREN 1954) der Insel ist von mehreren Seiten her beleuchtet worden, und eingangs wurde schon auf die mykologischen Untersuchungen von Karsten hier hingewiesen. Das Gebiet zerfällt, offenbar wenigstens zum Teil durch die Gesteinsbeschaffenheit, in einen östlichen Hainteil, in dem auch das ebenerwähnte Hainreservat liegt, und einen westlichen Teil mit vorherrschendem Nadelwald. Der östliche Teil wurde im vorliegenden Zusammenhang genauer untersucht.

Die Flora zeichnet sich namentlich durch die reiche Vertretung des südwestlichen und südlichen Elementes aus, und die grosse Heterogenität der 
Standorte bewirkt es, dass die Anzahl der Phanerogamenarten - im ganzen an die 510 - hier für finnische Verhältnisse sehr hoch ist. Dazu kommt noch, dass viele Inlandarten auf der Insel nur selten zu finden sind. Ganz fehlen in Ruissalo z.B. Lycopodium complanatum, Carex globularis, Gymnadenia conopea, Rubus arcticus, Daphne mezereum, Pyrola chlorantha und Centaurea phrygia, und auch Alnus incana, Cirsium heterophyllum und Hypochoeris maculata gibt es hier wenig; diese letzteren gelten denn auch bei JALAs (1957) als Arten, die vom Inland her ziemlich selten die Grenze der Eichenzone überschreiten.

In etwa der Hälfte der Wälder von Ruissalo dominiert die Eiche, und hier finden sich die zusammenhängendsten, grössten und am wenigsten kulturbeeinflussten Eichenbestände in ganz Finnland. Die frischen Eichenhaine wurden von LEA JAHNSSON (op.c.) nach der Vegetation in die folgenden vier Typen eingeteilt: 1) Milium-Typ, mit der reichsten Feldschicht (durchschn. 20 Phanerogamenarten je $4 \mathrm{~m}^{2}$ ), aber einer verhältnismässig schwachen Moosdecke. 2) Calamagrostis-Typ, weniger reich als der vorige und flächenmässig zurücktretend. 3) Calamagrostis-Myrtillus -Typ, oft mit Kiefern, weist schon deutlich in die Richtung des trockeneren Heidewaldes hin, in der Bodenschicht reichlich zumal Rhytidiadelphus triquetrus, durchschn. 16.7 Phanerogamenarten auf $4 \mathrm{~m}^{2}$.4) Convallaria-Aegopodium -Typ, ein schattiger und dichter Eichen- und Haselstrauchhain, wo Convallaria majalis und Aegopodium podagraria oft je für sich fast reine Bestände bilden und Rhytidiadelphus triquetrus nur stellenweise zusammenhängender auftritt. Weiter hat man hier noch kleine Hainabhänge, die in mehreren anderen Gegenden in Südwestfinnland, wo es Eichen gibt, den einzigen von diesem Baum geprägten Vegetationstyp darstellen. Kennzeichnend für jene gewöhnlich felsigen $\mathrm{Ab}$ hänge sind neben Eiche und Hasel oft Ribes alpinumund Lonicera xylosteum -Gebüsche sowie Dryopteris filix mas, Poa nemoralis, Melica nutans, Carex digitata, Anemone hepatica, A. nemorosa, Corydalis solida, Lathyrus vernus, L. montanus, selten dazu noch Urtica dioica, Actaea spicata, Pulmonaria officinalis und Adoxa moschatellina.

Die Haine sind stellenweise von kleinen Flächen grasheideartiger Vegetation gekantet, die es indessen in Ruissalo nur ziemlich wenig gibt.

Turku, Katariinanlaakso (9). - Ein aus felsigen und bewaldeten Ackerhügeln gebildeter Komplex am Meere, der zweitwichtigste der Untersuchungspunkte. Die Eichen- und Lindenbestände treten hier hauptsächlich an Hainabhängen auf, die in mehreren Beziehungen denen von Ruissalo gleichen. Der Felsgrund besteht hauptsächlich aus Granit, es gibt aber auch stellenweise etwas Amphibolit. Der Waldboden und die Grasheiden zeichnen sich durch ein in hiesigen Verhältnissen recht hohes $\mathrm{pH}-\mathrm{Standard}$ aus, die Werte liegen nämlich bei $6.0-6.2$, und die Flora lässt deutlich einigermassen »basophile» Züge erkennen. Im Vergleich zu Ruissalo sind die in Verbindung mit den genannten Hangwäldern und den Äckern vorkommenden Grasheideflächen reichlicher. Dem Milium- oder Convallaria-Typ von Ruissalo entsprechende frische Haine sind hier nur fragmentarisch vorhanden. Kennzeichnend für die Flora ist das reichliche Vorkommen südlicher Arten zumal der Trockenwiesen (vgl. Nikoskelainen 1955). Ein Verzeichnis wie das nachstehende von einer
Fläche von nur einigen hundert Quadratmetern dürfte sich anderswo auf dem finnischen Festland wohl schwerlich zusammenbringen lassen: Allium oleraceum, Luzula campestris, Briza media, Arrhenatherum elatius, A. pubescens, A. pratense, Carex contigua, $C$. Pairaei, C. caryophyllaea, Silene nutans, Ranunculus bulbosus, Arabis hirsuta, Saxifraga granulata, Filipendula vulgaris, Rosa villosa, Agrimonia eupatoria, Cotoneaster integerrima, Trifolium montanum, $\mathcal{T}$. arvense, Lathyrus monianus, Hypericum perforatum, (Helianthemum nummularia), Seseli libanotis, Primula veris, Plantago media.

Turku, Muhkuri (8). - Ein 5.4 Hektar grosses, fast ausschliesslich von Laubwald eingenommenes, früher von Äckern, heute teilweise von Behausungen umgebenes Hügelgebiet. Am Südabhang typische trockene Hainvegetation mit Eichen und Haselsträuchern, Ribes alpinum, Lonicera xylosteum, Poa nemoralis, Calamagrostis arundinacea, Convallaria majalis, Anemone hepatica, A. nemorosa, Geranium silvaticum, Lathyrus montanus, $L$. vernus und anderen von Ruissalo her schon bekannten Arten der Hainabhänge. Das dichte Haselgesträuch prägt auch den Nordabhang, hier ist aber der Boden immer einigermassen feuchter und auch kleine floristische Unterschiede sind $\mathrm{zu}$ verzeichnen, u.a. das Vorkommen von Viola mirabilis und Actaea spicata. Die Flora von Muhkuri wurde von AuER (1937) untersucht. In Hauptzügen dürfte gesagt werden können, dass der Artenbestand einigermassen dürftiger als der von sowohl Katariinanlaakso als Ruissalo wirkt und auch kein ausgesprochenes Sondergepräge besitzt. Indem aber die Nadelbäume mit Ausnahme von zwei Fichten und einigen kleinen Kiefern hier gänzlich fehlen, kommt dem Gebiet immerhin eine Bedeutung vom Standpunkt pilzökologischer Studien zu. Zumal im Anschluss an das westliche Ende des Gebietes gibt es Trockenwiesen mit z.B. Luzula campestris, Arrhenatherum pratense, A. pubescens, Filipendula vulgaris und Lathyrus montanus, am Gipfel der Anhöhe etwas Felsenvegetation. Als Schutzwald der Forstlichen Forschungsanstalt hat sich das Gebiet in letzter Zeit so gut wie in unberührtem Naturzustand befunden. Meine Pilzstudien in Muhkuri umfassen die Zeit von 1953 bis 1962.

Turku, Metsäkylä (10). - Am Nordrand der Stadt etwa $4 \mathrm{~km}$ von Stadtzentrum nicht weit vom gleichnamigen Haus. Untersucht wurden ein in den letzten Jahren intensiv beweidetes, mässig trockenes und zum Teil felsiges, mit Kiefern und einigermassen auch mit Fichten bestandenes Moränengelände westlich vom Hause und ein Ackerrand nebst einem kleinen, etwa ein halbes Hektar umfassenden Ackerhügel mit Eichen und Haselsträuchern, ziemlich reichlich grasbewachsen und weniger stark beweidet als die erstgenannte Fläche. Die Eichen sind gross und stehen verhältnismässig licht verteilt, der Gesamteindruck ist parkartig. Am Fusse des Felsens stehen einige grosse Eichen in einer Hainvegetation, die der von entsprechenden Standorten in Ruissalo beschriebenen sehr ähnlich ist. Vereinzelte Eichen gibt es dazu auch im umgebenden Nadelwald; die Pilzflora im Umkreis dieser Bäume wurde gleichfalls beobachtet. Diesen Untersuchungspunkt habe ich in den Jahren 1952-62 jedherbstlich mehrmals besucht.

Turku, Artukainen (11). - Eichenhain westlich der Stadt, reichlich 2 ha, ziemlich üppig und arten- 
reich mit gutwüchsigen Eichen, Birken, Ahornen und Fichten, erinnert in bezug auf die Vegetation am nächsten an die artenreichen Hainflächen von Ruissalo, mit stellenweise deutlich ausgebildetem Calamagrostis-, stellenweise wiederum CalamagrostisMyrtillus- und Convallaria- sowie Aegopodium-Typ.

Raisio, Perno (12). - Einzelne grosse Eichen am Südrand eines Nadel-Birkenmischwaldes in unmittelbarer Nähe des Hauses. Stark kulturbeeinflusst.

Kaarina, Karpanmäki (15). - Ackerhügel mit frischerem Nadelwald ringsum den zentralen Fels, an der von Turku nach $\mathrm{E}$ ausgehenden Wasserstrasse Kuusistonsalmi. Besonders am Nordabhang gibt es Fichtenwald, am Südabhang findet sich ein teils parkartiges, teils mit Hasel und Eiche dicht bestandenes und von Grasheideflächen umgebenes Hainfragment. Die Flora ist nicht so reich wie vorhin in Katariinanlaakso, der Allgemeineindruck ist aber derselbe. Von Phanerogamen mögen erwähnt werden Luzula campestris, Gagea minima, Silene nutans, Anemone nemorosa, $A$. hepatica, Corydalis solida und Thlaspi alpestre. Das Gedeihen der Pilze wird nicht wenig durch das zum Teil sehr reichliche Vorkommen von Elytrigia repens, Trifolium medium u.a.m. in den Eichenhainen des Gebietes erschwert. Diesen Platz habe ich in der Pilzsaison nur dreimal, in den Jahren 1959—61, besucht.

Piikkiö, Tuorla (16). — Der Südabhang des Birkenund Nadelwaldes S vom Gehöft Tuorla trägt mit seinen Haselsträuchern und einigen Eichen ein hainartiges Gepräge. Er grenzt ziemlich schroff an Acker, und dadurch ist es nicht zu der Ausbildung von erwähnenswerteren Grasheideflächen gekommen. Frischere Stellen wechseln mit trockeneren ab.

Halikko, Vaisakko (21). - Zweiteiliger schmaler Hain mit Fichten, Haselsträuchern, Eichen, Ahornen und Linden zwischen Fels und Acker nicht weit vom Meeresufer; trägt ein sehr wechselvolles Gepräge, im ganzen ist aber der Anteil der Linde hier grösser als in den Hainen näher Turku, und auch gewisse floristische Unterschiede sind $\mathrm{zu}$ verzeichnen; u.a. Viola mirabilis, Impatiens noli tangere und die Grauerle (Alnus incana) deuten schon auf einen östlicheren Haintyp hin. Im übrigen sind die Ähnlichkeiten mit Ruissalo sowohl hinsichtlich Flora als Vegetation gross. Der Frühlingsaspekt ist vor allem durch Gagea lutea, G. minima, Corydalis solida, Pulmonaria officinalis, Ranunculus ficaria, Anemone nemorosa, A. ranunculoides und Primula veris geprägt. Calamagrostis arundinacea und Milium effusum bilden auch hier typische Mischbestände ganz wie in Ruissalo, ebenso tritt Convallaria majalis in bedeutenden Anteilen auf.

Halikko, Pihko (22). - Süd- und südwestexponierter Hainabhang mit Eichen, Fichten und Haseln am Rande einer Ackerfläche, nunmehr Naturschutzgebiet. Tonangebend im Frühling sind Gagea minima, G. lutea, Luzula campestris, Anemone hepatica, Corydalis solida, Primula veris und Adoxa moschatellina. Kennzeichnend sind ferner Actaea spicata, Ribes alpinum, Lathyrus montanus, L. vernus, Selinum carvifolia, Galium boreale und Agrimonia eupatoria.

Nousiainen, Linnamäki (5). - W-Abhang am Fusse eines Felsens (Kinzigite-Granite, Diorit) an der Landstrasse. Am Abhang stehen einige Haselsträucher und am Felsrand sowie oben auf dem Fels vereinzelte ältere, kümmernde Eichen. Der Standort ist mässig trocken, offen nach Westen und stark durch die angrenzenden Anbauflächen beeinflusst.

Mietoinen, Saari (2). - Üppiger Birken-Eichenhain, Schutzgebiet der Forstlichen Forschungsanstalt, mit einigen Haseln und einer dichten Strauchschicht von jungen Eichen. Die Feldschicht umfasst u.a. Dactylis glomerata, Melica nutans, Calamagrostis arundinacea, Convallaria majalis, Anemone nemorosa, Vicia cracca, V. sepium, Geum rivale und Galium boreale.

Kakskerta, Kulho (14). - An Kulturflächen grenzende Haine am Fusse des Linnavuori-Berges, mit grossen Eichen, Linden und Ahornen. Von Sträuchern Ribes alpinum, Lonicera xylosteum und Viburnum opulus gemein. Ausser den typischen Hainpflanzen von Ruissalo sind noch zu nennen Epipactis helleborine, Brachypodium pinnatum und Actaea spicata.

Folgende Eichenstandtorte (die Kreise auf Karte 1) wurden zwei- bis einigemal besucht.

Taivassalo, Ketarsalmi (1). - Stark kulturbeeinflusste Grasheidefläche mit spärlichen grossen Eichen.

Askainen, Lempisaari (3). - Einsame Eichen an hainartigem Waldrand in der Nähe des Hauses.

Lemu, Ohensaari (4). - Geschützter Eichenhain, dazu hier und da kleine Eichenvorkommnisse, gewöhnlich Ackerhügel und Ackerrandhaine, wo es auch Haselsträucher gibt.

Rymättylä, Kepuinen (6). - Einsame Eichen am Rande von Kiefernwald. Haseldickichte.

Lieto, "Kunnanvuori» (17, vgl. TAPANA 1958 , p. 45). - Am Abhang und oben auf dem Fels vereinzelte kleine (aber alte) Eichen. Einen eigentlichen Hain gibt es nicht, sondern die Vegetation ist wohl am nächsten zum moosreichen Oxalis-Myrtillus -Typ zu rechnen.

Piikkiö, Fauhosaari (18, vgl. Mäkınen \& TARÉN 1956).

Korppoo, Lohm (19). - Felsige Kiefernwälder. Kleine Haselhaine und einzelne Eichen.

Parainen, Attu (20). - Am Südufer der Insel hat es stellenweise Mischwälder mit Eichen gegeben, nach durchgeführten Abholzungen findet man aber heute meistens nur niedrigen Jungwuchs. Weiter im Inneren der Insel ein mässig trockener Abhang mit Eichen. Auch v. Schulmann (1960) hat hier gesammelt.

Halikko, Nummi (23). - Abhang am Acker. Eichen, reichlich Hasel, dazu Ribes alpirum, Lonicera xylosteum, Viburnum opulus und Daphne mezereum.

Uskela, Veitukkala (24). - Südexponierter Hainabhang am Fusse eines Felsens am Ackerrand, mit Eichen, Fichten und Haseln, reichlich Primula veris und Corydalis solida. 
Uskela, Tupuri (25). - Hainsaum am Fusse eines Felsens, in unmittelbarer Nähe von Acker und Behausungen, teilweise auf den Hof eines Hauses übergreifend. Eichen und Haselsträucher.

Perniö, Ylikylä (26). - Hain mit Eichen, Linden, Fichten und Hasel. Der Felsgrund besteht in der Gegend aus Amphibolit (LAine 1960).

Pohja, Fiskari (27). - Abhänge mit Corylus avellana und an Acker grenzende Mischwaldränder in der Nähe der Fabrik. Die auf dieses Gebiet bezüglichen Angaben stammen zum grossen Teil von Apotheker H. Såltin, selbst war ich hier einmal im Oktober 1961, als die Pilzsaison schon so gut wie beendet war.

An das in diesen Punkten zusammengebrachte Material schliessen sich noch hier berücksichtigte Einzelfunde u.a. aus Mynämäki (Nadelwald), Askainen, Parainen (Kirjala, Peksor), Nauvo, Korppoo, Rymättylä, Turku (u.a. Piispanristi) und Masku an. Für Uusikaupunki habe ich Proben von Mag. phil. Unto Laine zur Einsicht erhalten.

Zum Vergleich habe ich während mehrerer Jahre Beobachtungen auch in Satakunta (St), Yläne ausserhalb der Eichenzone angestellt. Dazu kommen zahlreiche Exkursionen noch in V. Mynämäki, Rusko, Aura, Tarvasjoki und Pöytyä.

Im Kirchspiel Yläne trägt die Laubwaldflora schon ausgesprochene Inlandzüge; so sind hier z.B. die Turku am nächsten gelegenen reichlicheren Vorkommnisse von Poa remota, Galium triflorum, Viola mirabilis, Chrysosplenium alternifolium und Impatiens noli-tangere zu verzeichnen. Der südwestliche Artenbestand der Trockenwiesen erscheint stark vermindert, und obschon man hier immer noch ziemlich typischen Pflanzenarten der Eichenzone begegnet, wie etwa Lathyrus montanus sowohl häufig als reichlich, Luzula campestris selten sowie Arrhenatherum pratense an ihren äussersten Inlandstandorten, weicht der Artenbestand der Trockenwiesen und der
Haine immerhin von den entsprechenden Floren in der Eichenzone ab (vgl. Jalas 1957). Die Vegetation und Flora der Felsen weist noch typische küstennahe Züge auf, u.a. durch das Vorkommen von Spergula vernalis Silene rupestris - Rhacomitrium - CladinaVerbänden. Eichen gibt es im Gebiet nur angepflanzt auf einigen Höfen. Die ausgedehnten Moorflächen sind gewissermassen ein Anzeichen dafür, dass man sich schon im Inland befindet.

In der Umgebung der Subarktischen Biologischen Forschungsstation Kevo in Utsjoki $\left(69^{\circ} 45^{\prime}\right.$ n. Br.) in Finnisch-Lappland (Kallio 1960) ist im Verlauf der letzten drei Jahre ein dermassen umfangreiches Makromycetenmaterial zusammengebracht worden, dass es möglich ist, es als Fingerweis bei der Klärung der über das ganze Land verbreiteten Arten zu benutzen. Das Gebiet ist in der nördlichsten Kiefernwaldexklave Finnlands gelegen, und Untersuchungen wurden besonders gerade in dieser Region, dazu in der Birkenregion und der baumlosen alpinen Region durchgeführt. In ganz groben Zügen möge das weit reichlichere Vorkommen vieler Pilze der Kiefernwälder festgestellt werden, als nach vorhandenen Angaben im Schriftum hier oben zu erwarten gewesen wäre.

Bei der Untersuchung wurden auch die Sammlungen des Botanischen Museums der Universität Helsinki (HMF) ausgenutzt; ich danke dem Kustos des Museums, Herrn Dr. phil. Heik i Roivainen, für liebenswürdiges Entgegenkommen.

Das von mir gesammelte Pilzmaterial, das das eigentliche Gerüst der vorliegenden Untersuchung bildet, ist zum überwiegenden Teil in den Sammlungen des Botanischen Museums der Universität Turku (TUR) untergebracht.

\section{III. ÜBERSICHT DER ARTEN}

Die Grundlagen für die Wahl der Arten, die hier genauer behandelt werden, sind zweierlei. Erstens sind solche Arten mitgenommen, die nach der Literatur z.B. in Skandinavien als Begleiter der Eiche oder der »Eichenzone» gegolten haben. Zweitens sind es Arten, die in Finnland nicht oder seltener ausserhalb der genannten Zone gefunden worden sind. Besonders meine eigenen
Beobachtungen in Yläne und in Utsjoki haben diesbezüglich einige Hinweise gegeben.

Nachstehend gilt bezüglich der Nomenklatur und der systematischen Anordnung der Agaricales hauptsächlich Singers Werk »The Agaricales in modern Taxonomy» (1962). Dazu habe ich mich auf das Exsikkat von Lundell und Nannfeldt (1934-61) gestützt, weil dieses Werk auch gebietlich uns 
am nächsten steht, und weil namentlich die genannten Autoren über spezielle Voraussetzungen zur richtigen Deutung der bis auf Fries zurückgehenden Artennomenklatur verfügen.

In betreff der Standortsnomenklatur möge hier noch eingeschoben werden, dass mit $\mathrm{H}$ a i n in diesem Text ein humusreicherer und gewöhnlich auch artenreicherer Waldtyp gemeint wird, in dessen Feldschicht die Zwergsträucher keine grosse Bedeutung erlangen.

\section{Die Polyporaceen und andere xylophile Grosspilze der Eiche}

Die wichtigsten mitteleuropäischen $»$ Grossparasiten» und Saprophyten der Eiche - sie gehören grösstenteils in die Familien der Polyporaceae, Hymenochaetaceae, Meruliaceae, Ganodermataceae, Stereaceae und Poriaceae sind auch in der Eichenzone Finnlands zu finden. Von den wichtigeren von KREISEL (1961, p. 189) genannten Pilzen der Eiche (Psathyrella spadicea, Pholiota squarrosa, Armillariella mellea, Fistulina hepatica, Ganoderma lucidum, G. Pfeifferi, Inonotus cuticularis, I. dryadeus, I. dryophilus, Phellinus robustus, Grifola frondosa, $G$. umbellata, Laetiporus sulphureus, Poria versipora, Trametes quercina, T. unicolor, Stereum rugosum) sind nur Ganoderma pfeifferi und Inonotus dryophilus in Finnland nicht gefunden worden.

Von diesen Arten sind Psathyrella spadicea, Pholiota squarrosa, Armillariella mellea, Inonotus cuticularis, Poria versipora, Trametes unicolor und Stereum rugosum weit nördlich der Eichenzone verbreitet.

Inonotus dryadeus (Pers. ex Fr.) Murrill, eine Art der Eichen und namentlich ein Parasit »an den Wurzeln und untersten Stammteilen) (KREISEL 1961, p. 122; vgl. auch Rostrup 1931, p. 383 und OverHolts 1953, p. 409), wurde von mir einmal (IX. 1957) in Ruissalo an zwei Eichenstämmen 5-6 m hoch (!) angetroffen. Die Probe (TUR) wurde von Dr. S. Eriksson in Schweden bestimmt. Die Art, deren Fruchtkörper sich überhaupt sehr launenhaft entwickeln (vgl. Buahwald \& Jörgensen 1948, p. 383 ), ist seither nicht mehr an diesen Eichen wiedergefunden worden.

Phellinus robustus habe ich nur in Ruissalo am Locus classicus der Art angetroffen, dort aber vielenorts.

Grifola umbellata, im Norden eine grosse Seltenheit (vgl. Störmer 1931), wurde 1944 in U. Espoo von einem Nichtbiologen gefunden (HMF); der angebliche Kiefernwaldcharakter des Standorts ist vielleicht nicht ganz sicher.
Fistulina hepatica Schaeff.

Die Art wurde schon von Karsten (1859) in seiner akademischen Abhandlung aus Ruissalo erwähnt. Im HMF liegen von hier drei Proben, dazu eine von W. Nyberg 1937 aus V. Lohja, Jalassaari. FREY (1944) fand zahlreiche wohlentwickelte Exemplare auf Eichenstöcken am 25. IX. $1942 \mathrm{im}$ Ostteil von Geta auf Ahvenanmaa. HÄYrÉn (1942, p. 7) nennt den Pilz aus V. Uskela, EkLUnd (1943 b) aus Korppoo. Da die Art von Thesleff (1919) nicht aus den Eichenwäldern bei Viipuri erwähnt wird, dürfte sie allein schon gemäss dem Schrifttum als ein Pilz des südwestlichen Teiles der finnischen Eichenzone betrachtet werden können. Der östlichste Fund ist aus dem Botanischen Garten der Universität Helsinki (TUOMIKoski mündl.).

Im Untersuchungsgebiet wurde die Art am reichlichsten in Turku angetroffen, wo sie beinahe alljährlich - selbst in den trockensten Sommern, wie etwa 1951 (vgl. Kallio 1953), 1955 und 1959 $\mathrm{zu}$ finden gewesen ist (in dem sehr kühlen und $\mathrm{zu}-$ gleich niederschlagsreichen Sommer 1962 fehlte die Art dagegen ganz). In Ruissalo kann man dem Pilz im Laufe des Herbstes auf manchen Exkursionen begegnen, am häufigsten im Naturreservat und dem westlich davon gelegenen Hain. Auch in Katariinanlaakso ist der Pilz regelmässig zu finden, in Muhkuri dagegen habe ich ihn nur dreimal (vgl. auch Auer 1937, p. 32) angetroffen, dazu einmal in Metsäkylä. Aus der Umgegend der Stadt habe ich folgende Funde: Lieto, Kunnanmäki, zwei stattliche Fruchtkörper an einer etwa $20 \mathrm{~cm}$ dicken Eiche am Felsabhang 24. IX. 1960; Piikkiö, Tuorla, Kuninkaanniitty, an lebender Eiche 1960; Nousiainen, Linnamäki, zwei wohlgebildete Fruchtkörper an den kleinen Eichen im oberen Teil des Abhangs 16. X. 1960; Lemu, Ohensaari, ein grosser Fruchtkörper an der Wurzel einer Eiche 4. X. 1960; Rymättylä, Kepuinen und Askainen, Lempisaari, am Stammgrund lebender Eichen 19. X. 1958. Im TUR gibt es dazu eine Probe aus V. Sauvo, Saustila (1953, O. Siitonen).

Der Pilz wurde in Ruissalo sowohl an Eichenstöcken als auch am Stamm der Eichen angetroffen, stets aber in geringer Höhe in den unteren $\mathrm{Ab}$ schnitten, höchstens bis $4.5 \mathrm{~m}$ (Parmasto 1956 gibt aus Estland $3 \mathrm{~m}$ an). In Südwestfinnland ist die Art offenbar durch die ganze Eichenzone zu finden; Lieto und Nousiainen gehören zu den letzten Naturstandorten der Eiche nach dem Inland hin.

In Schweden bewohnt der Pilz ausschliesslich Eichen (INGELSTRÖM 1940) und dürfte dort kaum viel häufiger als in Südwestfinnland zu finden sein. Bijlow (1889) bezeichnet ihn als das Ergebnis seiner Exkursionen in Skåne geradezu als sehr selten und führt im ganzen nur drei Fundorte an, und nach Lundell (1932) ist die Art auch in der Gegend von Uppsala selten.

\section{Polyporus sulphureus Bull.}

Auch diesen Pilz erwähnt Karsten (1859) aus Ruissalo, dazu aus Raisio, Viheriäinen und Merimasku, Mälsälä, ferner (1876, p. 256) aus Tammisaari und (1889, p. 289) von Ahvenanmaa. LAURILA (1939) bezeichnet die Art in Ruissalo als häufig. Andere Erwähnungen im Schrifttum: Ahvenanmaa, Geta (Frey 1944), Korppoo (EkLund 1944), Parainen, Attu (v. Sahulmann 1955). Nach Thesleff im HMF: U. Inkoo (1891, Hisinger); Kirkko- 
nummi (1909, Collander); Tammisaari (1951, (1919) auch im Eichengebiet von Viipuri. Proben Häyrén); EK. Valkjärvi (1907, H. Lindberg); Johannes (1892, Thesleff).

Im Untersuchungsgebiet darf der Pilz als häufig gelten. Zumal in Ruissalo gehört er zu den häufigsten Schwämmen der Eiche, dem man während einer Sommerexkursion zu mehreren begegnen kann, und zwar sowohl hoch oben am Stamm als auch an Stöcken und an liegenden Stämmen. Ausser in Ruissalo habe ich den Pilz im Stadtgebiet von Turku noch in Katariinanlaakso, Muhkuri (auch Auer 1937), Metsäkylä, Pahaniemi, Pitkämäki, Pansio und beim Zentralkrankenhaus angetroffen, ausserhalb der Stadt in Raisio, Perno; Masku, Niemenkulma; Piikkiö, Tuorla; Kaarina, Karpanmäki; Mietoinen, Saari; Lemu, Nyynäinen; Taivassalo, Ketarsalmi; Lokalahti, Pinipaju; Rymättylä, Kepuinen; Parainen, Attu, Lofsdal und Simonkylä; Korppoo, Lohm; Halikko, Vaisakko. Weiter befindet sich im TUR eine von K. Linkola gesammelte Probe aus Bodnäs in Parainen. Tuomikoski (briefl.) erwähnt die Art auch aus Bromarv, Framnäs.

Aus den Angaben im Schrifttum sowie aus den Museumsbelegen ist zu schliessen, dass man es mit einem vor allem eichenbewohnenden Pilz der Eichenzone zu tun hat. Die Art dürfte allgemein fruchten und ist anscheinend u.a. von der Niederschlagsarmut des Sommers unabhängig (vgl. Kallio 1953).

Die Art ist streng ein Eichenbegleiter. Ich habe sie nur zweimal an einer anderen Holzart angetroffen, nämlich im Naturreservat von Ruissalo an Salix caprea. In Dänemark liegt die Art u.a. von der Schwarzerle vor (Bjoerne KAER 1938), in Norwegen von Prunus avium, $P$. cerasus und sogar von Birken (Jörstad 1948, p. 366). Parmasto (1956, p. 27) nennt als Wirte des Pilzes in Estland auch Weiden.

In England greift der Pilz nach Raмsвоттом (1954, p. 226) allerlei Bäume an. Es ist also gegen den Norden hin eine immer grössere Spezialisierung zu beobachten.

In Schweden ist der Pilz im Gebiet der Eiche recht häufig (INGELSTRÖm 1940, p. 46; FRIES 1849, p. 319 . rad Dalelfven usque»). In Norwegen vielenorts (BLYтT 1905), in Dänemark als Schädling alter Eichen (Lind 1913, p. 380; Ferdinandsen \& WINGE 1943).

\section{Polyporus frondosus Dicks. ex Fr.}

Der Pilz wurde 1859 von Karsten in Ruissalo am vorläufig einzigen Standort der Art in Finnland gefunden. Hier findet man ihn überall, wo es frische Eichenhaine auf der Insel gibt. In den verschiedenen Teilen des Naturreservats ist er beinahe jedjährlich sicher antreffbar (einzige Ausnahme: 1962!), im üppigen Eichenhain westlich davon womöglich noch reichlicher, seltener auch bei Honkapirtti und südlich davon, auf der Südseite der Landstrasse und noch in Marjaniemi sowie nahe des Volksparks, im ganzen auf mindestens 20 Quadraten von LINDGREN (1955).

Angesichts dieses häufigen Vorkommens erscheint es um so merkwürdiger, dass der Pilz nur hier angetroffen worden ist, gibt es doch üppige Flächen mit Eichen auch anderswo im Untersuchungsgebiet. Auch im Schriftum fehlen jegliche übrige Angaben über die Art in Finnland. Vielleicht hat man es hier mit einer so extremen Spezialisierung der ökologischen Ansprüche zu tun, dass im ganzen Gebiet nur der Eichenwald von Ruissalo dem Pilz zusagt. Meistens, jedenfalls in kräftigster Ausbildung, begegnet man ihm auf schattigen und dickerdigen Flächen mit der üppigsten Vegetation, am reichlichsten u.a. im Aegopodium-Convallaria-Bestand auf der Westseite des Reservats. Dagegen kenne ich keinen einzigen Fall des Vorkommens auf sonniger Grasheide unter Eichen oder in den vielen EichenHeidewäldern, die es hier z.B. auf der Anhöhe nördlich vom Reservat gibt, oder auch auf gewissen mit Eichen bewachsenen Felsen, wo man gelegentlich Fistulina hepatica oder Polvporus sulphureus antreffen kann.

Der Pilz lebt denn auch an den Wurzeln der Eiche meistens als Parasit (KREISEL 1961). Doch erhebt sich der Fruchtkörper nicht immer direkt aus dem Wurzelhals des Wirtes, sondern aus der Erde. Es ist möglich, dass im vorliegenden Fall das Myzel in dem die Wurzeln umgebenden Boden lebt (vgl. Rамsвоттом 1954, p. 132), sowie dass dieser für den Pilz eine grössere Bedeutung hat als für die xylophilen Saprophyten oder Parasiten insgemein, die ja weitgehend unabhängig von dem Erdreich sind, in dem ihr Wirt wurzelt. Gute Haine gibt es aber im Untersuchungsgebiet auch anderswo, wie z.B. in Mietoinen der Eichenhain von Saari, und ausserdem gedeiht der Pilz nach Kreisel (op.c.) in Mitteleuropa vorzüglich auch in saurem Boden. Hat man es hier vielleicht geradewegs mit Schwierigkeiten bei der Ausbreitung zu tun, denen zufolge die heutige Verbreitung des Pilzes eigentlich auf einwanderungsgeschichtlicher Grundlage $\mathrm{zu}$ klären wäre?

In Schweden häufen sich die meisten Funde auf Skåne (vgl. ANDERsson 1939). Im Eichengebiet von Uppsala kennt man den Pilz nicht (Dr. phil. SeTH LUNDELL briefl.).

Daedalea quercina L. ex Fr.

Karsten (1889) meldet den Pilz als sehr selten aus Ruissalo, V. Merimasku und Kirkkonummi, und TheslefF (1919) aus seinem Untersuchungsgebiet. EKLUND (1943) nennt ihn aus Korppoo und Hiittinen, v. Scimulmann (1960) von Ahvenanmaa sowie aus Parainen, Tammisaari und Ruissalo und Auer (1937) aus Muhkuri. Im TUR befindet sich eine Probe von Laurila aus V. Lohja, Jalassaari, 1937 und eine von Auer aus Kakskerta, Kulho, 1943.

Die Art ist in Ruissalo fast an jedem Eichenstock zu finden, häufig und zugleich reichlich ist sie auch in Katariinanlaakso und in Muhkuri; ferner in Raisio, Perno; Kaarina, Karpanmäki; Piikkiö, Tuorla; Mietoinen, Saari; Nousiainen, Linnamäki; Parainen, Attu, Peksor und Lofsdal; Kulho.

Auf Grund des Obigen darf geschlossen werden, dass die Art über die ganze Eichenzone Finnlands verbreitet ist.

Bei uns an Eichenstöcken (einzige bekannte Ausnahme: Thesleff 1919 , p. 18 erwähnt die Art auch von der Kiefer).

\section{Agaricales}

Hydrocybe punicea $\mathrm{Fr}$.

Im Schrifttum nur aus dem südwestlichsten Teil des Landes erwähnt. Karsten (1889, p. 137) für die Turku-Gegend und Ahvenanmaa: »m.r. Ábo, Jomala»; EKLUND (1943, p. 13): Korppoo, "ge- 
büschiger Wiesenboden»; REUTER (1944, p. 42) Parainen, Lofsdal; Stenlid (1947, p. 86) für Ahvenanmaa: Lemland und v. Sahulmann (1960, p. 10) : Eckerö; letzterer nennt dazu die Orte V. Paimio und Tammisaari, Prof. Risto Tuомıкоккі (briefl.) erwähnt den Pilz aus Espoo, Bodom und den nördlichen Randteilen von Helsinki (Länsi-Pakila).

Im Untersuchungsgebiet am häufigsten und reichlichsten in Ruissalo, hier besonders in den üppigsten und am dichtesten bewachsenen Teilen des Naturreservats (vgl. Abb. 2), oft an sehr grasreichen, anderseits aber auch an fast nur mit blosser Streu bedeckten Stellen, oft zusammen mit Tricholoma columbetta, T. sulphureum, Lactarius mitissimus, L. pyrogalus und Craterellus cornucopioides. Im Stadtgebiet von Turku wurde der Pilz noch in Muhkuri, im übrigen Untersuchungsgebiet in Taivassalo, Ketarsalmi (1960, gesunde Fruchtkörper reichlich noch am 16. X.; Lemu, Ohensaari; Halikko, Vaisakko und Kulho, Linnavuori gesammelt.

Die hiesigen Funde entfallen vorläufig durchgehends auf die Eichenzone, und trotz ihrer geringen Zahl von nur etwa einem Dutzend dürfte aus ihnen die allgemeine Verbreitungstendenz deutlich $\mathrm{zu}$ erlesen sein. Alle meine eigenen Funde sind aus Eichenwäldern, so auch ein Teil der anderen hier erwähnten; für einen Teil fehlen die Angaben.

In Schweden bezeichnet Ingelström (1940) den Pilz als verhältnismässig häufig auf Wiesen und in Parken, und vor allem an solchen Stellen findet man die Art auch in Mitteleuropa (vgl. Michael/Hennig 1958; siehe auch Tuomikoski 1959). NATHorstWindahl (1956) erwähnt den Pilz aus seinem Untersuchungsgebiet überhaupt nicht. Nach BLytT (1905, p. 90) auf moosbewachsenen Wiesen und Hügeln in Norwegen nicht sehr selten. Nach Boнus \& BABOs (1960) gehört der Pilz zu den Dominanten der Eichenwälder von Ungarn.

\section{Laccaria amethystina (Fr. ex Bolt.) R. Maire}

Die Art wurde erst i.J. 1946 von Nyberg als neu für die Flora des Landes gemeldet, muss aber in der Umgebung von Helsinki sehr selten sein, da der genannte Autor dort ausdrücklich ein Auge auf die Art gehalten hat. In Wirklichkeit nennt aber schon EKLUND (1943b, p. 16) den Pilz aus Väsby in Korppoo (1941), und auch Malmström (1943, p. 72) erwähnt eine "gredelin Form» von Laccaria laccata, die wohl als $L$. amethystina zu deuten sein dürfte. STENLID (1947) erwähnt den Pilz aus dem bekannten Edellaubhain von Lemland, Apalholm auf Ahvenanmaa. Auch nach Tuomiкoski (1959) handelt es sich um einen Pilz der üppigen Haine, den er (nach briefl. Mitteilung) u.a. in Bromarv, Framnäs und Espoo, Bodom gesammelt hat. Nur Nyberg (op. c.) gibt als Standort ein steiniges moosreiches Nadelwaldgelände an. Von Schulmann (1960) erwähnt den Pilz, ausser von Ahvenanmaa, Lohja und Tammisaari, auch aus Parikkala, Elimäki und Lapinlahti, wonach also der Eichenhaincharakter der Art keineswegs klar wäre. Offenbar liegt aber der Schwerpunkt der hiesigen Verbreitung im allersüdlichsten Teil des Landes.

In den besten Hainen im Ostteil der Insel Ruissalo begegnet man dem Pilz ziemlich häufig; der Schwerpunkt des Vorkommens liegt im Naturreservat und gleich westlich davon. Hier wächst er zusammen mit solchen Arten wie Lactarius serifluus, L. quietus, $L$. piperatus, Craterellus cornucopioides, C. sinuosus, Hygrocybe punicea, Tricholoma album, T. columbetta, T. sulphureum.
In Katariinanlaakso ist der Pilz gleichwie mehrere seiner aus Ruissalo genannten Begleiter seltener. In Turku ist er dazu in Muhkuri und im übrigen Untersuchungsgebiet in Lemu, Ohensaari; Halikko, Pihko und Kakskerta, Kulho gesammelt worden.

Ausserhalb des Eichenwaldes ist die Art im Untersuchungsgebiet nicht angetroffen worden.

In den Hainen Mitteleuropas ist Laccaria amethystina ein häufiger Pilz. NeuHoff (1956, p. 28) erwähnt ihn z.B. als einen Bewohner der feuchtgründigen Ulmen-Eschenwälder. Nach WOJEwODA (1961) hauptsächlich in Hainen, seltener jedoch auch im dortigen Kiefernwald vom Myrtillus-Typ. Anderseits bezeichnet Pilát (1954) diese Art und L. laccata als standortsgleich. Was aber Finnland betrifft, so ist besonders die "anspruchsvollere» Natur des Pilzes im Vergleich zu L. laccata hervorzuheben, welche letztere auf sehr verschiedenen Biotopen bis hinaul in die Regio alpina der Fjelde Lapplands anzutreffen ist. Michael/Hennig (1958) betrachtet denn auch die Art als einen Pilz der Laubwälder. Auch in Skandinavien verhält sich der Pilz ähnlich. So bezeichnet BLyTt (1905, p. 31) die »blaue Form» von L. laccata in Norwegen als seltener besonders in den Eichen- und Buchenwäldern der südlichen und westlichen Küstenbereiche, im Fichtenwald als sehr selten (vgl. auch Blyttia 1957, p. 30). Dieselbe Auffassung vertritt auch INGELSTRÖm (1940, p. 167), der ausdrücklich auf das Vorkommen des Pilzes auf nacktem Boden - also ganz wie in den besten Hainen von Ruissalo - in Schweden hervorhebt. Auch im Begleittext zur Nr. 1111: »Amongst heaped-up beech-leaves» (Femsjö in Småland) im Exsikkat von LuNDELL und NANNFELDT kommt dieser LaubwaldCharakter des Pilzes deutlich zum Ausdruck.

Tricholoma columbetta (Fr.) Kummer

Karsten (1889, p. 52) erwähnt die Art als sehr selten aus Turku, Ruissalo (»m.r. (Runsala)»). EKLUND (1943) fand den Pilz im Haselgesträuch von Långviken in Korppoo. Nach Tuomikoski (1959) ist die Art in Finnland wahrscheinlich südlich und offenbar selten sowie an Birken und Eichen gebunden. Er hat sie (briefl.) in V. Bromarv, Framnäs und U. Espoo, Kasberg und Bodom angetroffen, in zwei Fällen in der Nähe von Eichen. In der Umgebung von Helsinki ist der Pilz in manchen Jahren sogar reichlich zu finden (vgl. Sienitietoja 1956, n:o 3, p. 5). Von Schulmann (1960) erwähnt die Orte Tammisaari und Elimäki. Schon der letztgenannte Fund erweist, dass es sich auch in diesem Falle keineswegs um eine obligatorische Art der Eichenzone handelt. Weiter ist der Pilz auch noch in Heinola gesammelt worden (det. Lic.phil. Vеткко HглтгккA), wo er bei der Pilzschau i.J. 1959 ausgestellt war (Mag.phil. Unto Larne mündl.).

In den Eichenwäldern des Untersuchungsgebietes begegnet man dem Pilz allgemein. Besonders in Ruissalo ist er häufig, obwohl fast nie reichlich zu finden, und zwar ist das Vorkommen ganz deutlich auf den östlichen Teil der Insel mit dessen mehr hainartiger Natur konzentriert. Jedherbstliche Fundstellen im Stadtgebiet von Turku sind auch Muhkuri und Katariinanlaakso. Übriges Untersuchungsgebiet: Kaarina, Karpanmäki (bes. im Jahre 1961 ausserordentlich reichlich); Piikkiö, Tuorla und Jauhosaari; Mietoinen, Saari; Taivassalo, Ketarsalmi; Rymättylä, Kepuinen; Parainen, Lofsdal; Halikko, 


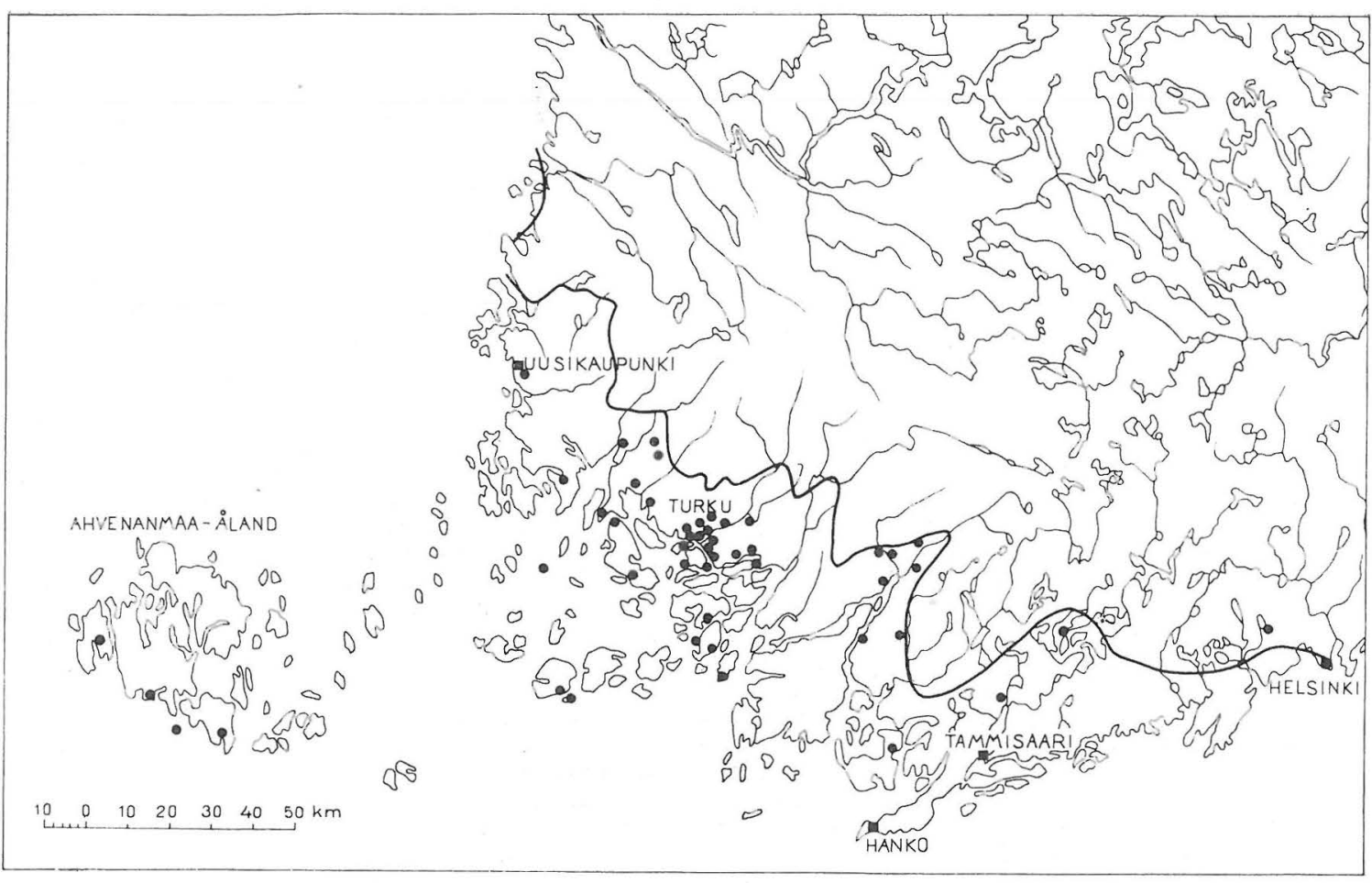

Abb. 3. - Die bekannten Fundorten von Tricholoma sulphureum.

Vaisakko, Pihko und Nummi; Uskela, Veitakkala; Perniö, Ylikylä und Teijo.

Das Auftreten der Art in den hiesigen Eichenwäldern dürfte dem in der Eichenzone Skandinaviens gleichkommen. Im Untersuchungsgebiet von Nathorst-Windahl (1956) wird der Pilz als verhältnismässig selten bezeichnet, INGELSTRÖM (1940) hält ihn für relativ häufig. In Dänemark ist die Art nach LANGE (1940) »rather rare in woods of Fagus», und in Norwegen ist sie nach Buytr (1905) namentlich an der Südküste im Birken- und Buchenwald, selten im Kiefernwald $z u$ finden.

Im allgemeinen gilt der Pilz als ein Begleiter der Birke (Buch 1952, p. 50). Nach Bresadola (1927, Erklärung zu Taf. 74) »in silvis coniferis et frondosis». In Polen zieht die Art Buchenwälder vor Kiefernwäldern vor (WOJEwodA 1961). Nach RAMSBOTTOM (1954) in England in Hainwäldern, nach STORDAL (1953, p. 292) in Norwegen in der Grasvegetation am Rande von Laub- und Mischwäldern.

Die Fundstellen im Untersuchungsgebiet liegen fast ausnahmlos in der Nähe von Eichen. Es ist zu bemerken, dass z.B. in Ruissalo sich immerhin auch Birken befinden. Hier wurde der Pilz aber nur ein einziges Mal, im Birken-Fichtenmischwald, unbestritten ausserhalb der Reichweite der Eichenwurzeln angetroffen. Auch wenn also die Art in ihrem Vorkommen nicht einzig von der Eiche abhängig ist, trägt dieser Baum immerhin ganz offenbar zu der Entstehung besonders günstiger Standortsbedingungen für den Pilz bei.

Tricholoma sulphureum (Bull. ex Fr.) Kummer Nach dem Schrifttum nur im südlichsten Finn- land. Schon bei Karsten (1876, p. 42) heisst es: »Fenniae salten australis, praecipuae quercetis», später (1889) erwähnt er den Pilz aus Turku, Ruissalo. EKLUND (1943) fand den Pilz in Korppoo, Stenlid (1947, p. 83) in Lemland auf Ahvenanmaa und v. Schulmann (1960) in Eckerö ebendort; hieraus ergibt sich schon die Verbreitungsnatur der Art als Bewohner der Eichenzone (vgl. Тчомгковкі 1959). Auch Thesleff (1919) erwähnt einen Fund aus seinem Untersuchungsgebiet.

Im HMF liegen folgende Proben: V. Turku, Metsäkylä (1935, Laurila); Merimasku (1885, Karsten); Bromarv, Framnäs (1952 und 1957, Tuomikoski); U. Espoo, Bodom, (1953, Tuomikoski); Porvoo (1932, Nyberg); EK. Johannes (1894, Thesleff). Im TUR ist die Art durch 34 Proben vertreten.

An fast sämtlichen besuchten Eichenstandorten oft reichlich und in mehreren Jahren angetroffen: Turku, Ruissalo, Katariinanlaakso, Muhkuri, Metsäkylä, Artukainen, Kurala, Pääskyvuori und Takakirves; Uusikaupunki; Taivassalo, Ketarsalmi; Mietoinen, Saari; Lemu, Ohensaari; Askainen, Lempisaari; Nousiainen, Linnamäki; Mynämäki, Kallavuori, unter Haseln und Eichen; Masku, Niemenkulma; Raisio, Perno; Maaria, Paimala; Lieto, Vankio, Kunnanvuori; Kaarina, Karpanmäki; Piikkiö, Tuorla und Jauhosaari; Rymättylä, Kepuinen; Korppoo, Kuraklintti und Lohm; Parainen, Lofsdal, Peksor, Attu und Vånå; Kakskerta, Kulho und Järvistensaari; Halikko, Pihko, Nummi und Vaisakko; Uskela, Tupuri und Veitakkala; Perniö, Ylikylä und Teijo; Pohja, Fiskari; Karjalohja, Karkali (Matti Laurila, TUR). Diese Art gehört auch tatsächlich zu denjenigen Pilzen, die meiner Auffassung nach 
um leichtesten die Grenze der Eichenzone in Südwestfinnland zu markieren vermögen. Die Art wächst hier auch in Haselhainen ohne Eichen (z.B. Korppoo, Kuraklintti, vgl. auch STENLID (1.c.e., p. 83), aber in den Haselhainen von Yläne (und St. Säkylä, Kolvaa) habe ich die Art nicht gefunden.

In Ruissalo ist Tricholoma sulphureum einer der häufigsten Pilze der Eichen-Haselhaine auch in solchen Jahren, in denen die Fruchtkörperbildung bei den Pilzen im allgemeinen benachteiligt ist. Man findet ihn meistens von Ende August bis Ende Oktober.

Die Standortsbezeichnung unter Nr. $32 \mathrm{im}$ Exsikkat von LUNDELL und NANNFELDT : »On heapedup decaying leaves under oak at margin of mixed wood» für Schweden ist auch für hiesige Verhältnisse durchaus massgebend. Das Vorkommen des Pilzes in Schweden überhaupt ist von INGELSTRÖM (1940, p. 182) charakterisiert worden, der ihn als relativ häufig wenigstens in den südlichen Teilen des Landes bezeichnet. Im Untersuchungsgebiet von NATHORSTWrndarl (1956) ist der Pilz ziemlich selten. In Dänemark nach LANGE (1940, p. 59) häufig »in frondose woods», in Norwegen nach BLyTt (1905, p. 26) zumal in Eichen- und Buchenwäldern. In den floristischen Verzeichnissen aus dem mitteleuropäischen Querceto-Carpinetum nimmt die Art eine wichtige Stellung ein (z.B. NeuHoff 1956, p. 27), ebenso des öfteren in verschiedenen trockeneren Eichenwäldern Ungarns (BoHus \& BABOs 1960). Den Laubwaldbiotop erwähnen in ihren Untersuchungen auch RIGKeN (1915), HAAs (1933) und Wojewoda (1961). Nach Buch (1952, p. 56) in Sachsen besonders unter Eiche und Hasel; die Art ist namentlich auf Hainstandorte spezialisiert und ist daher nicht z.B. in den Auwaldungen zu finden. Dieselben allgemeinen Biotopansprüche hat die Art wahrscheinlich auch in Finnland bewahert, d.h. es handelt sich in erster Linie lediglich um einen bestimmtartigen Hain der Eichenzone.

\section{Tricholoma irinum (Fr.) Kummer}

Auf diese vordem aus Finnland nicht gemeldete Art stiess ich auf einer Studentenexkursion nach Halikko am 14. September 1961 in der Parkallee des Gehöfts Vuorentaa. Von den zahlreichen Fruchtkörpern war ein Teil schon überaltrig. Der Habitus erinnerte sehr an Lepista personata Fr., der Hut war aber hell gelbbraun, mit deutlichem rötlichen Ton besonders auf der Mitte; kein Blau. Der Duft sehr typisch.

Der Pilz ist auch in Schweden selten. INGELSTRÖM (1940) erwähnt ihn von ein paar Stellen in Uppland, und Karlvall (1949, p. 406) hat ihn in Västergötland gefunden. Im Untersuchungsgebiet von NATHORST-WINDAHL (1956, p. 324) wird die Art als selten bezeichnet. In Dänemark nach LANGE (1935, p. 62) »not uncommon», nach FERDINANDSEN \& W INGE $(1943$, p. 205) hier und da.

Tricholoma lascivum $\mathrm{Fr}$.

Von Karsten (1889, p. 54) aus Turku, Ruissalo erwähnt, und auch ThesLefF (1919) nennt diesen typischen Pilz der Eichenwälder (op.c., in Übersetzung: »Er wird nur zwischen welkem Eichenlaub angetroffen») aus der Gegend von Viipuri. VON Schulmann (1960) fand die Art im Gebiet von Tammisaari und in A. Lemland, Slätholm.

In HMF liegt auch eine mit diesem Namen ver- sehene Probe aus Helsinki (Hain, u.a. mit Prunus padus, 1952, V. Erkamo).

Ich habe die Art nur einigemal angetroffen, durchgehends im Gebiet von Turku. In Ruissalo wächst der Pilz im Naturreservat, in Katariinanlaakso findet man ihn auf der einzigen verhältnismässig frischen Hainfläche nahe beim Ufer im Teilgebiet 9 von Nikoskelainen (1955) unter Eichen, und unter diesen Bäumen wurde er auch in Metsäkylä gesammelt. Es ist möglich, dass dieser Pilz zum Teil mit $\mathcal{T}$. album Fr. verwechselt worden ist.

In Dänemark ist $T$. lascioum nach LANGE (1935, p. 59) verhältnismässig häufig in Laubwäldern, besonders unter Eichen.

Tricholoma saponaceum Fr. var. ardosiacum Bres.

Diese Art möge hier gleichfalls genannt werden, weil sie im Schrifttum nur aus S-Finnland erwähnt worden ist und weil ich ihr nur in den Eichenhainen von Turku begegnet bin, nämlich in Ruissalo, Katariinanlaakso und Muhkuri. Der Pilz ist in seiner Jugend vor allem kenntlich durch den dunklen Stiel, der dann bei fortgesetztem Wachstum heller wird und die frühere dunkle Farbe nur noch als lichtes zerstreutes Oberflächenmuster erkennen lässt. Auch die Hutoberfläche ist dunkler als bei der Hauptform. Die Tafel 86 bei Bresadola (1927) vermittelt ein ausgezeichnetes Bild von diesem Pilz. Irgendwelche speziellen ökologischen Züge werden für die Art im ausländischen Schrifttum nicht angegeben (vgl. auch LANGE 1935, p. 60). Auf das Auftreten des Pilzes in Finnland müsste achtgegeben werden.

Im HMF liegen folgende Proben: V. Karjalohja (1950, Ulla Bärlund, det. Malmström); Kirkkonummi (1956, Mäkitalo), U. Espoo (1949, T. Rautavaara); Tuusula (Ruotsinkylä, 1952, N. Malmström).

Xerula longipes (Bull. ex Fr.) Maire

Syn.: Oudemansiella longipes (Bull. ex St-Amans) Moser - Collybia pudens (Pers. ex Fr.) Lundell

Diese Art ist überall in Nordeuropa selten und im Schrifttum nicht für Finnland angegeben (vgl. Tuomrkoskr 1959). Im Jahre 1956 fand jedoch Stud.rer.nat. A. Petäjä den Pilz an dem Abhang (Grasheide mit Eichen) des Berges Linnavuori in Kakskerta, Kulho, wo auch andere südliche Arten, wie z.B. Helvella crispa, Amanita vaginata var. lividopallescens, A. pantherina, Xerocomus chrysenteron und Lactarius zonarius gesammelt worden sind. Die Probe befindet sich wohlpräpariert in den Sammlungen des TUR.

In Schweden selten in der Gegend von Stockholm und auf Gotland (INGELSTRÖM 1940). Im Exsikkat von Lundell und Nannfeld liegt der Pilz als $\mathrm{Nr}$ 2525 gleichfalls von Gotland ( $\gg$ Heavily grazed meadow with Rosa, Crataegus, Malus silvestris etc.») und als Nr. 1717 selbst noch aus Uppland (Funbo, »in lawn emerging from dead oak roots») vor. In Dänemark gilt die Art als ein gleichfalls sehr seltener Bewohner der Buchenwälder (LANGE 1940). In Mitteleuropa wird der Pilz ausdrücklich als Begleiter der Eiche erwähnt (BuGH 1952, p. 90; Michael/Hennio 1958, p. 198), auch wenn freilich seine pflanzensoziologische Bedeutung wegen des meist vereinzelten Vorkommens gering ist (BRESINSKY \& Zeitllayir 1960; vgl. auch BohUs \& Babos 1960, p. 61-62). Auch nach Riaken (1915, 


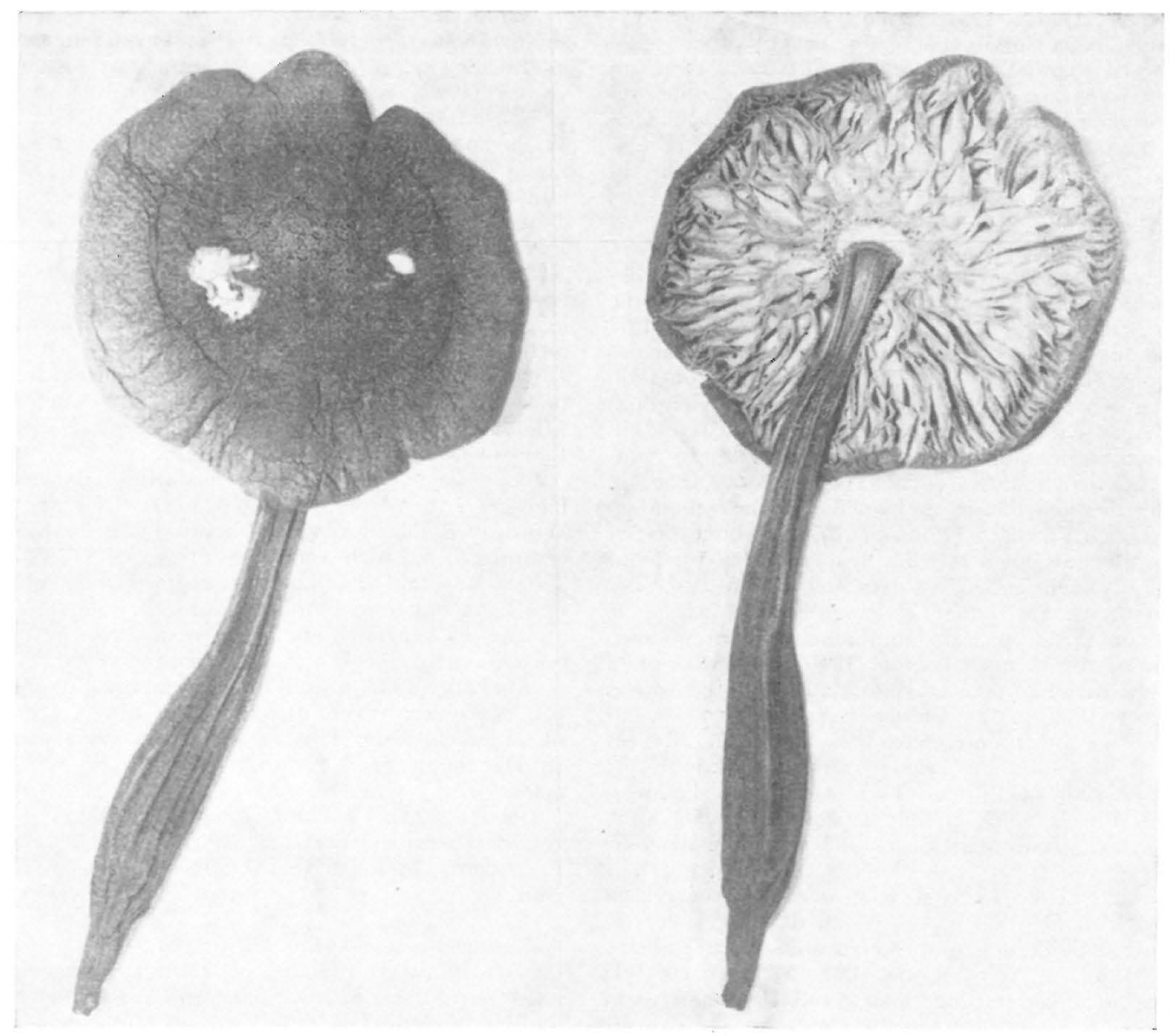

Abb. 4. - Xerula longipes aus Kakskerta, Kulho.

p. 407) »besonders unter Eichen». Aus der Untersuchung von KREISEL (1961, p. 96) erhält man das Bild, dass es sich vor allem um einen xerothermen und zugleich edaphisch ziemlich anspruchsvollen Pilz der Eichenwälder handelt, der namentlich »in Muschelkalkgebieten» gern gedeiht, aber meistens selten auftritt. Anderseits gibt es Beispiele auch einer Unabhängigkeit von Hainstandorten. HAAs (1933, p. 100) meldet nämlich den Pilz auch aus Nadelwäldern in Württemberg, allerdings auf kalkhaltigem Boden.

Der Fundort in Kulho entspricht wenigstens in gewissem Masse den mitteleuropäischen Biotopansprüchen der Art.

Die Massverhältnisse und übrigen Merkmale des Pilzes passen ausgezeichnet auf die Beschreibung und $\mathrm{Abb} .41 \mathrm{~A}$ bei Lange (op.c.). Die Grössenmessungen an 100 Sporen ergaben durchschnittlich $7.76 \pm 0.46$ $\times 6.56 \pm 0.06 \mu$, was weniger ist, als LANGE (op.c.: $8-9 \times 6-6.75 \mu)$ und LUNDELL \& NANNFELdT (1949: 9-10.5 $(-12) \times 8-9 \mu)$ angeben.

Ein zweiter, womöglich noch ausgesprochenerer Eichenbegleiter, Collybia fusipes (Bull. ex Fr.) Quél., ist für Finnland nur ein einziges Mal, aus Helsinki, erwähnt worden (vgl. Tчомıкоsкi 1959). Ich habe besonders nach dieser Art ausgeschaut, vorläufig aber ohne Erfolg.

Oudemansiella radicata (Relh. ex Fr.) Sing.

Syn. Collybia radicata Quél.

EkLund (1943 b, p. 16) erwähnt diesen Pilz aus Korppoo (Lempersö: Eichen- und Haselhain, 1941), Malmström (1943 c, p. 79) aus Bromarv, Framnäs (kleine Eichen- und Birkenwaldung, 24. VIII. 1939), Nyberg (1945, p. 49) aus Kauniainen (bei morschem Baumstumpf in feuchtem Niederwald mit Birken und Weiden), Stenlid (1947, p. 84) aus Lemland auf Ahvenanmaa (Nåtö: Laubwiesenhang mit Hasel, Eiche und Birke) und v. Schulmann (1960), p. 23) aus Lemström ebendort, Tammisaari und Karkkila.

Für das Untersuchungsgebiet sind folgende Funde zu verzeichnen.

Turku: Ruissalo, Santala, 9. IX. 1960, für die Pilzschau von Stud.rer.nat. Terho Valanne eingereicht; Ackerrand W vom Naturreservat, halbfaules überaltriges Exemplar (September 1960).

Übriges Untersuchungsgebiet: Raisio, Perno (unter Eichen); Piikkiö, Finnby, Südabhang mit Eichen und 
Fichten (13. IX. 1957, Niina Tarén); Lemu, Nyynäinen, etwa ein Dutzend grosse Fruchtkörper - die grössten $7 \mathrm{~cm}$ im Durchmesser und etwa $30 \mathrm{~cm}$ hoch - gesellig um einen morschen Eichenstumpf auf Grasheide am Rande einer von Acker umgebenen Eichenwaldung, 4. X. 1960), Rymättylä (Kepuinen, auf Grasheide unter Eichen), Parainen, Peksor, in morschem Eichenstumpf.

Alle Funde stammen vorläufig aus der Eichenzone, die meisten ausdrücklich aus der Nähe von Eichen. Der Pilz entspricht morphologisch der Beschreibung bei LANGE (1936, p. 8-99), und auch die Sporengrösse - durchschn. $15.59 \pm 0.017 \times 11.63$ $\pm 0.36 \mu, 100$ Messungen, Trockenmaterial stimmt gut mit der von LANGE angegebenen überein.

In den Hainen Skandinaviens und Mitteleuropas offenbar ein häufiger (z.B. RIGKeN 1915) und in verschiedenen Biotopen gedeihender Pilz. In Südwestschweden nach NATHORST-WINDAHL (1956, p. 323) ziemlich häufig und an die Buche gebunden, und auch LUNDELL (1932, p. 26) bezeichnet die Art vor allem als einen Pilz des Buchenwaldes (für Femsjö: allgemein in den Wäldern hier und überall, aber vereinzelt). In Dänemark nach FERDINANDSEN \& Winge (1943, p. 222) in Buchenwäldern überaus häufig, ebenso nach LANGE (1940, p. 9: »Common everywhere in woods of Fagus»). In Norwegen nach BlytT (1905, p. 32) von ein paar Buchenwaldstandorten bekannt, nach STORDAL (1953, p. 283) in Vestfold, Våle, an offener Stelle im Laubwald; später sind noch neue Fundorte hinzugekommen (vgl. Blyttia 1957, p. 29; 1958, p. 47). Da auch Michael/Hennig 1958, p. 198 den Pilz als sehr häufig vor allem unter Buchen bezeichnen, erhält man aus dem Schriftum leicht die Auffassung, dass es sich namentlich um einen an die Buche gebundenen Pilz handelt (vgl. hierzu auch noch KREISEL 1961, p. 97; WoJewoda 1961: in Polen ein Pilz der Buchenhaine, dem man im Kiefernwald nicht begegnet; SINGER 1962, p. 338: »not transgressing the northern and altitudinal limit of the area of Fagus» [die Gattung Oudemansiella]). Das Vorkommen ausserhalb des Verbreitungsgebietes der Buche erweist jedoch, dass jene Korrelation keineswegs bedingungslos ist. Die Art ist denn in Mitteleuropa auch in sauren Eichen-Hainbuchenwäldern zu finden (NEUHOFF 1956 , p. 26), ebenso wird sie in manchen anderen Untersuchungen aus Eichenwäldern erwähnt (z.B. Bohus \& Babos 1960; Bresinsiky \& ZeitlMAYR 1960).

\section{Panellus stipticus Fr. ex. Bull.}

Gilt vor allem als ein Saprophyt der Eiche (vgl. Buch 1952: „Eichenknäuling»), kann aber auch an anderen Bäumen zu finden sein (vgl. KREISEL 1961). Im Untersuchungsgebiet von ThesLefF (1919) an verschiedenen Bäumen (Birke, Erle, Espe, Eiche) nicht besonders selten. EKLUND (1943) erwähnt den Pilz aus Korppoo (Eichenstumpf), ebenso v. SchulMANN (1960) aus Tammisaari. La URila (1939) fand die Art an Eichen in Turku (Ruissalo), Hirvensalo und Karjalohja, erwähnt aber ausdrücklich das Vorkommen des Pilzes auch ausserhalb der Eichenzone in Kankaanpää und Kurkijoki.

In Ruissalo begegnet man dem Pilz hier und da, stets nur in Eichenstümpfen. Auch in Schweden ist die Art hauptsächlich an die Eiche gebunden, ist aber auch u.a. an Birken und Salweiden zu finden SVENSSON 1944).
Marasmius prasiosmus Fr.

Nach Karsten (1889, p. 108) in Turku sehr selten in Eichenwäldern zwischen Laub, nach RAUTAVAARA (1947) selten in den Gebieten I und II, v. Schulmann (1960, p. 24) erwähnt den Pilz aus V. Bromarv, Framnäs und Tammisaari. TuomIкоski (briefl.) fand ihn i.J. 1958 in Porvoo (Tamminiemi). Im HMF nur die Probe von Karsten aus dem Jahre 1858 (Ruissalo). Meine eigenen Funde sind die folgenden.

Turku: Ruissalo. Die Probe ist irgendwie abhanden gekommen, ich erinnere mich aber, dass ich den Pilz im Naturreservat von Ruissalo sammelte.

Übriges Untersuchungsgebiet: Nousiainen, Linnamäki, 16. X. 1960 an ein Eichenblatt angewachsen; Mietoinen, Saari; Taivassalo, Ketarsalmi; Halikko, Eichenwald von Pihko und Nummi.

Bleibt leicht unbemerkt und dürfte daher weit häufiger sein, als es das obige Verzeichnis angibt. Wurde von mir durchgehends auf Eichenlaubstreu gesammelt, so auch von v. Schulmann (1960) in Tammisaari und von Tuomıкoski (briefl.) in Porvoo und kann daher in Finnland wohl als obligatorisch an die Eichenzone gebunden betrachtet werden. Gleiches wird für die Art in Schweden u.a. von NANNFELDT (1952, p. 269) angegeben, nicht dagegen von Nathorst-Windahl (1956), in dessen Untersuchungsgebiet der Pilz als selten bezeichnet wird. In Dänemark nach LANGE (1936, p. 24) »rather rare».

Der Pilz ist in Finnland nie vor dem Oktober angetroffen worden, und u.a. 1961 befand sich die Fruchtkörperbildung Anfang Oktober erst im Beginn.

Marasmius ramealis (Bull.) Fr.

Nach Karsten (1889, p. 108) auf trockenen Ästen von Hasel, Eiche, Kiefer und Wacholder hier und da im südlichen Finnland. Im Untersuchungsgebiet von Thesleff (1919) auf Hasel-, Eichen- und Wacholderstreu. Dazu erwähnt EkLund (1943, p. 15) den Pilz aus Korppoo, Frey (1944, p. 11) aus Ahvenanmaa und v. Schulmann (1960, p. 24) aus Parainen und Tammisaari. LAurila (1939), der in verschiedenen Teilen Finnlands (u.a. in Satakunta) Pilze sammelte, erwähnt Marasmius ramealis nur aus Ruissalo in Turku. Tuomroskr (briefl.) nennt die Art aus Bromarv, Framnäs. Im HMF liegen folgencle Proben: V. Merimasku (Karsten); Turku (ders.), U. Helsinki, Sörnäs (ders.); Tammisaari (Malmström); Espoo (Tuomikoski); Sipoo, Söderkulla (Karsten); St. Tyrvää (ders.).

In Ruissalo allgemein und oft sehr reichlich. Andere Fundorte: Katariinanlaakso, Metsäkylä, Artukainen; Raisio, Perno; Lemu, Ohensaari; Mietoinen, Saari; Nousiainen, Linnamäki; Kakskerta, Kulho; Korppoo, Kuraklintti (unter Hasel); Kaarina, Karpanmäki; Piikkiö, Tuorla; Parainen, Peksor; Halikko, Vaisakko; Pohja, Fiskari; Aura (beim Bahnhof). Im ganzen scheint es sich also um einen Pilz zu handeln, dessen Verbreitung recht stark auf die Eichenzone konzentriert ist.

In Schweden und Dänemark besonders im Verbreitungsgebiet der Buche gemein (NATHORsTWindahl 1956; Lundell \& NanNFeldt, Exsikkat, Nr. 2550), häufig noch in der Gegend von Uppsala an der Nordgrenze der Eichenzone (LUNDFLL 1932), bei Karlstad selten (Svensson 1940, p. 11). 
Marasmius rotula (Scop.) Fr

Offenbar weiter verbreitet als voriger, dürfte aber gleichfalls auf den Süden des Landes beschränkt sein. Karsten (1876, p. 232) erwähnt den Pilz aus U. Helsinki und Sipoo St. Tyrvää und EH. Tammela, Malmström (1934, p. 73) gleichfalls aus Helsinki, EKLUND (1943) aus Korppoo und FreY (1944) aus A. Finström, Godby. Tuомгковкі (briefl.) erwähnt die Art aus EH. Lammi. Ich selbst habe ihn nur in Ruissalo, Katariinanlaakso und Muhkuri sowie in Kakskerta, Kulho und Mietoinen, Saari gefunden, halte aber sein Vorkommen auch anderwärts für möglich.

Sehr typische Marasmien im Untersuchungsgebiet sind die namentlich in Eichenhainen kennzeichnenden Arten Marasmius urens Fr. und M. (Collybia) confluens Pers. ex Fr., beides ausserordentlich tonangebende Pilze der Eichenhaine Mitteleuropas (vgl. Neunoff 1956, p. 26). M. urens ist jedoch bis hinauf ins nördlichste Finnland - Utsjoki, Kevo - angetroffen worden (TUR) und kann daher nicht als ein südlicher Pilz betrachtet werden, so typisch er in den Eichenwäldern von Ruissalo etc. auch ist. Es ist mit der Möglichkeit zu rechnen, dass es im Bereich dieser Art mehrere Rassen gibt, die sich auf die Zersetzung des Fallaubes ganz bestimmter Bäume spezialisiert haben. $M$. confluens ähnelt dem vorigen darin, dass er im Untersuchungsgebiet namentlich die üppigsten Eichenhaine besiedelt, anderseits aber vielenorts auch ausserhalb der Eichenzone bis hinauf nach Utsjoki angetroffen wird (vgl. v. Sahulmann 1960).

Mycena inclinata (Fr.) Quél.

Wohl zu den charakteristischsten Mycena-Arten des Untersuchungsgebietes gehört $M$. galericulata (Scop. ex Fr.) S. F. Gray, der man besonders in morschen Eichenstümpfen begegnet. Auch $M$. alcalina (Fr.) Kummer und $M$. polygramma (Bull, ex Fr.) S. F. Gray dürften im Gebiet häufiger namentlich in Eichenwäldern $\mathrm{zu}$ finden sein (vgl. LAURILA 1935). Der eigentliche Pilz der Eichenstümpfe, und zwar in Finnland nur in solchen angetroffen, ist indessen $M$. inclinata (Fr.) Quél. Diese Art wird von LAURILA (op.c.) aus Turku, Ruissalo, von EkLUND (1943, p. 16) aus Korppoo und von v. SchulmanN (1960) aus Parainen (Attu), Tammisaari und gleichfalls aus Ruissalo erwähnt.

Der Pilz ist in Ruissalo keineswegs selten, sondern ist im ganzen östlichen Teil der Insel im Vorkommensbereich der Eiche zu finden. Dazu ist er im Stadtgebiet von Turku in Katariinanlaakso und Metsäkylä und im übrigen Untersuchungsgebiet in Raisio, Perno; Lemu, Ohensaari; Nousiainen, Linnamäki; Parainen, Peksor und Kaarina, Karpanmäki gesammelt worden.

In Mitteleuropa ist die Art hauptsächlich an die Eiche, doch auch, obwohl seltener, an Buche und Kastanie gebunden (KREISEL 1961).

Amanita raginata (Bull. ex Fr.) Vitt. f. lividopallescens Secr.

Syn: Amanita livido-pallescens Gill.

Am Südrand des mit Eichen bewachsenen Hügels Linnanvuori in Kakskerta, Kulho, an der Grenze von Acker und Wald, wurden i.J. 1953 grosswüchsige Exemplare von Amanita vaginata gefunden, wie ich solche vordem nicht gesehen hatte. Der Pilz wurde auch 1959 an der Stelle gefunden. Die grössten

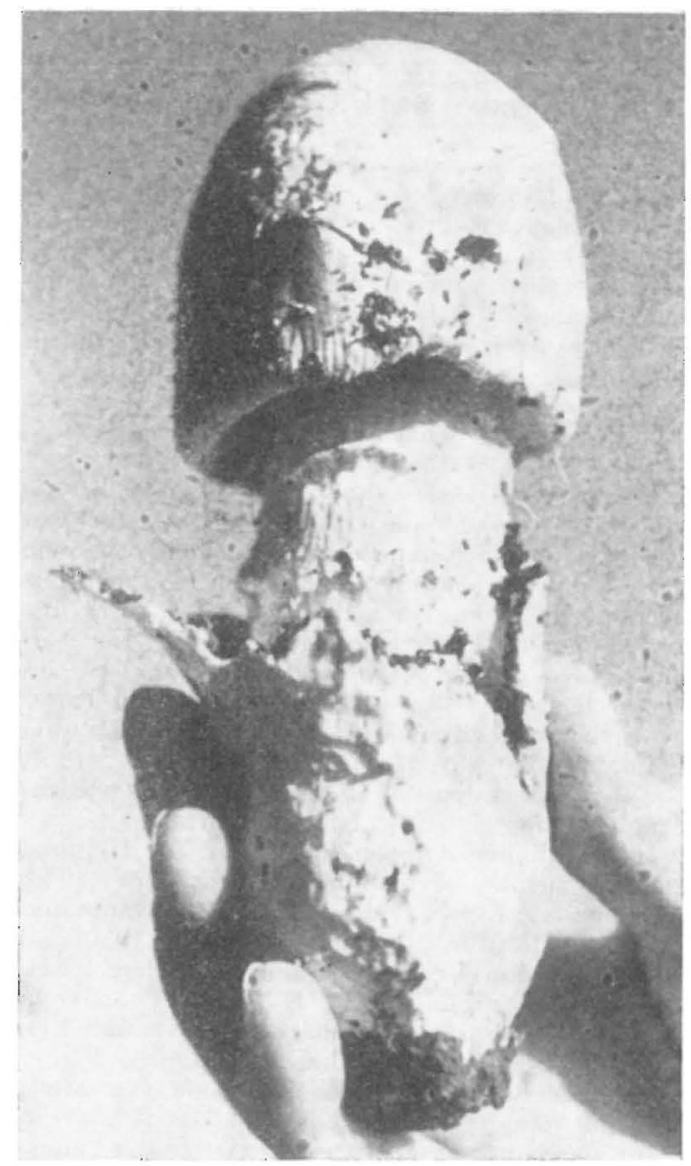

Abb. 5. Amanita vaginata f. livido-pallescens aus Kakskerta, Kulho.

Exemplare waren $20 \mathrm{~cm}$ hoch, mit $14 \mathrm{~cm}$ breitem Hut. Die Farbe kann am nächsten als hell rahmfarben bis gelblichbraun bezeichnet werden; die u.a. von Kühner \& Romagnesi (1953) benutzte Bezeichnung nussbraun mag hier gleichfalls gut am Platze sein. Die Hutoberfläche zeigt grosse einheitliche, dickliche, hellgraue Reste der Hülle. Der kammartige Rand ist nicht so deutlich ausgebildet wie bei den hiesigen kleineren Formen der Art. Der Hut ist auch relativ betrachtet verhältnismässig dickfleischig. Der Stiel ist weisslich, jedoch mit einer 'Nuance des Hutes, seine Oberfläche wie marmoriert, an die Abb. 7 A bei LANGE (1935) erinnernd. Die Scheide ist geräumig und gut ausgebildet; auf der Höhe ihres Randes erkennt man wie Anlagen eines zweiten Randes.

Grösse und Ökologie des Pilzes scheinen auch auf Amanitopsis strangulata (Fr.) hinzuweisen. Die Scheide ist aber ganz anders geformt (vgl. LANGE l.c.) und auch ihre Anatomie ist eine andere, mit langen, nicht wie bei $A$. strangulata (KüHNER \& RomAGNeSI 1953, p. 434) grossen und kugeligen Zellen.

In Schweden ist Svensson (1940) bei Karlstad im Eichenwald auf eine Form gestossen, für die er den Namen $A$. vaginata f. major Gillet braucht und die er 
äusserlich gewissermassen als Zwischenform von $A$. vaginata und $A$. strangulata bezeichnet. Der Fuss ist bei diesem Pilz gleichfalls marmoriert.

Die Proben liegen im TUR, HMF und im Museum zu Uppsala.

Die echte $A$. strangulata, die aus verschiedenen Teilen des Landes angegeben worden ist (FREY 1944: Ahvenanmaa; Eriund 1944: Korppoo; Tuomikoskr 1959 und v. Schulmann 1960: ausser Ahvenanmaa und Parainen in der Eichenzone auch Lammi und Elimäki), obwohl betreffende Belege nicht in Museen vorliegen, habe ich nie angetroffen.

\section{Amanita citrina (Scharff ex Fr.) S. F. Gray}

Syn.: Amanita mappa (Batsch ex Lasch) Quél.

KaRsten (1876) erwähnt zum erstenmal die Art aus Ruissalo und (auf Grund einer Angabe von Nylander) aus Helsinki. Erst 1889 meldet er sie auch aus Tammela, Mustiala, und bezeichnet den Pilz dort als sehr selten. Nach EKLUND (1943, p. 18) begegnet man der Art vielenorts in Korppoo, Houtskari und Nauvo, v. Schulmann (1960) erwähnt sie aus der Eichenzone (Ahvenanmaa, Tammisaari, Parainen), dazu aus Elimäki. Stenlid (1947) hat drei Fundorte auf Ahvenanmaa. RautavaARA (1957, p. 5) bezeichnet den Pilz als sehr häufig, was (stellenweise) für das südlichste Finnland zutrifft.

Im HMF liegen folgende Proben: V. Helsinki, Vantaa, zieml. allgemein in Heidewäldern (1953, Tuomikoski); Espoo, Bodom (desgl.) und Ramsöudd (1952, Malmström); Kauniainen (1938, 1939 und 1941, Nyberg); Porvoo (1925 und 1935, ders.), EH. Tammela, Mustiala (1866, Karsten). Tuomikoski (briefl.) hat die Art in Bromarv, Framnäs und EH. Lammi, Haselhain von Untula gefunden. Ferner wurde der Pilz noch in ES. Puumala von Mirja Korvenheimo gefunden (Tuomikoski briefl.).

Im Untersuchungsgebiet ist die Art an den untersuchten Punkten in allen Jahren reichlich zu finden und charakteristisch. Proben bzw. Aufzeichnungen liegen von folgenden Stellen vor: Ruissalo mehrmals, Katariinanlaakso häufig und reichlich, Muhkuri, Piispanristi, Pansio, Pahaniemi, Pitkämäki, Metsäkylä, Pääskyvuori und Takakirves; Kaarina, Karpanmäki; Piikkiö, Tuorla; Paimio, Juntola und Sanatorium; Halikko, Vaisakko und Pihko; Raisio, Perno und Kaanaanmaa; Nousiainen, Linnamäki; Lemu, Nyynäinen; Taivassalo, Ketarsalmi; Uusikaupunki (Lgm.); Parainen, Attu, Peksor und Lofsdal; Rymättylä, Kepuinen; Kakskerta, Kulho und Järvistensaari; Korppoo, Hevosluoto und Pohja, Fiskari. Im TUR liegen im ganzen 22 Proben.

Im Gegensatz zu diesem reichlichen Beobachtungsmaterial liegt z.B. aus Yläne keine einzige Beobachtung vor. Såltin hat den Pilz in St. Lappi nicht angetroffen, wohl aber oft in Pohja, Fiskars. Aus diesen Gründen betrachte ich die Art in Finnland als streng südlich, mit Hauptvorkommen in der Eichenzone.

In Mitteleuropa begegnet man dem Pilz sowohl in Hainen als auch in Nadelwäldern (z.B. HAas 1933, p. 104; Neuhoff 1956), in Dänemark gemein besonders in Laubwäldern (FERDINANDSEN \& Winge 1940), in Schweden häufig (etwa wie Amanita muscaria) sowohl in Laub- als Nadelwäldern, weniger häufig noch auf der Höhe von Karlstad (Svensson 1940 , p. 11). Nach der Peripherie der Eichenzone hin wird er jedoch auch in Schweden immer seltener, wie man u.a. aus dem Text zu Nr. 1701 im Exsikkat von Lundell und NANNFELDT ersehen kann. Die Art tritt jedenfalls bei Kiefer und Fichte als Mykorrhizenbildner auf (vgl. Modess 1941), und auch im Gebiet von Turku wurde sie u.a. in Ruissalo, Pahaniemi, Pitkämäki, Paimio und Nauvo in reinem Kiefernwald gefunden. Am zahlreichsten wächst jedoch der Pilz an eichenbewachsenen Abhängen; zu den besten Standorten gehört der Südrand von Teilgebiet 9 (Nikoskelainen 1955) in Katariinanlaakso, wo man Massen des Pilzes auf einmal antreffen kann. $\mathrm{Da}$ zudem der Pilz auch in Muhkuri zu finden ist, erweist dies seine vollständige Unabhängigkeit von Nadelbäumen.

\section{Amanita spissa (Fr.) Kummer}

Syn.: A. excelsa (Fr.) Kummer

Lundell (Lundell und Nannfeldt 19, Nr. 2704) zählt Amanita excelsa und $A$. spissa in den Variationskreis ein und desselben Taxons, wobei $A$. excelsa ursprünglich auf gewisse Typen der frischen Haine zu beziehen wäre. Die Variationsbreite der Gruppe dürfte in Skandinavien insgemein gross sein (vgl. SVENSSON 1940, p. 11).

Der Pilz wurde aus Finnland zum erstenmal von EKLUND (1943 b, p. 18) gemeldet, der ihn auf einer Hainwiese mit Eichen und Haselsträuchern in Kjölingby in Korppoo fand. Andere Angaben über den Pilz habe ich im Schrifttum nicht gefunden. Im HMF liegt eine Probe aus Helsinki, Sillböle (1953, Tuomikoski).

Die einzige Fundstelle der Art im Untersuchungsgebiet ist das Teilgebiet 9 von NikoskelaineN (1955) in Katariinanlaakso, wo am 13. IX. 1957 und 4. IX. 1961 je ein Fruchtkörper des Pilzes an genau derselben Stelle an kieferbewachsenem Nordhang mit Fichten, Birken und kleinen Ebereschen in der Nähe gefunden wurde. Im letztgenannten Jahre war der Fruchtkörper stattlicher und heller, aber leider überaltrig und zertreten und konnte darum nicht konserviert werden. Die Untervegetation besteht an der Stelle aus kräftigem Astmoos, Rhytidiadelphus squarrosus und Vaccinium myrtillus. In der Nähe befindet sich jedoch ein ausgehobener Graben, und ganz am Wuchsort hat es fast nackten Boden gegeben. Der Boden besteht hier aus lehmgemischter Moräne. Der Standort ist somit weit dürftiger als derjenige, wo EkLund den Pilz in Korppoo fand. Tuomikoskis Probe wurde nach dem Etikettenvermerk am Fusse eines Abhangs mit Wald vom OxalisMyrtillus-Typ gesammelt.

Der Pilz dürfte in Südschweden als selten gelten (INGELSTRÖM 1940, p. 198) und besiedelt dort die Nadel- und Mischwälder. Nach Andersson (1941, p. 394) findet man ihn in den südlichen und mittleren Teilen des Landes sowohl in Buchen-, Nadel- als gemischten Wäldern, am nördlichsten bei Uppsala. Im ganzen sind für Schweden etwa ein Dutzend Fundorte aus Skåne und ebensoviel aus Uppland bekannt, dazu kommen zerstreute Funde aus Blekinge, Småland, Västergötland, Närke und Värmland. In Norwegen ist der Pilz bis hinauf nach Bergen (siehe Blyttia 1958 , p. 47 ; 1959 , p. 36) und zum Tal des Storelv verbreitet (BLyтT 1905).

In Mitteleuropa ist der Pilz kein anspruchsvoller Hainwaldbewohner, sondern ist sowohl in Laub- als Nadelwäldern zu finden (Neuhof 1956 , p. 25) optimal in den letzteren. Auch nach MichaeL/HeNNIG (1959) ist die Art nicht wählerisch in bezug auf 
die Holzart. HaAs (1933, p. 117) und Veselý (1934, p. 42) halten den Pilz für einen Nadelwaldbewohner, dagegen sagt LOBANOw (1960), dass er in Eichenwäldern zu finden sei.

Die Art dürfte in der Eichenzone nicht an eine bestimmte Pflanzengesellschaft gebunden sein - jedenfalls ist sie (an sich) nicht von der Eiche abhängig. Dagegen dürften ihre klimatischen Ansprüche gross sein und bedingen es, dass sie nicht weit nördlich vordringt. VESELÝ (op.c., p. 41) stellt sie in bezug auf die Nordgrenze A. junquillea Quél. an die Seite und betrachtet schon den 55. Breitengrad gewissermassen als Grenzgebiet. Karlvall (1949) erwähnt den Pilz aus Laubwäldern, einem Mischwald und einem Park in der Gegend von Göteborg.

\section{Amanita pantherina (DC. ex Fr.) Schumm.}

Eine deutlich typisch mitteleuropäische Art, schon in Dänemark nach LANGE (1935, p. 15) »not uncommon», in Südschweden nach NATHORST-WiNDAHL (1956) ziemlich selten. Ingelström (1940) bezeichnet den Pilz in Schweden als ziemlich häufig. In Finnland nach Tuomikoski (1959) selten und südlich. Im Schrifttum werden folgende Fundorte genannt: Helsinki (Karsten 1889); Viipuri, Liimatta (Thesleff 1919); Porvoo (Nyberg 1938); Tvärminne (Malmström 1942); Korppoo, Strömma und Kjölingby (EKLund 1943); Bromary und Lohja (v. Samulmann 1960). Proben im HMF: U. Helsinki (1883, Nylander); Espoo, Bodom (1949, Tuomikoski) und Kasberg (1950, ders.); Porvoo (1937, Nyberg); Kauniainen (1939, ders.). Ganz für sich steht ein Fund aus EP. Jalasjärvi (1859, Karsten), den aber Karsten nicht in seinen späteren Arbeiten erwähnt.

Im Untersuchungsgebiet kann die Art auf Flächen. mit Eiche nicht als selten betrachtet werden. Unbedingt am reichlichsten tritt der Pilz in Katariinanlaakso auf, wo man ihn in dem guten Pilzjahr 1960 Anfang September zu mehreren Dutzenden auf einer einzigen Exkursion finden konnte. Andere Fundorte: Turku, Ruissalo (vielenorts), Muhkuri, Metsäkylä, Pansio, Hirvensalo; Taivassalo, Ketarsalmi; Rymättylä, Kepuinen; Nousiainen, Linnamäki; Kakskerta, Kulho; Kaarina, Karpanmäki; Piikkiö Tuorla und Harvaluoto; Parainen, Attu und Lofsdal; Halikko, Viurila. An sämtlichen diesen Stellen wuchs der Pilz entweder an lichtreichem Hainrand, in parkartigem hellen Eichenwald oder auf südexponierter Grasheide - stets in der Nähe von Eichen. In Begleitung von Eiche und Hasel fand auch EKLund (op.c.) die Art in Korppoo. Für einen Hainwaldbewohner hält auch LANGE (1935) den Pilz in Dänemark, doch kann man ihm auch im Fichtenwald begegnen. Nach Buch (1952) in Sachsen unter Quercus, nach Neunof $(1956$, p. 25) in Mitteleuropa in sauren Laubwäldern. Nach Bresinsky \& Zeitumayr (1960) kann die Art in Bayern geradezu als Indikator sauren Bodens angesehen werden. Für Schweden wird der Pilz von Nathorst-Windahl (1956, p. 323) aus Laub- und Mischwäldern erwähnt, für Osteuropa von LoBANow (1960) aus Eichenwäldern, während VeselÝ (1934) ihn aus allerlei Wäldern angibt. Nach Wojewoda (1961) ist die Art in Polen sowohl in üppigen Buchenhainen als auch in Vaccinium myrtillus -Gesellschaften zu finden.

Anderseits wird die Art in Finnland auch aus Nadelwäldern angegeben (Nyberg 1938, p. 49: Kiefernheide). Malmström (op.c.) fand den Pilz auf reinem Dünensand in Tvärminne, Tuomıкoski (1959) in hainartigen Wäldern mit eingestreuten Fichten.

Selbst fand ich den Pilz in Metsäkylä bei Turku auf südexponiertem, licht mit Kiefern bestandenen Sandboden, am Rande der hier befindlichen Sandgrube.

Der Pilz scheint also vor allem sonnenbeschienene und leicht erwärmbare Bodenflächen zu bevorzugen, und dabei bietet ihm anscheinend der Sand die besten Vorteile. Der allgemeine Schwerpunkt des Vorkommens liegt aber deutlich im Bereich der Haine, und hier wächst der Pilz vornehmlich auf warmen und somit auch verhältnismässig trockenen, an die Haine grenzenden Grasheiden, mit Vorliebe in der Nähe von Eichen.

Macrolepiota rhacodes Vitt. var. puellaris Fr.

Die Erstmeldung für Finnland kommt von STENLID (1947), der den Pilz an drei Orten auf Ahvenanmaa fand. Später sammelte ihn v. Schulmann (1960) gleichfalls dort und dazu in Elimäki und Lammi.

Es handelt sich offensichtlich um eine südliche, obwohl nicht einzig auf die Eichenzone beschränkte Art. Ich selbst fand den Pilz nur am 4. IX. 1960 im Fichtenwald nahe dem Meeresufer in Nauvo, Seili. Stud.rer.nat. Pirjo SEwón sammelte ihn 1961 in Kakskerta, Järvistensaari. Im Nordosten Mitteleuropas in Fichtenwäldern »sehr häufig» (NEUHOFF 1956, p. 24).

\section{Naematoloma sublateritium (Fr.) Karst.}

Die Verbreitung dieses wenigstens im südlichsten Finnland häufigen Pilzes der Laubbaumstümpfe nordwärts ist verhältnismässig unbekannt.

Karsten (1882, p. 242) hielt die Art für sehr selten und hatte sie nur in Turku (Ruissalo) und in Tammela gefunden. Am letztgenannten Ort muss die Art tatsächlich selten gewesen sein. Sicherlich richtiger ist aber das Bild, das v. Schulmann (1960) von der Art gibt, wenn er sagt, dass der Pilz an 8 von seinen 10 Beobachtungspunkten gefunden wurde. Gemäss der Zeitschrift »Sienitietoja» (1961) ist die Art auch in Kuopio angetroffen worden.

Nichtsdestoweniger dürfte man die Art als einen sehr typischen Pilz der Eichenstümpfe betrachten können, der in den Eichenhainen des Untersuchungsgebietes stets zu finden ist. Die von Laurila (1939) beobachtete deutliche »Vorliebe» des Pilzes für die Eiche (von seinen Beobachtungen sind 8 von Eichen, 2 von Birken und eine von der Erle) ist auch nach meinem Dartun im Gebiet feststellbar. In Ruissalo, wo es doch recht viel auch Birken gibt, ist Naematoloma sublateritium fast einzig an Eichenstümpfen zu finden.

In Südschweden häufig (NATHORst-WindahL 1956) in der Gegend von Uppsala nur von einer Stelle (an Laubbaum) erwähnt (LUNDELL 1932) und dürfte also dort nicht häufig sein.

Der Pilz tritt manchmal schon sehr früh auf oft schon mitten im Sommer (nach Sienitietoja 1959, n:o 3, p. 6 bereits Anfang Juni).

Naematoloma fasciculare (Huds. ex Fr.) Karst. var. pusillum Lange

Diese äusserlich offenbar leicht identifizierbare Varietät ist auch ökologisch von ihrer Hauptform verschieden. Schon LANGE (1940) erwähnt sie als einen Pilz der Eichenstümpfe. Im Schrifttum sind 
die Angaben spärlich. Lundell (1932) führt jedoch die Varietät aus der Gegend von Uppsala an, und zwar namentich von einer grossen Eiche.

Ich selbst habe die Varietät im Untersuchungsgebiet nur dreimal gefunden, und zwar in Ruissalo, in Raisio, Perno und in Kakskerta Järvistensaari, jedesmal an einem Eichenstumpf. Im hiesigen Schrifttum sind mir keine Angaben über die Varietät begegnet, und auch im HMF befinden sich keine Proben.

\section{Rhodophyllus lividus (Bull. ex Mérat) Quél.}

Diesen Pilz, der als einer der seltensten in ganz Finnland gegolten hat, erwähnt KARsten (1879) aus Turku, Ruissalo. Später (Sienitietoja 1954) ist er auch noch in Espoo gefunden worden. Im HMF liegen aus Ruissalo folgende Proben: Elfving 1877, Karsten 1879 und 1881, Kallio 1952. Im TUR ist die Art durch 17 Proben vertreten.

Meine eigenen Funde beschränken sich lediglich auf Ruissalo und Katariinanlaakso. In Ruissalo habe ich den Pilz im Laufe der letzten zehn Jahre wiederholt in verschiedenen Teilen der Insel angetroffen, und zwar IW vom Volkspark (Grasheide, einige Exemplare unter Eichen 1952); Honkapirtti (in verschiedenen Sommern unter Eiche und Hasel zwischen Honkapirtti und der Landstrasse, im allgemeinen jedoch nur vereinzelt); Botanischer Garten der Universität (vor allem an dem seicht gegen Süden abfallenden Abhang mit licht stehenden Eichen in der Mitte des Gartens); Südrand des Reservats, Grasheide am Wegrand 1960 (hier der grösste gefundene Fruchtkörper, $28 \mathrm{~cm}$ im Durchmesser); Ajatinniemi (Südabhang mit Eiche und Hasel, möglicherweise Karstens "Locus classicus», hier in vielen Jahren).

In Katariinanlaakso gibt es den Pilz auf ziemlich beschränkter Fläche, in den Teilgebieten 9 und 10 von Nrkoskelainen (1955), aber wenigstens in manchen Jahren um so zahlreicher, und zwar auf offener Grasheide unter Eichen, stellenweise auf fast blosser Erde. Die beste Stelle ist der parkartige Abschnitt im unteren Teil des Abhangs im Teilgebiet 9, wo im Herbst 1960 nahe des Ackerrandes mehrere Dutzend Fruchtkörper gefunden wurden. Im Teilgebiet 10 gibt es den Pilz am reichlichsten in der Nähe des Nordrandes, und z.B. Mitte September 1960 wurden hier gleichzeitig mehr als hundert Fruchtkörper beobachtet. Der Hutdurchmesser übertrifft manchmal bis um das Doppelte den von LANGE (1936, p. 95) angegebenen Wert von $12 \mathrm{~cm}$, was als ein Zeichen günstiger Standortsverhältnisse $z u$ deuten sein dürfte. Die Fruchtkörperbildung ist bei der Art an und für sich nicht kälteempfindlich, denn um die Monatswende September--Oktober 1960 wurden noch nach mehreren Nachtfrösten wenigstens zwei gut erhaltene Fruchtkörper angetroffen. 350 Messungen ergaben als grössten Sporendurchmesser durchschnittlich $11.03 \pm 0.2 \mu$ (bei LANGE op.c. 7.5-10; LUNDELL und NANNFELDT, Fungi exsiccati Nr 1131: $8-10 \times 7-8 \mu$ ).

In Mitteleuropa wird die Art zu den typischen Pilzen der schwach sauren oder alkalischen EichenHainbuchenwälder gezählt, ist aber auch in andersartigen Eichenwäldern zu finden (Neuhoff 1956, p, 27). Nach Micihael/Hennig (1958) nimmt die Häufigkeit des »besonders unter Eichen, Buchen und anderen Laubbäumen» vorkommenden Pilzes (vgl. hierzu auch PILÁt 1954) von Süddeutschland nordwärts ab. In Dänemark nach L.ANGE (op.c., p. 95) srather rare, growing on moist ground (clayey soil) in open spaces in frondose woods (chiefly Quercus)». BüLow (1889) hält die Art in Skåne für selten, im Verzeichnis von NATHORST-WINDAHL (1956) aus Südwestschweden ist der Pilz überhaupt nicht aufgenommen. Nach INGELSTRöM (1940) selten u.a. in der Gegend von Stockholm. Im Exsikkat von LUNDELL \& NANNFELDT (1942) als Nr. 1131 aus Uppland »on lawn, under oaks, hazel and Pyrus malus».

Muss als ein typischer Pilz der Eichenzone betrachtet werden.

Über die Eignung der Boleten für die pflanzengeographische Forschung schreibt Singer (1949, p. 108-109) u.a.: »The boletes are an excellent field for those who are interested in the mycological aspect of historical plant geography and the evolution of the species in fungi.»

Im Vergleich zu Mitteleuropa ist die Familie in Finnland recht schwach vertreten. Anderseits gehört sie gerade zu denjenigen Familien, die in unserem Lande eine bemerkenswerte Zahl von südwestlichen Arten aufzuweisen haben. Von diesen sind nur ganz wenige an südliche Holzarten gebunden. Die meisten sind offenbar in bezug auf ihre klimatischen Ansprüche z.B. den Phanerogamen der Eichenzone gleichzustellen. Dadurch eignet sich diese Familie vorzüglich auch als Grundmaterial für eine Charakterisierung der Eichenzone.

Gyroporus cyanescens (Bull. ex Fr.) Quél.

Nach Thesleff (1919) in Liimatta bei Viipuri unter Eichen. Malmström (1943 b, p. 73) fand die Art an zwei Stellen bei der Zoologischen Station in T'värminne nahe Tammisaari, Tuomıкoski (1943) meldet den Pilz aus Sortavala und Espoo und v. Schulmann (1960) aus V. Pohja, Fiskari (hier wurden auch i.J. 1960 fünf Fruchtkörper gefunden; einer befindet sich im TUR. Im Jahre 1962 wurde die Art auch in Kirkkonummi, Österby gesammelt (Sienitietoja 4, p. 1).

Ich habe diesen Pilz nur in Ruissalo gefunden, und zwar auf blosser Erde unter Eichen und Linden am Wegrand am westlichen Hainabhang des Naturreservats am 1. September 1954 einen Fruchtkörper (TUR), später trotz Suchens nicht mehr.

In Schweden ist die Art im ganzen Südteil des Landes offenbar ziemlich selten (ANDERSSON 1954, Fig. 3: 16 Fundorte; Nathorst-Windahl 1956 für Südwestschweden: »Ziemlich selten»). In Norwegen nach BLyTT (1905,)ein seltener Begleiter von Buche und Eiche. Stordal (1955, p. 72) teilt bereits etwa 30 Fundorte aus Südnorwegen mit, und demnach dürfte der Schwerpunkt der Art sowohl in bezug auf Verbreitung als Vorkommen gerade hier im Westen liegen. Die Art folgt nach Stordal in grossen Zügen dem Verbreitungsgebiet der Eiche und geht somit an der Westküste hinauf bis Vinje in SörTröndelag.

In Dänemark ist der Pilz selten. So liegen nach Möller (1956, p. 313) aus Lolland und Falster im 
ganzen nur drei Funde vor, und im westlichen Dänemark dürfte die Art völlig fehlen (vgl. AnDERsson op.c.).

Sowohl hier (ausser dem Fund von Tuomikoski in Sortavala) wie in Skandinavien dürften die Funde durchgehends auf das Vorkommensgebiet der Eiche beschränkt sein. Doch ist der Pilz nicht an sich von diesem Baum abhängig, und in Mitteleuropa wird die Eiche in Verbindung mit ihm gar nicht erwähnt. Man findet ihn entweder in Nadelwäldern oder »in Laub- und Nadelwäldern auf Sandboden, oft mitten auf sandigen Wegen, gern unter Birken» (Mrahaes/ Hennig 1960, p. 51). Nach Ramsbottom (1954, p. 227) wächst der Pilz in England vornehmlich unter Fichten. Die Korrelation mag ähnlich derjenigen sein, wie sie z.B. zwischen der Eiche und z.B. Carex caryophyllea besteht: eine Erfüllung der bioklimatischen Ansprüche im gleichen Raum. Diese zeigen sich in der allgemeinen Verbreitung, doch auch in der Natur des Standortes. Der Pilz gilt allgemein als ein Bewohner offener, sonniger und sandiger (Hain-) Böden. Nach IngeLström (1940) begegnet man ihm an sandigen Wegrändern, auf Laubwiesen usw., nach STORDAL (1955, p. 74) mit Vorliebe auf sandigem Boden. Auch Andersson (op.c., p. 190) unterstreicht die Vorliebe für offene und sandige Standorte. In Tvärminne (Malmström 1.c.) wuchs der Pilz gleichfalls auf Sand, in Fiskari (Apoth. H. SăLTiN mündl.) an sandigem Grabenrand in Südexposition unter Corylus. Die Erwähnung von Tчомгкоsкi (op.c.) über das Vorkommen des Pilzes auf entblösster, feuchter Moräne (Weggrabenrand) in Sortavala ist gleichfalls mit dem allgemeinen ökologischen Schema vereinbar. Noch in Mitteleuropa äussern sich dieselben ökologischen Ansprüche der Art, und der optimale Biotop dürfte dort der kiefern- und eichenreiche Heidewald sein (z.B. NeuHoff 1956, p. 23). Selbst noch die amerikanische Form ist ökologisch gleich beschaffen (CokeR \& BeERs 1943, p. 15: »In sandy soil», »on a bank by road», usw.).

Gyroporus castaneus (Bull, ex Fr.) Quél.

Die Art wurde in Finnland zum erstenmal erst 1937 von Malmström (1943 a, p. 72) auf Dünensandboden mit Kiefern bei Tammisaari gefunden. EKLUND (1943, p. 213) erwähnt den Pilz aus Korppoo im Schärenhof von Turku »auf sandig. Gehölzwiesenboden in offener Lage».

Im Untersuchungsgebiet wurde die Art am 8. September 1961 auf der gleichen früher schon öfters erwähnten südexponierten Grasheidefläche im Teilgebiet 9 (NIKosKeLAINEN 1955) von Katariinanlaakso gefunden (2 gutgewachsene Fruchtkörper unter Eichen), wo auch $B$. edulis var. reticulatus, $B$. luridus, B. miniatoporus und Xerocomus chrysenteron vorkommen. Die Farbe war offenbar durchaus typisch, Hut und Fuss kastanienbraun, Röhrenschicht weiss. Das eine Exemplar wurde der Länge nach gespalten und zeigte so den gefächerten Aufbau des Fusses. Das Fleisch verfärbt sich nicht. Der schwache Glanz der Hutoberfläche ist derselbe wie bei dem von MALMsтröм (op.c.) gefundenen Pilz. Der Hutdurchmesser betrug bei dem einen Stück $6 \mathrm{~cm}$, bei dem anderen $4 \mathrm{~cm}$.

Der Pilz ist innerhalb der skandinavischen Eichenzone selten. INGELSTRÖM (1940) bezeichnet ihn als ziemlich selten auf sandigen Laubwiesen und an Waldabhängen, ebenso ist er nach NATHORSTWindal (1956) in Südwestschweden selten. Im
Stockholmer Reichsmuseum befinden sich vier Proben, davon zwei unter Eichen in Blekinge und bei Stockholm gesammelt.

In Dänemark halten Ferdinandsen \& Winge (1943) die Art für sehr selten (vgl, auch Friesia 1956, p. 312). Aus Norwegen erwähnt Stordal (1955, p. 76) 5 Fundorte von grasbewachsenen Flächen in der Nähe von Corylus. Nach Pearson (1950) und Ramsвоттом (1954, p. 231) ist der Pilz auf den Britischen Inseln ein Begleiter der Eiche. Für Mitteleuropa sagt Michael/Hennig (1960, p. 205) : Im Laubund Nadelwald, besonders unter Eichen auf sandigem Boden». Der Standort bei Turku dürfte somit dem typischen mitteleuropäischen gleichkommen.

Gyrodon lividus (Bull. ex Fr.) Sacc.

Die ersten Angaben über diese Art in Finnland, wenn G. sistotrema ihr als Synonym zugestellt wird (vgl. Kallenbach 1926; Pearson 1950), stammen von Karsten (1859), der den Pilz aus Piispanristi bei Turku erwähnt. Der zweite Fund bei ihm, unter dem Namen G. labyrinthicus Fr., ist aus Mustiala. Malmström (1943) bespricht eingehend die Art auf Grund seiner Funde in Tammisaari. Stenlid (1947) meldet sie aus Lemland (Nåtö), Jomala und Sund auf Ahvenanmaa, durchgehends aus beweideten Erlenbeständen am Meeresufer. Im HMF liegen folgende Proben: Espoo, feuchtes Erlengebüsch (1945, Nyberg); ebendort, Bodom, feuchtes Grauerlengebüsch, (1953, Tuomikoski); Loppi, Sajaniemi, Frlengebüsch am Bachufer, (1955, Tuomikoski); Tammela, Mustiala (1910, Karsten).

Die Art wurde auf einer Studentenexkursion 1957 im Naturreservat von Ruissalo angetroffen. U'ber die Bäume und auch die übrige Vegetation der Fundstelle liegt leider nicht nähere Kunde vor, es gibt aber im Reservat u.a. feuchte Senken mit reicher Farnvegetation und Schwarzerlen.

Alle sicheren Funde aus Finnland sind aus der Nähe von Erlen, und irgendwie als von der Erle abhängig gilt der Pilz auch anderswo (u.a. PEArson 1950; NeuHofF 1956, p. 29; MrahaEL/Hennig 1960, p. 51). In Schweden ist der Röhrling nicht sehr selten, jedoch grösstenteils auf den Süden beschränkt Andersson 1939). In Norwegen ist er nach BLYTT (1905) selten und meistens an der Süd- und Westküste zu finden. Auch in Finnland liegt der Schwerpunkt im Süden, aber sicherlich nicht ausschliesslich in der Eichenzone. Es ist möglich, dass sich das jetzt gewonnene Bild in bezug auf diese Art noch viel verändern wird.

Suillus granulatus (L. ex Fr.) O. Kunze

Karsten (1868) hält die Art in Tammela für "passim frequens», und im Schärenhof von Turku ist sie nicht ganz selten (EKLUNd 1943). FREY (1944) erwähnt den Pilz von Ahvenanmaa und ThesLefF (1919) aus der Gegend von Viipuri. Da v. SchulMANN (1960) ihn von allen seinen Untersuchungspunkten mit Ausnahme des nördlichsten (Iapinlahti) erwähnt, dürfte der Pilz in Südfinnland ziemlich weitverbreitet sein.

In HMF liegen folgende Proben: V. Karjalohja (1957, Ulla Bärlund); Vihti (1957, Malmström); Tuusula (1953, Malmström); Porvoo (1925, Nyberg); EH. Tammela, Mustiala (1881, Karsten); Hämeenlinna (1955, Lahja Hakala).

Im Untersuchungsgebiet ist dieser Röhrling offenbar ziemlich selten. Ich bin ihm nur im Kiefernwald 
von Kuuva in Ruissalo, in Parainen, Peksor (Waldrand mit Eichen) sowie auf der Insel Haverö in Nauvo begegnet, durchgehends an sonnigen grasbewachsenen und mit Kiefern oder Eichen bestandenen Abhängen mit nur wenigen Sträuchen. Alle Standorte sind stark kulturbeeinflusst und am Wege in der Nähe von Behausungen gelegen. Im TUR liegt eine Probe, gesammelt 1958 von Yrjö Mäkinen im Kiefernwald von Uittamo in Turku. Die Art gilt als einigermassen kalkhold (vgl. RAмsвоттом 1954, p. 205). In Haverö ist diese Standortsbedingung tatsächlich erfüllt, und es ist ganz offenbar, dass $E_{K}-$ LUNDS (op.c.) verhältnismässig zahlreiche Feststellungen der Art in der Gegend von Korppoo gerade darauf beruhen, dass sich der Silurkalk hier schon recht stark bemerkbar macht.

In Norwegen hält Stordal (1956) den Pilz für einen Bewohner der östlichen kontinental betonten warmen Täler und stellt ihn chorologisch Calocybe georgii (Clusius ex Fr.) Kühner (= Tricholoma gambosa (Fr.) Sing.) gleich. Auch in Finnland dürfte der Schwerpunkt der Verbreitung beider Arten in denselben Gegenden im südwestlichen Schärenhof liegen, doch so, dass Suillus granulatus allem Anschein nach weiter gegen das Inland verbreitet ist.

Die Standorte der Art dürften in ganz Europa ziemlich ähnlich sein. PrlÁts (1954) Erwähnung vom Auftreten der Art »vor allem in Kiefernwäldern in Lichtungen im Gras, am Waldrand und an den Wegen» passt ausgezeichnet auch auf die hiesigen Standorte des Pilzes. Die Art tritt als Mykorrhizenbildner bei verschiedenen Pinus-Arten auf (SLIPP \& SNELL 1944).

Xerocomus chrysenteron (Bull. ex St. Am.) Quél.

Wird zum erstenmal aus Finnland von KarsteN (1859, p. 15) als Unterart von Xerocomus subtomentosus aus Turku erwähnt: »Uti skogsängar rar. Eg. Finl., Ảbo.» TheslefF (1919) meldet die Art aus Viipuri, Nyberg (1934) aus Porvoo, Laurila (1939) aus Turku (Ruissalo), EkLund (1943 b) aus Korppoo und Houtskari verschiedenorts, Tuomı́oskI aus Sortavala (1943) und Helsinki (1948), Stenlid (1947) von Ahvenanmaa (Lemland) und v. Schulmann (1960) aus Parainen, Attu. Ausser den betreffenden Proben von Thesleff, Nyberg und Tuomikoski, befinden sich im HMF solche noch von mir aus Turku (Ruissalo) und von Unto Laine aus Tvärminne (1955). Nach Prof. Dr. R. Tuomikoski (briefl.) begegnet man dem Pilz in Bromarv (Framnäs) manchmal sogar reichlich.

Diese Funde erweisen, dass man es mit einem südlichen Pilz zu tun hat. Da die Art aber offenbar nicht unbedingt an eine bestimmte Holzart gebunden ist, mag sie wohl auch ausserhalb der Eichenzone gefunden werden können. Dies wird schon durch die Funde von v. Schulmann $(1955,1957)$ aus Karkkila und Lapinlahti erwiesen (die betreffenden Belege habe ich allerdings nicht gesehen). Ich habe aber die Art hier namentlich als einen $\mathrm{Pil}_{z}$ aufgenommen, dessen Häufigkeit und Reichlichkeit in der Eichenzone ihn zu einem charakteristischen Bewohner dieses Gebietes machen, selbst wenn er selten auch ausserhalb desselben angetroffen würde.

Nachstehend gebe ich die Fundorte der Art im Untersuchungsgebiet.

Turku, Ruissalo: Regelmässig in allen Jahren. In normalen Pilzjahren begegnet man dem Röhrling im Frühherbst auf jeder Exkursion zumal im Natur- reservat, im Eichenwald bei Honkapirtti und in allen anderen auch nur etwas grösseren Eichenbeständen, doch auch anderswo, obwohl selten, u.a. unter Linden am Wege. In dem einzigenQuercus Struthiopteris -Hain von Ruissalo ist der Pilz mehrmals angetroffen worden.

Muhkuri, öfters im Haselgesträuch mit Eichen am verhältnismässig trockenen Südabhang; Katariinanlaakso, vornehmlich auf eichenbewachsenen Grasheiden und an den Waldrändern am Südabhang der Teilgebiete 9 und 10 (Nikoskelainen 1955), u.a. an der Böschung eines Ackergrabens unter Eichen; Pansio; im Eichenwald beim Gut Artukainen, wurde aber auch anderswo angetroffen; Pääskyvuori, unter Eichen an der Bahn.

Übriges Untersuchungsgebiet: Kaarina, Karpanmäki, gegen Süden abfallende Grasheide, unter Eichen, dazu am Graben an der Grenze zwischen ihr und dem anliegenden Acker; Piikkiö, Tuorla, teils sehr ähnlich wie vor, dazu auch in schattigem EichenHaselstrauchhain, Jauhosaari, auf Grasheide unter Eichen auf gleichfalls üppiger hainartiger Fläche (vgl. Mäkinen \& Tarén 1960); Parainen, in den Eichenmischwäldern von Attu und Lofsdal; Korppoo, Hevonkak, unter Haselsträuchern; Kakskerta, Kulho, im Eichenbestand der Anhöhe Linnavuori; Halikko, im Eichenhain von Vaisakko; Pohja, Fiskari, an reichlich mit Haselsträuchern bewachsenem Hainabhang 1960 (Apoth. H. SÅltıN mündl.); Raisio, Perno, Ackerhügel mit lichtständigen Eichen Askainen, Eichenpark nahe dem Gehöft Lempisaari; Rymättylä, Kepuinen, beweidete Grasheide mit licht stehenden Eichen (hier u.a. das in Finnland seltene Trifolium montanum); Lgm. Uusikaupunki. Hier sammelte Mag.phil. Unto Laine den Pilz im Nahbereich von Eichen an dem nördlichsten Eichenstandort der Provinz V.

Auch EkLund (1943 b) hält den Pilz für einen Bewohner der Eichenwälder, die anderen haben ihn unter Erlen und/oder unter Birken gefunden. Ganz offenbar sind aber in Finnland die Eichenbestände die typischsten Standorte der Art, denn gerade in ihnen ist der Pilz so gut wie regelmässig zu finden. Anderswo begegnet man ihm nur zufällig als grosse Seltenheit. Man beachte, dass Karsten über keinen einzigen Fund der Art aus Tammela verfügt, und auch ich selbst habe den Pilz in Yläne, einschliesslich des nahegelegenen üppigen Haingebietes von Kolvaa, nie angetroffen.

In Südschweden ist die Art sicherlich ebenso häufig wie in Finnland in der Eichenzone (vgl. InGeIström 1940, p. 60; Nathorst-Windahl 1956). Auch dort ist sie oft in Eichenwäldern gesammelt worden, wie es die Bezettelungen im Naturhistorischen Reichsmuseum zu Stockholm zeigen, anderseits - z.B. in Småland - auch unter Fichten. Nach Blytт (1905) gedeiht der Röhrling in Norwegen in Laubwäldern, gemischten Eichenwäldern und gemischten Fichtenwäldern, und aus Fichtenwäldern wird er auch von Stordal (1953, p. 279) angeführt. Im übrigen Europa dürfte es sich ähnlich verhalten. So bewohnt der Pilz nach WojewodA (1961) in Polen das Fagetum carpaticum. In Württemberg (HAAs 1933, p. 105) ist die Art auch in Nadelwäldern zu finden, der Schwerpunkt des Vorkommens liegt aber in den Laubwäldern.

In den Eichenwäldern von Turku ist der Pilz nicht nur als häufig, sondern auch als reichlich zu bezeichnen. So wurden auf einer Studentenexkursion 
am 7. September 1960 gleichzeitig mehr als 50 Fruchtkörper festgestellt. - Die Anzahl der Proben im TUR beträgt 22 .

\section{Xerocomus badius (Fr.) Kühner et Gilbert}

Diese Art hat sich in Südfinnland als weitverbreitet, obschon offenbar nirgends als sehr häufig erwiesen. TUOMIKoski (1959, p. 205) erwähnt den Pilz aus dem südlichsten Finnland, oft aus frischen Fichtenwäldern in Begleitung von Oxalis acetosella. Das Verzeichnis bei v. Sarulmann (1960) erweist, dass die Art keineswegs auf das südlichste Finnland beschränkt ist. Er nennt Funde von Ahvenanmaa, aus Parainen (Attu), Tammisaari, Punkaharju, Lapinlahti und Karkkila. Im HMF liegen folgende Proben: Helsinki (1949, Malmström; 1952, Tuomikoski); ebendort, Haaga (1950, Rautavaara); Porvoo (Malmström); Loppi (1949 und 1950, Tuomikoski); Orivesi (1959, Jääskeläinen); Tammela, Mustiala (1871, Karsten). Nach Tuomrkoski (mündl) ist der Pilz in der Gegend von Helsinki nicht selten. Mag.phil. U. Laine sammelte die Art noch in Uusikaupunki.

Im Untersuchungsgebiet kommt der Pilz verschiedenorts spärlich vor. In Finnland (siehe TuomKoski op.c.) und in Mitteleuropa (HAAs 1933, p. 117; Neuhoff 1956; Bresinsky \& Zeitlmayr 1960) dürfte er am häufigsten im Nadelwald zu finden sein, tritt aber auch in reinen (Eichen-) Hainen auf. So ist er an Standorten letztgenannter Art in Ruissalo unter Schwarzerlen am Wege, in Piikkiö, Jauhosaari in der Nähe von Eichen und in Katariinanlaakso und Muhkuri am Abhang mit Eichen angetroffen worden. Auch in Schweden erwähnt NATHORST-WINDAHL (1956, p. 21) die Art namentlich aus Eichenwäldern (vgl. auch Ne uHoff 1956 b, p. 25). Woje wodA (1961) hat aus Polen ähnliche Beobachtungen. Im Nadelwald wurde die Art im Untersuchungsgebiet u.a. in Korppoo, Kuraklintti (sehr trockene Kiefernheide; vgl. auch EKLUND 1943b, p. 10 und INGELSTRÖM 1940) und Rumar (Ilkka Kukkonen, TUR); in Rymättylä (Röödilä, Kiefernwald am Ufer) und Turku, Metsäkylä (mit Kiefern bewachsene Viehweide) sowie in der Lgm. Uusikaupunki angetroffen. In Yläne, Elijärvi, Korpinnokka habe ich den Pilz im Fichtenwald gesammelt. Inwiefern die Hainformen der Art verschiedene systematische Typen vertreten, ist wenigstens auf Grund des hiesigen Materials nicht erschliessbar. Zwar sind die Exemplare von Ruissalo und Piikkiö dunkler als gewöhnlich, doch dürfte auch bei dieser Art eine bestimmte Variation auch unabhängig vom Standort vorhanden sein.

Das finnische Verbreitungsbild der Art bleibt vorläufig mangelhaft; auf jeden Fall ist der Pilz bisher nicht in Lappland gefunden worden.

Auch die skandinavischen Angaben und Funde vermögen nicht viel Klarheit über die Nordgrenze der Art zu geben. Increls'röm (op.c.) bezeichnet die Art als häufig an Kiefernwurzeln, die Angabe dürfte sich indessen lediglich aul die Limgebung von Stockholm beziehen. In Dänemark ist die Art gleichfalls ein häufiger Bewohner des Nadelwaldes (FERDTNANDSEN \& WINGE 1943).

In Norwegen ist der Pilz nach BLyTT (1905) nicht häufig in Nadelwäldern. STORDAL (1952) erwähnt einen Fund unter Birke.

Iulveroboletus sulphureus (Fr.) Sing.

Ich sammelte am 17. September 1955 im westlichen Eichenhain des Naturreservats von Ruissalo (hier jedoch in der Nähe Abies balsamea, Pinus cembra, Eiche und eine Linde, dazu ein Haufen fremder Waldabfall) einen Pilz (nunmehr im HMF, den ich trotz Nachsuchens später nicht mehr wiedergefunden habe. Es war eine kräftige Gruppe von 7 zusammenhängenden Fruchtkörpern. Die Felderung der Hutoberfläche erinnert ein wenig an die bei Xerocomus chrysenteron Bull., aber die Grundfärbung ist deutlich gelb, mit roten Flecken. Der Stiel ist hoch, bräunlichgelb, die streifige Röhrenschicht grünlichgelb ungefähr wie bei $X$. chrysenteron, aber mit kleineren Röhren. Die Merkmale passen gut auf die Beschreibung von Pearson (1950). Der Pilz wurde im Botanischen Museum der Universität Helsinki von Mag.phil. N. Malmström bestimmt.

Die Art dürfte überall selten sein (vgl. Hennig 1960 , p. 56). Für Schweden liegt nur die kurze Erwähnung bei FRIES (1849, p. 316) vor: »r. Upsaliae! Nobilissimus, meteor». In den Sammlungen des Botanischen Museums der Universität Uppsala befindet sich eine im Jahre 1935 in der Gegend gesammelte Probe. Dazu ist der Pilz nach briefl. Mitteilung von Dr.phil. Seth Lundell dort erneut gefunden worden; dieser Fund ist aber nicht in den Sammlungen belegt.

Es möge erwähnt werden, dass weder KüHNER \& Romagnesi (1953, p. 43) noch Michael/Hennic: (1960, p. 196) etwas über die Neigung der Art zur geselligen Wachstumsweise berichten.

Boletus edulis (Bull.) Fr. var. reticulatus (Schaeff.) Boud.

Syn.: Boletus Atkinsonii Peck (Bull. N.Y. State Mus. 94, p. 20; 1905). - B. reticulatus Schaeff. ex Boud.

Meine Kenntnis dieses Taxons gründet sich auf etwa 50 Fruchtkörper aus dem Untersuchungsgebiet sowie die mir im Naturhistorischen Reichsmuseum zu Stockholm unter dem Namen Boletus reticulatus vorgelegenen Proben. Hut hell gelblichbraun, sehr fein filzig. Röhrenschicht anfangs fast weiss, später gelblich. Stiel hellbräunlichgrau, besonders oben fast weiss, sehr deutlich und oft bis weit hinab retikuliert (Abb. 6). Die angetroffenen Fruchtkörper waren kleiner als beim echten $B$. edulis, durchschnittlich nur 7-8 cm (Maximum $12 \mathrm{~cm}$ ), stets leicht von denen der genannten Art unterscheidbar. Der Pilz ist identisch mit Nr. 2601 unter dem Namen $B$. Atkinsonii Peck bei Lundell \& NANnfeldt, wie Dr.phil. Seth Lundell im Botanischen Museum der Universität Uppsala auf Grund einer ihm zugesandten Probe feststellen konnte. Farbe und Form entsprechen der Abb. 42 bei PILÁT \& UŠ́́ (1955), der hiesige Pilz ist aber noch heller und der Stiel womöglich noch deutlicher retikuliert.

Die Abb. 23 für B. variipes Peck, ein Synonym des B. Atkinsonii, bei Coker \& Beers (1943) zeigt einen anderen Typ, der kaum in den Rahmen derjenigen Variation einfügbar ist, die ich bei der Art hierzulande gefunden habe. Dieser $B$. variipes hat einen schlankeren Stiel sowohl im Vergleich zum hiesigen $B$. Atkinsonii sensu Lundell als auch zum amerikanischen $B$. edulis, an den er angeblich stark erinnern soll. Auch die Oberflächenstruktur des Hutes (»minutely tomentose to squamulose usually areolated, the tomentum sometimes gathered all over into small flakes or warts») entspricht nicht der feinen, fast glatten Oberfläche der finnischen Proben. Auch die Farbe des Stieles (»liver color, rarely stained with rose») passt nicht gut auf die hiesige Art. 


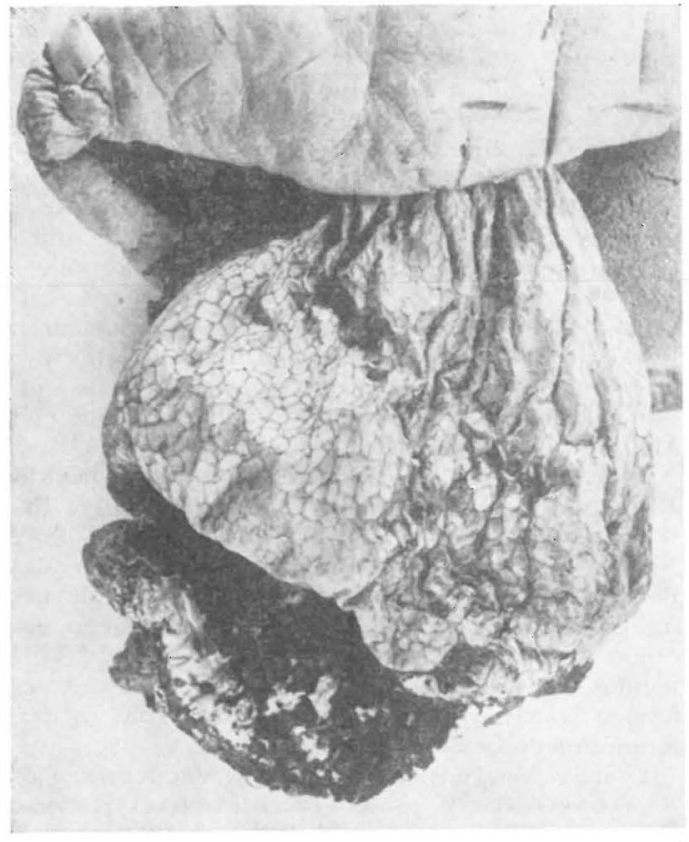

Abb. 6. - Boletus edulis var. reticulatus aus Katariinanlaakso.

Da die Varietät sowohl von der Hauptform des $B$. edulis als auch von der Varietät pinicola leicht unterscheidbar ist und dennoch jegliche Angaben über sie im einheimischen Schrifttum fehlen, dürfte sie hierzulande sehr selten sein. Während die Hauptform des $B$. edulis und var. pinicola hinauf bis ins nördlichste Lappland häufig zu finden sind, ist die erwähnte helle Form nicht ausserhalb der Eichenzone aufgefunden worden.

Die finnischen Fundorte des Boletus edulis var. reticulatus sind die folgenden.

Turku, Katariinanlaakso (Teilgebiete 9, 10 und 12 bei Nikoskelainen 1955): Die Standorte sind die besten durch südliche Phanerogamen gekennzeichneten offenen oder halboffenen und regelmässig von Eichen gekanteten südexponierten Grasheiden Finnlands. Ein Bild von der Natur dieser Standorte geben Arten wie etwa Carex caryophyllea, Ranunculus bulbosus, Trifolium montanum, Filipendula hexapetala, Seseli libanotis, Plantago media und $P$. lanceolata (Gebiet 9 ) oder Origanum vulgare und Brachypodium pinnatum (Gebiet 12). Die übrige Pilzflora des zentralen Gebietes 9 bildet einen Exponenten des allgemeinen südlichen Zuges in der Flora. Hier findet man auf nur einigen hundert Quadratmetern die folgenden Boletaceen: Gyroporus castaneus, Xerocomus chrysenteron, Boletus luridus, B. erythropus und Leccinum griseum. Zum speziellen Artenbestand der Stelle gehören ferner Amanita pantherina und Lactarius azonites (liegt in Finnland nur von ganz vereinzelten Orten vor). $\mathrm{pH}$ des Bodens beträgt etwa 6 , und das Lokalklima dürfte günstig sein, indem ein hochgelegener felsiger Nadelwald gegen den Norden und ein Hügel gegen den südlichen Meerwind schützt. Das Gefälle beträgt an der untersuchten Stelle etwa $20^{\circ}$. Die Art wurde in den Jahren 1960 und 1961 beobachtet.
Turku, Ruissalo: Auf ziemlich offener Grasheide nahe der Landstrasse unter Eichen am Südrand des Naturreservats. Die Grasheide am Südabhang des licht mit grossen Eichen bestandenen Hügels auf dem Grundstück des Botanischen Gartens der Universität, u.a. mit reichlichem Thlaspi alpestre, erinnert an den ebengenannten Standort von Katariinanlaakso, doch dürfte hier die hohe Grasvegetation das Gedeihen des Pilzes nicht wenig erschweren. Die Bodentemperatur wurde hier bedeutend höher als am schattigeren Nordhang gefunden; $\mathrm{pH}$ 6.2.

Kaarina, Karpanmäki: Auch diese südexponierte Grasheide gehört noch zu den hier besprochenen offenen und parkartigen Eichenstandorten. $\mathrm{pH}$ des Bodens 5.9. Die Art wurde hier 1960 angetroffen.

Rymättylä, Kepuinen: Von Eichen gekantete, beweidete Grasheide, u.a. mit Trifolium montanum und $T$. arvense als kennzeichnenden Phanerogamen. Hier ausser Boletus edulis var. reticulatus auch Xerocomus chrysenteron nebst Oudemansiella radicata, beides Arten mit südlicher Verbreitung in Finnland. Wurde hier sowohl 1960 als 1961 angetroffen. Von finnischen Proben liegen im TUR 14, im HMF 2 und im Museum zu Uppsala 1.

Boletus edulis var, reticulatus ist in den nordischen Ländern ein verhältnismässig seltener oder wenig bekannter Pilz. Für Schweden wird er zum erstenmal unter der Nummer 2601 im Exsikkat von Lundell und Nannfeld erwähnt; die Proben sind 1940 und 1943 eingesammelt, in »dry sunny grassgrown wood with oak, spruce and funiperus communis». Nach den Fundortsbezeichnungen im Herbarium des Naturhistorischen Reichsmuseums zu Stockholm ist der Pilz bei Stockholm und in Östergötland unter Eichen, in Småland jedoch auch unter Fichten gesammelt worden. NATHORST-WrNDarl (1956, p. 323) bezeichnet die Art als einen Bewohner der Laubwälder Südwestschwedens, der vor allem von der Eiche abhängig ist. Blytтs (1905, p. 117) »en hvidagtig form $i$ egeskov» für Norwegen bezieht sich möglicherweise auf diese, unter $B$. edulis zusammengefasste Art. Für Dänemark habe ich den Pilz nicht erwähnt gefunden.

In Mitteleuropa gilt die Art allgemein als ein Pilz der Eichenwälder. Pilát (1954, p. 42) sagt über diesen »Eichensteinpilz»: »Vor allem in lichten Laubwäldern, zumeist auf Lichtungen und am Waldrand. — - Am häufigsten in Eichenwäldern in wärmeren Gegenden) (vgl. auch Mrahael/HenNig 1960 , p. 58). Neuhoff (1956, p. 25) nennt in seinem Beispiel der Eichen-Birkenwälder ( Laubwald auf saurem Boden») unter den Pilzen auch Boletus reticulatus. BRESINSKY \& ZEITLMAYR (1940) führen aus den Eichenwäldern Bayerns unter den Pilzen der sog. Lohwälder auch drei Boletus-Arten an, nämlich $B$. reticulatus, $B$. luridus und $B$. erythropus. Alle drei sind auch am obenbeschriebenen Standort in Katariinanlaakso zu finden.

Im Lichte der bisherigen finnischen Funde muss Boletus edulis var. reticulatus in Finnland als ein Pilz der Eichenzone betrachtet werden, der aber auch dort nur an den wärmsten und mikroklimatisch günstigsten offenen Standorten, namentlich an grasheideartigen Abhängen unter Eichen vorkommt.

Die Art gilt in Mitteleuropa ausdrücklich als ein Pilz des Vorsommers (z.B. Mighael/Hennig 1958, p. 154: "Mai bis Anfang Juli»; siehe auch PEARson 1950, p. 7 und Pilát 1954). Im Handbuch von 
KüHNER \& Romagnesi (1953, p. 38) ist dieser Zug sogar in der Bestimmungstabelle aufgenommen.

In Finnland ist die Art hauptsächlich im September und (1960) auch noch im Oktober angetroffen worden. Auch im Naturhistorischen Reichsmuseum $\mathrm{zu}$ Stockholm finden sich im Oktober gesammelte Proben (die Stücke im Exsikkat von Lundell und NANNFELdT sind vom 5. und 3. September). Im Norden wird die Entwicklung des Fruchtkörpers durch den späteren Sommereintritt verzögert. Man könnte sich denken, dass hier eine Parallele zu dem verspäteten Blühen in den Norden verpflanzter südlicher Ökotypen mancher Phanerogamen vorliegt.

Das Auftreten der Fruchtkörper dürfte indessen z.B. im Vergleich zu B. edulis recht unregelmässig sein. Wenigstens gegen Ende der 1950er Jahre traf ich den Pilz in Katariinanlaakso nicht an, B. edulis dagegen wohl.

Boletus luridus (Schaeff.) Fr.

Der erste sichere Fund der Art in Finnland stammt von Malms'röm (1943), der den Pilz auf Ahvenanmaa, Ramsholm fand. Danach sind aus der Provinz mehrere Funde zu verzeichnen gewesen: Lemland (EKLUND 1943), Apalholm und Nåtö (STENLID 1947), Eckerö, Finström und Maarianhamina (v. Sahulmann 1955). Eklund (1943, p. 9) fand die Art in Nauvo: »Wecklax Näs. st. cp. im üppigen Haine auf Kalkgrund.»

Alle älteren Erwähnungen über den Pilz in Finnland gründen sich auf die einigermassen unsichere Angabe bei Karsten (1876, p. 246) betreffend das Vorkommen der Art im Eichenwald von Kaita bei Naantali (vgl. nachstehend unter B. erythropus). Auf jeden Fall dürfte man berechtigt sein zu sagen, dass die Art auf dem finnischen Festland bisher unbekannt gewesen ist.

Am 6. September 1960 wurde aber ein wohlentwickelter Fruchtkörper unter einer Linde an ziemlich offenem südexponierten Grasheideabhang im Teilgebiet 9 (Nrkoskelainen 1955) von Katariinanlaakso gefunden. Hut oberseits ziemlich hellbraun, Röhrenmündungen orangerot getönt, Stiel rötlichgelb, sehr deutlich retikuliert (die Probe im TUR befindet sich in gutem Zustand). Die Formausbildung des Pilzes entspricht gut der Abb. 37 von UŠÁk bei PrLÁt (1954).

Die Art dürfte in Südschweden nicht sehr selten sein. INGELSTRÖM (1940) bezeichnet sie als ziemlich allgemein, und ANDERsson (1943) erwähnt 19 Fundorte. Nach Lundele (1932) ist der Pilz in der Gegend von Uppsala sehr selten, NATHorst-WinDAHL (1949) erwähnt ihn als ziemlich selten in Mischlaubwäldern in Südschweden, wo er nicht deutlich an eine bestimmte Holzart gebunden ist. In Norwegen betrachtet BLyTT (1905) den Pilz als selten, und Stordal (1955) vermindert die Anzahl der sicheren Funde auf nur zwei. In Dänemark ist der Röhrling nach FERdinandsen \& Winge (1943) hier und da, nach Rostrup (Lind 1913, p. 383) aber häufig in Wäldern zu finden.

Die Art gilt als ein Begleiter von Eiche und Buche (KALlENBACH 1921), gedeiht aber auch im Nadelwald, am liebsten auf Kalk (Michael/Hennig 1960, p. 57). Nach Pilát (1954) vor allem »in lichten Laubwäldern im Gras, in den Gräbern entlang der Waldstrassen, auch in Parks unter Laubbäumen, vor allem unter Eichen, Buchen, Linden verstreut». Nach Lobanow (1960, p. 129-130) gilt der Pilz in Südwestrussland als Mykorrhizenbildner u.a. bei Eiche. In Bayern bewohnt die Art die Eichenhaine (BRESINSKY \& Zeitlmayr 1960). In den Biotopbeschreibungen wird öfters auf die Offenheit oder Helligkeit des Standorts hingewiesen (ANDERsson op.c.; Ferdinandsen \& Winge op.c.; MalmSTRÖM op.c.); der Wuchsort des Pilzes in Katariinanlaakso dürfte in dieser Hinsicht typisch sein.

In Finnland ist der Pilz offenbar extrem südwestlich (er fehlt u.a. im Südostabschnitt der Eichenzone) und klimatisch anspruchsvoll. Der obengenannte Fund in Katariinanlaakso wurde in einem günstigen Pilzjahr gemacht.

Die Art gilt als kalkhold (u.a. Andersson op.c., p. 196), und auch die finnischen Funde zeigen Ähnliches. In Katariinanlaakso kann indessen der Boden kaum als besonders kalkreich angesehen werden, denn mit Ausnahme eines kleinen Amphibolitvorkommnisses besteht der Felsgrund hier aus Granit. Der Phanerogamenbestand zählt jedoch mehrere Arten, die auf einen für finnische Verhältnisse überdurchschnittlichen Nährstoffreichtum bzw. unterdurchschnittlichen Säuregrad des Bodens hindeuten (vgl. Nrkos kelainen op.c.).

\section{Boletus erythropus Fr.}

Syn.: B. miniatoporus Secr.

Dürtte für Finnland zuerst von EKLUND (1943) festgestellt worden sein, der den Pilz im Eichenhain von Strömma in Korppoo im Schärenhof von Turku sammelte. Tuомıкоsкi (1959) erwähnt einen Fund aus dem Eichenwald von Framnäs in Bromarv (Probe vom 13. IX. $1957 \mathrm{im}$ HMF). Nach v. Schulmann $(1960$, p. 8) auch auf Ahvenanmaa.

KARSTEN (1876, p. 246) fand 1862 im Eichenwald von Kaita bei Naantali einen Röhrling, den er als B. luridus Schaeff. bezeichnete. Die Artbeschreibung ist indessen so unbestimmt, dass der Fund ebensogut als $B$. miniatoporus gedeutet werden kann, wie es KalienBAGH (1926) auch wirklich getan hat, Es möge hier auch auf Coker \& Beers (1943, p. 42) hingewiesen werden, die die Unbestimmtheit der Grenze zwischen diesen zwei Arten erörtern.

Im Untersuchungsgebiet wurde der Pilz 1960 (insges. 9 Fruchtkörper, davon befinden sich $6 \mathrm{im}$ TUR, 1 im HMF und 1 in Uppsala) und 1961 (nur 1 aufbewahrungstauglicher Fruchtkörper, dazu einige schon völlig zerfallene) im Teilgebiet 9 (NikoskeLAINEN 1955) von Katariinanlaakso auf der besten südexponierten Trockenwiese gefunden, wo sich die charakteristischsten südlichen Grasheidepflanzen des Landes zusammengefunden haben. Am einen Rande der Fläche gibt es Crataegus coccinea und in der Nähe auch stattliche Fichten und Eichen. Die meisten Fruchtkörper des Pilzes wurden unter den Eichen, einige jedoch auch in dem ziemlich schattigen Weissdorngesträuch gefunden.

Die Fruchtkörper waren 8-12 cm breit. Der Hut ist sehr dunkelbraun, die Röhrenmündungen dunkel blutrot. Der Stiel gleichfalls sehr dunkel, etwas fleckig, stellenweise fast schwarz, ganz oben jedoch, obwohl nicht durchgehends ebenso deutlich, klargelb. Die Schnittfläche verfärbt sich ausserordentlich stark und rasch. Die Abb. 38 von UšÁ K bei Pilát (1956) entspricht sonst vorzüglich dem Pilz von Katariinanlaakso, der Stiel ist aber nicht ganz so dunkel wie bei den hiesigen Stücken (Abb. 00). Die Fruchtkörper wurden am 3., 10. und 14. September gefunden. 


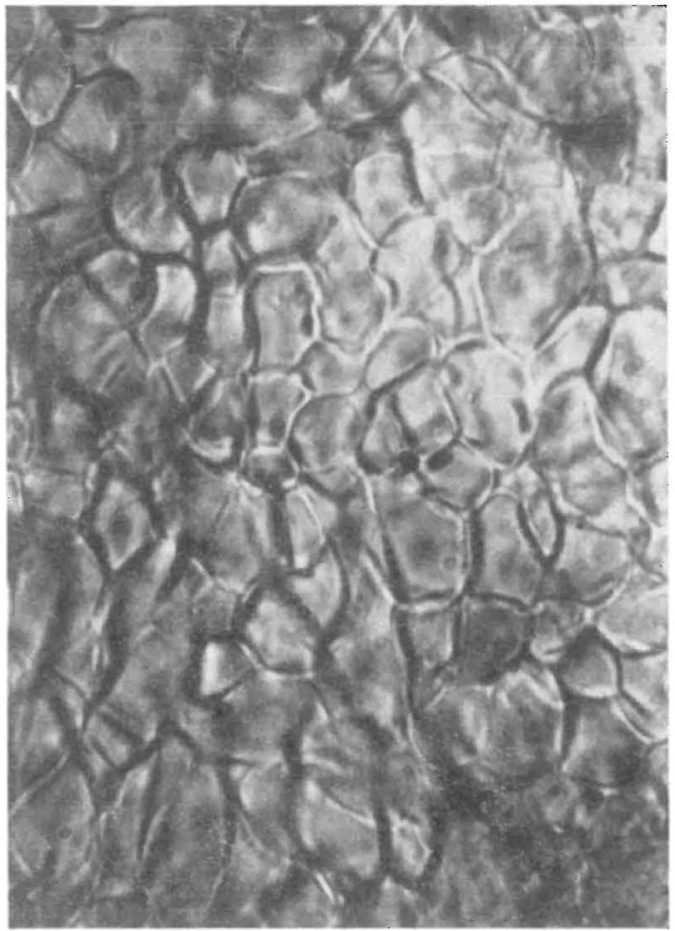

Abb. 7. - Leccinum nigrescens. Pseudoparenchym aus Hutmembran. Ruissalo.

Die Art gilt in Südwestschweden, wo sie als selten zu bezeichnen ist (etwa 20 Fundorte), namentlich als ein Bewohner der Eichenwälder (ANDERSSON 1943; Nathorst-Windahl 1956). Nach IngelSTRÖM (1940) begegnet man diesem offenbar seltenen Pilz auf Laubwiesen und in Parken. Auf der Höhe von Uppsala ist er nicht mehr zu finden (Dr.phil. S. LUNDELL briefl.).

Auf den dänischen Inseln vielenorts (A.NDERSSON op.c.), nach Ferdinandsen \& Winge (1943) sowohl im Nadel- als im Laubwald. Stordal (1955, p. 73) nennt aus Norwegen im ganzen 10 Fundorte, befasst sich aber nicht näher mit der Ökologie der Art. Interessanterweise erstreckt sich die Verbreitung des Pilzes ähnlich vieler »südlichen» Phanerogamen längs der Westküste Norwegens verhältnismässig weit gegen Norden (bis Stjördal). Andersson (op.c., p. 199) bezeichnet die Art namentlich als einen Bewohner der Eichenzone, ohne dass der Pilz an sich von der Eiche abhängig wäre. Vgl. Suillus cyanescens!

In Mitteleuropa ist der Pilz typisch in Eichenwäldern (u.a. NEuHoff 1956, p. 26), ebenso nach Lobanow (1960) im Gebiet von Stalingrad und Rostow. Nach PEARson (1950) wäre er dagegen in England in allerlei Wäldern (»in all woods») zu finden, und auch Michael/Hennig (1960, p. 57), führt ihn von Sandboden in Laub- und Nadelwäldern an.

Es hat den Anschein, dass der Pilz, wie es der Begleitartenbestand und die Topographie des Platzes selbst schliessen lassen, in Katariinanlaakso an einem der mikroklimatisch wärmsten Standorte Finlands vorkommt. Das Verhältnis zu der Eiche dürfte wenigstens hier lediglich durch die Gleichheit der ökologischen Ansprüche bedingt sein.

Leccinum nigrescens (Rich. et Roze) Sing.

Syn.: Boletus tesselatus Gill., B. crocipodius Letel., $B$. luteo-scaber Schaeff,, B. luteoporus (Bouch. apud Barbier) Sing., Krombholzia tesselata (Gill.) R. Maire.

Ich habe in Ruissalo einen Pilz gefunden, dessen systematische Unterbringung mir einigermassen Schwierigkeiten bereitet hat, über dessen Zugehörigt keit zu Boletus nigrescens ich aber nunmehr überzeugbin. Merkmale des einzigen in frischem Zustand untersuchten Fruchtkörpers: Hut $6-7 \mathrm{~cm}$ im Durchmesser, gelb, getrocknet gelbbraun, oberseits glatt. Die Oberhaut griff etwa $1-2 \mathrm{~mm}$ über den Hutrand über. Röhrenschicht gelb, bei Berührung dunkelbraun anlaufend. Röhren zylindrisch, klein und dünnwandig. Stiel gelb, stellenweise mit schwach grünlichem Ton, $7 \mathrm{~cm}$ lang und maximal etwas unterhalb der Mitte $1.5 \mathrm{~cm}$ dick, mit feinen dunkleren flockigen Schuppen, die besonders beim frischen Pilz deutlich in Reihen angeordnet erschienen. Sporen (beim getrockneten Exemplar) $6.5 \times 14.5 \mu$. Struktur der Hutoberfläche sehr ähnlich wie bei L. griseum (Quél.) Sing., die äusserste Zellschicht pseudoparenchymatisch und arm an Pigment (Abb. 7). Von L. griseum unterscheidet sich jedoch der Pilz einwandfrei sowohl durch die Farbe der Hutoberfläche und der Röhrenschicht als auch durch die Beschaffenheit des Stieles. Die Bruchstelle zwischen Hut und Stiel färbte sich in einigen Sekunden blauschwarz. Die Verfärbung vollzog sich rascher als bei allen anderen mir jemals vorgelegenen Arten.

Die Beschreibung des $B$. crocipodius Letel. bei PeArson (1950) passt ausgezeichnet auf den Pilz von Ruissalo, abgesehen von der Farbe des Hutes (»tawny olive to olive brown»). Die Verfärbbarkeit des Fleisches wird von PEARson als sehr variabel bezeichnet.

Mit dieser Beschreibung wie auch mit dem Pilz von Ruissalo deckt sich weitgehend, obwohl nicht in allen Punkten die Beschreibung von PrLÁt (1954) und die Abb. 34 von Uš́́k daselbst. Der Stiel erscheint im Bilde sehr lang. Indem aber seine Länge im Text in den Grenzen von $5-20 \mathrm{~cm}$ angegeben wird und sie sich bei vielen Arten auch sonst nicht als verlässliches Merkmal herausstellt, braucht diesem $\mathrm{Zug}$ im vorliegenden Fall keine allzu grosse Bedeutung beigemessen werden. Die Hutoberfläche ist beim Ruissalo-Pilz stärker gelb als auf dem ebengenannten Bilde. Die Abb. 11 bei Mrahael/HenNig (1960) entspricht, namentlich auch in betreff der Ornamentierung des Stieles, gut dem Exemplar von Ruissalo.

Im Schrifttum wird $B$. nigrescens nicht aus Finnland erwähnt. Der Röhrling gilt besonders als eine Art mit Vorliebe für Eichenwälder. Nach PILÁt (1954, p. 34) findet man den Pilz »in Laubwäldern unter Eichen und Buchen, im Ganzen selten und besonders in wärmeren Gegenden", nach Michael/ HENNIG (1960, p. 197) »besonders unter Eichen und Buchen, an warmen, sonnigen Abhängen», also ganz wie in Ruissalo. Pearson (1950, p. 15) sagt lediglich: "In deciduous woods uncommon».

In Ruissalo wurde der Pilz im unteren Teil des Südabhangs der Landzunge Ajatinniemi am Wege in einer helleren Lichtung des Waldes mit Hasel- 
sträuchern und Eichen an einer Stelle gefunden, wo es auch mehrere andere südwestliche Spezialitäten gibt, wie etwa Xerocomus chrysenteron, Lactarius glaucescens, L. azonites und Rhodophyllus lividus. Der Standort gehört zu den wärmsten in Ruissalo, denn auf dessen Südseite liegt ein offener Acker und hinter diesem ein Hügel, ganz wie im Teilgebiet 9 (NIkoskelainen 1955) von Katariinanlaakso. Auch eine zweite Ähnlichkeit besteht: Das Meer liegt hier ungefähr in gleicher Entfernung und sogar in derselben Himmelsrichtung. Hier befindet sich auch der einzige Standort von Dentaria bulbifera in der Gegend, einer Art, die hier ganz besonders als ein Vertreter des »südwestlichen» Elementes zu werten ist.

Leccinum griseum (Quél.) Sing.

Syn.: Boletus carpini (Schulz) Pearson; B. pseudoscaber Kallenb.; Krombholzia rugosa (Fr.) Pilát; Leccinum duriusculum (Schulzer apud Fr.) Sing.; Leccinum carpini (R. Schulz) Moser.

Steht äusserlich Leccinum scabrum (Bull. ex Fr.) S.F. Gray nahe und ist auch oft mit diesem verwechselt bzw, ihm taxonomisch unterstellt worden (var. carpini R. Schulz). Beide Arten dürften aber stets mit Gewissheit voneinander trennbar sein.

In Finnland wurde die Art zum erstenmal von Malmström (1942, p. 7) unter dem Namen $B$. pseudoscaber Kallenb. als nicht selten aus Tuusula, Ruotsinkylä gemeldet. Тиомгковкі (1959) erwähnt ihn aus dem Gebiet von Framnäs in Bromarv, bekannt für seine Eichenwälder, v. Schulmann (1960) aus derselben Gegend sowie aus Parainen und A. Lemland, Slätholm, durchgehends von Stellen mit reichlichem Einschlag des südlichen Florenelementes. Doch wird der Pilz von Tuomikoski (op.c.) auch aus U. Espoo und von v. Sahulmann (op.c.) aus Lapinlahti (PS!) genannt, dazu finden sich im HMF B. carpini bezettelte Proben aus der Umgebung von Helsinki, sowie aus V. Vihti, EH. Urjala und Forssa, insges. 10 Stück.

Die oberste Zellschicht der Hutoberfläche - die Sphaerozysten - möchte ich als dasjenige Merkmal ansehen, auf Grund dessen die Museumsproben von Leccinum griseum von L. scabrum unterscheidbar sind. Meiner Auffassung nach entsprechen im HMF nur die Proben von Tuomikoski aus Espoo, Bodom und Bromarv, Framnäs demjenigen Bild, das für die Art in Mitteleuropa gilt. Bei den finnischen Stücken ist aber das Fehlen des Pigments in den fast isodiametrischen und meistens bis ganz runden Sphaerozystenzellen kennzeichnend (vgl. Pearson 1950, Abb. 1). Die Zellen sind im Vergleich zu den langen Hyphen gross. Ihr Diameter beträgt gewöhnlich 10$15 \mu$ PEARSON: $10 \mu$, und überhaupt findet man gar nicht so längliche Zellen wie in der Abb. 91 bei KüHner \& Romagnesi (1953, p. 39), die auch sonst nicht dem Begriff "parenchymatisch» entspricht.

So beschaffen ist die oberste Zellschicht des Hutes bei den Proben aus Bromarv und Espoo sowie bei meinen eigenen Stücken aus Turku (Katariinanlaakso, TUR). Im übrigen ändert die Art äusserlich recht viel ab. Die Katariinanlaakso-Probe erinnert sehr an das Bild des Pilzes bei Pearson (op.c.). Sie ist sogar fast ebenso hell, die Hutoberfläche sogar stärker gefeldert als in der genannten Abbildung (vgl. Abb, 8!. Die Abb. 33 bei Pilát \& Ušák (1954) entspricht recht gut dem Pilz von Katariinanlaakso, der Fuss ist aber kürzer. Dagegen erinnern die von Tuomikoski gesammelten Proben

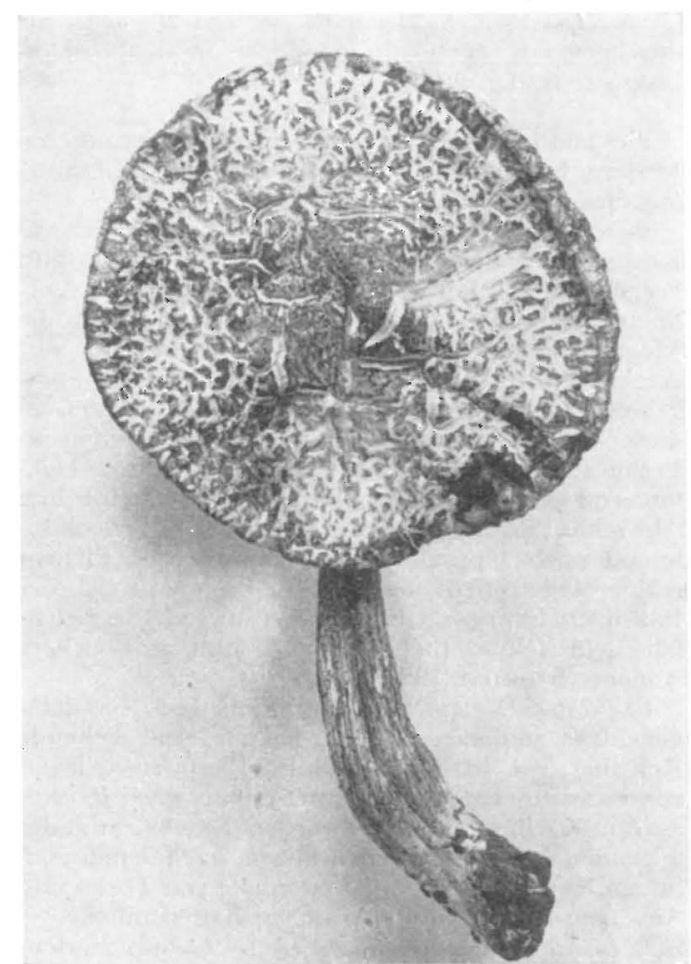

Abb. 8. - Leccinum griseum aus Katariinanlaakso.

sowohl durch den verhältnismässig dunklen Stiel als auch durch die gleichfalls dunkle Hutoberfläche mehr an die Abb. 13 (rechts) bei Michael/Hennig (1960).

Der Standort aller dieser ist der Haselstrauchhain der Eichenzone und wahrscheinlich auch des Eichenwaldes. Die Proben Tuomikoskis tragen folgende Standortsbezeichnungen: 1) Bromarv: Mischwald, auch Corylus, 2) Espoo: Haselstrauchhain. In Katariinanlaakso wuchs der Pilz im Teilgebiet 9 von Nikoskelainen (1955) im Weissdorngesträuch mit Corylus und grossen Eichen in der Nähe am Ackerrand am Fusse eines gegen Süden abfallenden Hanges.

Leccinum griseum ist in Finnland ein Pilz der Eichenzone. Die erwähnten offenbar in mehreren Beziehungen L. griseum -ähnlichen in den Variationskreis des L. scabrum (oder Boletus roseofractus Sing.) fallenden Proben in HMF sind sowohl aus Nadel- als zum Teil auch aus Laubwäldern, auch ausserhalb der Eichenzone.

Die Art ist auch überhaupt als ein »mitteleuropäischer» Begleiter z. B. von Weissbuche angesehen worden, und oft wird im gleichen Anschluss auch der Haselstrauch erwähnt (PILÁT 1954; Ramsвоттом 1954, p. 229; Michael/Hennig 1960, p. 56). Nathorst-Windahl $(1949,1956)$ bezeichnet den Pilz als seltenen Begleiter von Hasel und Espe in Südschweden und Andersson (1958, p. 44) als einen Begleiter von Eiche und Hasel. Neuho f F (1956) nennt beim Beschreiben der Pilzflora eines typischen mässig trockenen mitteleuropäischen Waldes vom Eichen-Hainbuchen-Typ die Art u.a. neben Xero- 
comus chrysenteron, Boletus erythropus und B. edulis, die durchgehends auch am Standort in Katariinanlaakso zu finden sind.

Für südliche Boletus-Arten, die nicht in unseren Museen belegt sind, sind noch folgende Literaturangaben zu erwähnen:

Boletus satanas Lenz. - Von EKLUND (1943) aus Korppoo erwähnt. Die Artbeschreibung stimmt gut, berücksichtigt man aber die dem Melder zur Verfügung gestandene knappe Literatur, so ist auch die Möglichkeit einer Fehlbestimmung nicht ganz ausgeschlossen. Auf jeden Fall wäre das Untersuchungsgebiet von EKLUND der nördlichste Vorposten in dieser Richtung für diesen Pilz, der im Norden als streng südlich und ausserdem als unbedingt kalkfordernd gilt. Auch in Schweden ist der Röhrling sehr selten; nach INGELSTRÖM (op.c.) ist er jedoch bis hinauf nach Uppsala an der Grenze der Eichenregion angetroffen worden. In Dänemark ist der Pilz nach Ferdinandsen \& Winge (1943) gleichfalls sehr selten, für Norwegen fehlt jede sichere Angabe (Stordal 1955, p. 71).

B. Fechtneri Velenovski (B. aestivalis Fr.). - Dieser gleichfalls südliche und als kalkfordernd geltende Röhrling (vgl. Miahael/Hennig 1960) ist vielleicht von EKLUND (1943, p. 10, unter dem Namen B. aestivalis) in Korppoo gefunden worden. Er gehört mit der folgenden Art zu denjenigen Pilzen, nach denen man in den Kalkgebieten der Schärenhöfe von Turku und Ahvenanmaa besonders Ausschau halten müsste.

B. calopus Fr. (B. pachypus Fr.). - Gehört zu denjenigen im Norden offenbar sehr südlichen und möglicherweise westlichen Arten, die in Finnland entweder sehr selten sind oder völlig fehlen, trotzdem sie in Südschweden und Norwegen vorkommen. Karsten (1859) erwähnt den Pilz aus Piispanristi bei Turku, und dies ist immer noch die einzige Angabe über die Art in Finnland. Da es sich um eine leicht kenntliche Art handelt und Karsten ausdrücklich erwähnt, dass die Kennzeichen typisch waren, muss die Angabe trotz Fehlens eines Beleges als zuverlässig gewertet werden. Auf jeden Fall ist der Pilz hierzulande viel seltener als in Norwegen, von wo Stordal (1955) etwa 15 Fundorte anführt.

Russula pseudointegra Arn. \& Goris.

Diese Art, die sich zumal durch ihre hell ockerfarbenen Sporen (Farbe $\mathrm{F}$ in der Farbskala von Schaeffer 1952), den weissen Stiel, die spezifische Hutfärbung, die Sporengrösse (100 Messungen): $7.65 \pm 0.47 \times 6.55 \pm 0.06$ und den Geschmack deutlich sowohl von Russula emetica Schaeffer ex Fr. als auch von $R$. lepida Fr. unterscheidet, an die sie sonst am meisten erinnert (vgl. NATHORST-WINDAHL 1949, p. 207; Lange 1950, p. 74; Schaeffer 1952 , p. 243), gehört zu den unverkennbaren Bewohnern der Eichenzone in Finnland. In den Eichenwäldern von Turku ist er regelmässig zu finden: Sammlungsbelege befinden sich von hier im TUR im ganzen 12 von folgenden Stellen, wo auch Beobachtungen über die Art gemacht wurden.

Ruissalo: Im Naturreservat und im üppigen Eichenwald westlich davon. Hier bezieht die Art die besten Hainböden der Insel, Flächen mit dicker Schicht von Hainhumus ( $\mathrm{pH}$ etwa 6.2), reichlicher Laubwaldstreu und oft lückiger Untervegetation. In der Feldschicht u.a. Dryopteris filix-mas, Convallaria majalis, Milium effusum, Anemone hepatica und Aego- podiurn podagraria. Von Pilzen dürften wohl Hygrocybe punicea, Inocybe geophylla, Lactarius quietus, L. serifluus, L. mitissimus, L. piperatus, Craterellus cornucopioides und C. sinuosus als die typischsten anzusehen sein.

Katariinanlaakso: Der Biotop ist eine im Vergleich zum vorigen trockenere und hellere, zum Teil parkartige Graswiese. Charakteristische Begleitpilze sind hier Amanita pantherina, A. citrina, A. rubescens, Clitopilus prunulus, Rhodophyllus lividus, Boletus edulis var. reticulatus.

In Turku habe ich den Pilz weiter in Muhkuri, Metsäkylä und Artukainen (auch unter einsamer Eiche) angetroffen Ausserhalb Turku: Raisio, Perno; Kakskerta, Kulho (Eichenhain); Parainen, Peksor. Ebenso wurde der Pilz am 5. IX. 1961 unter einsamer Eiche beim Hause Viurila in Halikko gefunden, dazu in üppigem und schattigem Eichen-und Haselhain in Piikkiö, Tuorla (hier u.a. auch Russula cyanoxantha) und Kaarina, Karpanmäki.

In Schweden im Südwesten selten in Begleitung der Eiche (Nathorst-Windahl 1956), in der Gegend von Göteborg stellenweise häufiger (ders. 1949, p. 207). In Dänemark nach LANGE (1950, p. 74) "not uncommon in frondose woods (particularly of Quercus and Corylus)». Für Norwegen wird die Art von BLytт (1905) nicht erwähnt.

In Mitteleuropa gilt die Art als typischer Pilz des frischen Querceto-Carpinetums (NeUHOFF 1956, p. 27 ; vgl. auch Bouvs \& BABos 1960, p. 14) oder als häufiger Bewohner des Buchenwaldes (SGHaeffer 1952, p. 243).

Russula cyanoxantha (Schaeff.) Fr.

Tuомпокок (1959, p. 195) bezeichnet das Vorkommen von Russula cyanoxantha in Finnland als unsicher. Doch ist die Art gerade unter diesem Namen schon früher aus Finnland gemeldet worden, und zwar von RAurAvaARA (1947) als selten aus der Südwestecke des Landes. Von Sahulmann (1960) erwähnt den Pilz aus Elimäki. Im TUR befindet sich eine Probe, gesammelt von N. Malmström an sonnigem, trockenen Ort am Waldrand zwischen Kräutern und Gräsern in Tvärminne. Sie erinnert an diejenigen Exemplare des Pilzes, die ich in der Gegend von Turku angetroffen habe.

Die Probe von Eklund (im HMF) aus Korppoo 1941, unter dem Namen $R$. heterophylla (vgl. EkLUND 1943 b, p. 14), bei welcher u.a. die feine radiäre Furchung der Hutoberfläche deutlich erkennbar ist, ist offenbar $R$. cyanoxantha, wie es auch die von $\mathrm{N}$. Malmström durchgeführte Namensänderung auf der Etikette angibt. - W. Nyberg sammelte 1939 in Kauniainen $\gg R$. cyanoxantha f. pallida» (HMF).

Die Erkennung bietet keine grossen Schwierigkeiten. Am nächsten dürfte wohl u.a. durch die gleichfalls verzweigten' Lamellen (siehe Abb. 9) $R$. heterophylla (Fr.) Fr. sensu Schaeffer stehen (vgl. Schaeffer 1952, p. 75). Die Hutoberfläche ist jedoch (selbst bei getrockneten Exemplaren) leicht kenntlich durch ihre feine, radiäre Furchung, die bunte Färbung, wo verschiedene rötlichblaue Nuancen mit einer Art von Braun und Grün abwechseln, den fettartigen Glanz sowie vor allem durch das typische indifferente Verhalten zum $\mathrm{FeSO}_{4}$. Der Stiel ist bei hiesigen Proben im allgemeinen sehr kräftig entwickelt (vgl. Schaeffer op.c., p. 83), mitunter bis $15 \mathrm{~cm}$ lang. Dies ist insofern bemerkenswert, als man hin und wieder auf ausdrückliche Erwähnungen über die Kürze des Stieles stösst (vgl. FerdinandSEN 


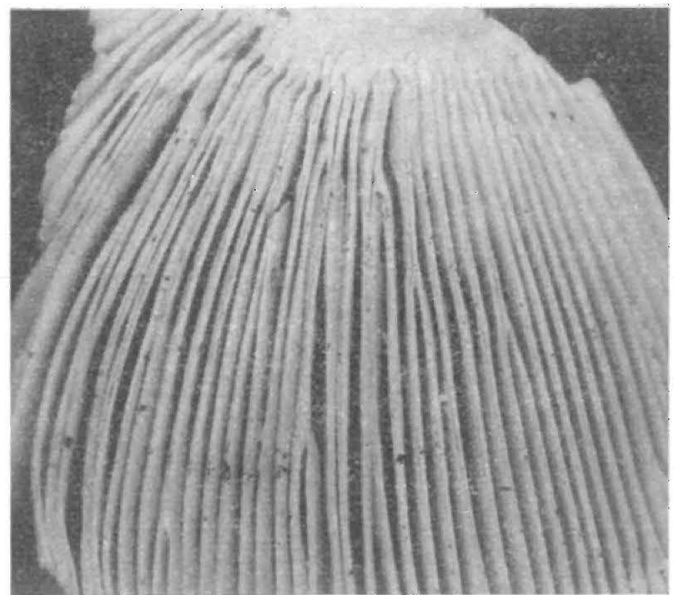

Abb. 9. - Lamellen von Russula cyanoxantha aus Katariinanlaakso.

\& Winge 1943, p. 155). Lange (1950, p. 70) nennt jedoch eine Form mit einem Stiel »rather firm» und präsentiert sie in seiner Abb. 187 D. Dr. Hans Haas in Stuttgart hat liebenswürdig eine von mir (1961) gesandte $R$. cyanoxantha-Probe aus Katariinanlaakso »ohne Zweifel als dieselbe Art wie $R$. cyanoxantha bei uns» (Mitteleuropa) bestätigt.

Im Untersuchungsgebiet ist der Pilz nicht ganz selten. In Katariinanlaakso wurde er in verschiedenen Teilgebieten angetroffen, ausserordentlich reichlich z.B. Anfang September 1960 auf der südexponierten grasreichen Grasheide mit Eichen, Birken und u.a. Origanum vulgare nebst Brachypodium pinnatum im Teilgebiet 12 (Nikoskelainen 1955). Die Fruchtkörper waren gross und wohlausgebildet.

In Ruissalo begegnet man der Art am reichlichsten im Eichen- und Haselhain am Südabhang von Ajatinniemi in Begleitung u.a. von Rhodophyllus lividus, Russula delica, Lactarius pyrogalus, L. piperatus (sensu Ne uhoff 1956), L. vellereus, L. quietus und L. azonites.

Andere Fundorte: Artukainen (unter Eichen); Metsäkylä, am Waldrand unter Kiefer; Halikko, Pihko, grasreicher Hainrand mit Eiche und Hasel; Rymättylä, Kepuinen, zwischen Eichen auf parkartiger Grasheide; Piikkiö, Tuorla, gegen Süden abfallender schattiger Eichen- und Haselhain.

Im ganzen dürften als Standorte des Pilzes bei uns mit Eiche und Hasel bewachsene Abhänge mit anschliessenden Grasheiden zu betrachten sein.

In Schweden wird der Pilz von Nathorst-WinDAHL (1956, p. 324) als ziemlich häufig bezeichnet. Nach InGelström (1940, p. 133) wächst der Pilz wunter Buchen, nicht häufig»; man hätte es also demnach mit einer südlichen Art zu tun (vgl. jedoch auch die Meldung von LANGE 1946, p. 168 über die Auffindung des Pilzes in Lappland!). In Norwegen findet man die Art in Laubwäldern an der Küste. In Dänemark ist sie nach Ferdinandsen \& Winge (1943, p. 155) schon sehr häufig.

Aus Mitteleuropa nennt Neuhoff (1956, p. 26) die Art unter den typischen Pilzen des EichenHainbuchenwaldes und (p. 28) auch des UlmenEschenwaldes. Nach Sahaeffer (1952, p. 84) ist die Art in Mitteleuropa fast überall einer der gemeinsten und bekanntesten Pilze des Laubwaldes, so auch nach Woje woda (1961) in Polen. Der optimale Biotop der Art ist der Hain, aus Württemberg meldet aber HAAs (1933) den Pilz auch aus Nadelwäldern.

Lactarius volemus $\mathrm{Fr}$.

Die Art wird von Karsten (1889, p. 123) aus Ruissalo erwähnt. Tuomikoskr (1953) kennt im ganzen 13 Fundorte aus Finnland. Diese liegen mit Ausnahme zweier - Kankaanpää und Yläne - in der Eichenzone (vgl. auch KarsTen 1868, p. 333), und zwar vom Schärenhof bei Turku beginnend bis Viipuri. Von Sahulmann (1960, p. 80) nennt den Pilz lediglich aus Tammisaari.

$\mathrm{Zu}$ diesen mögen noch folgende Fundorte hinzugefügt werden.

Turku: Ruissalo, am reichlichsten im Eichenwald W vom Volkspark, am eichenbewachsenen Nordabhang des Hügels $N$ vom Naturreservat und in der Umgebung von Honkapirtti. Dazu in Metsäkylä, Muhkuri und Piispanristi.

Úbriges Untersuchungsgebiet: Rymättylä, Kepuinen, 1957-61 am Randsaum eines mit Eiche und Hasel bewachsenen Hügels; Piikkiö, Tuorla, jährlich in südexponiertem Hain mit Eichen und Haselsträuchern, Jauhosaari; Parainen, Attu, unter Eiche; Raisio, Eichenwald von Perno; Halikko, Vaisakko; Kakskerta, Kulho; Laitila, sandiger Kiefernwald am Wegrand (1962, K. Parviainen, TUR).

Die meisten Fundorte stellen hain- oder laubwiesenartige Flächen mit Eichen und oft auch Haselsträuchern dar. Einen solchen Standort nennen bei uns ausdrücklich auch EkLUND (1943) und TUOMuKoski (1953).

Ein typischer mitteleuropäischer Pilz, der jedoch nach NEuHOFF (1956, p. 187) im norddeutschen Flachland und in Dänemark verhältnismässig selten und fast nur im Eichen-Hainbuchenwald besonders in der Nähe von Eichen anzutreffen ist. Die Standortsansprüche scheinen sich also mit denen im Untersuchungsgebiet zu decken. Doch begegnet man der Art nach NeuHoff anderwärts in Mitteleuropa auch in Nadelwäldern, namentlich im Fichtenwald, so auch nach HaAs (1933; vgl. auch Hennig 1958, p. 202). Hiervon gibt es Beispiele auch in Finnland, wie schon aus der Untersuchung von Tuомıкоsк (op.c.) hervorgeht. Von den oben aufgezählten Fundorten legt einer in Metsäkylä im Fichtenwald, wo es in der Nähe keinen einzigen Laubbaum gibt, und in Piispanristi an e.nem Abhang mit Kiefern (1961). Vgl. auch den Standort in Laitila!

Die Verbreitung des Pilzes erstreckt sich von Mitteleuropa offenbar fast gleichartıg bis nach Südschweden, wo die Art von Nathorst-WrNDahl (1956) als ziemlich selten bezeichnet wird. Nach INGELSTRÖM $(1940$, p. 142) ist die Art nicht selten und tritt gern unter Eichen auf. Für Norwegen gibt Buytr (1905, p. 98, in Übersetzung) an: »Laubwälder, z.B. Eichenwälder, Haselgesträuche, Buchenwälder, selten in Kiefernwäldern, an der südlichen und westlichen Küste nicht selten.» Dieselbe Auffassung hat sich bis heute berbehalten (ECKBLAD 1960).

\section{Lactarius vellereus Fr.}

TuomikoskI (1953) erwähnt von L. vellereus etwa zwanzig Fundorte, alle aus dem südlichsten Finnland (am nördlichsten in Jämijärvi). Im Untersuchungsgebiet ist die Art häufig in Eichenwäldern. Von den 
drei Fundorten bei v. Schillmann (1960) liegen zwei (Ahvenanmaa und Tammisaari) in der Eichenzone, der dritte in Lammi.

Im Untersuchungsgebiet häufig in den besten Hainen von Ruissalo, so besonders im Naturreservat und im Eichenhain westlich davon. In Turku ausserdem in Katariinanlaakso, Muhkuri, Artukainen, Pansio, Metsäkylä und Piispanristi. Andere Fundorte: Mynämäki, Kasurla; Lemu, Ohensaari; Mietoinen, Saari; Lokalahti, Varanpää; Raisio, Perno; Piikkiö, Tuorla; Halikko, Vaisakko; Rymättylä, Kepuinen; Kakskerta, Kulho; Parainen, Peksor und Korppoo, Lohm. Durchgehends in Eichenwäldern, in Turku, (Piispanristi) und Mynämäki jedoch im Heidewald mit Birken und Kiefern. Nach briefl. Mitteilung von Mag.phil. Torvo RäsäneN in der Umgebung von Kuopio vielenorts.

Kommt oft an gleichen Standorten wie L. piperatus vor und hat auch überhaupt eine ähnliche Verbreitung in Finnland. Bei näherer Betrachtung bekommt man jedoch den Eindruck, dass $L$. piperatus mehr auf die üppigeren Haine beschränkt ist.

Die Art gehört in Mitteleuropa zu den gemeinsten Milchlingen, den man zumal in Buchen- und Eichen-Hainbuchenwäldern findet (NEuHof 1956 , p. 92). Sie ist aber nicht obligatorisch an die genannten Holzarten geburiden, sondern kommt auch in frischen Fichtenwäldern vor. In Dänemark bewohnt, der Pilz allgemein die Buchenwälder (LANGE 1940 p. 36). NATHORST-WINDAHL (1956) bezeichnet den Pilz in seinem Untersuchungsgebiet als ziemlich selten, während INGELsTRöm (1940, p. 138) ihn für einen häufigen Bewohner der Laubwälder hält.

Der Formenbildung im Kreise der Art ist in Finnland keine Beachtung geschenkt worden. Ich selbst bin in Turku, Ruissalo, Katariinanlaakso, Muhkuri, und Artukainen; Lemu, Ohensaari; Mietoinen, Saari und Kulho, Kakskerta auf die var. Bertillonii Neuhoff (siehe Neunoff op.c., p. 93) gestossen. Durch den brennend scharfen Geschmack (vgl. Karsten 1879 p. 188; auch v. Schulmann op.c., p. 78), den ich bei dieser Art auch früher festgestellt habe, und die kräftig gelbe Färbung des Milchsaftes mit $\mathrm{KOH}$ oder auch spontan ist diese Art von der Hauptform unterscheidbar. Ich wurde auf diese Eigenschaft erst im Herbst 1961 aufmerksam; die früheren Proben sind darum mit dem kollektiven Artnamen versehen. Tuомıкоккі (briefl.) hat stets nur die Varietät angetroffen.

Lactarius serifluus (DC. ex Fr.) Fr.

Die ältesten Angaben über diese Art beschränken sich lediglich auf die Erwähnung bei Karsten (1881, p. 12) über das Vorkommen eines Lactarius subumbonatus Lindgr. benannten Pilzes in Ruissalo »locis arenosis». Die Probe wurde von TuомıкоsкI (1953) als Lactarius serifluus (DC. ex Fr.) Fr. bestimmt. Rautavaara (1947, p. 489) hat die Art (offenbar gleichfalls aus Ruissalo) unter dem Namen L. Cimicarius Batsch. gekannt. Von Schulmann (1960, p. 80) fand den Pilz 1957 in Tammisaari in ngemischten Anpflanzungen (viele Laubbäume, auch Eiche)».

In den Eichenwäldern des Untersuchungsgebietes wurde die Art an folgenden Orten angetroffen.

Turku, Ruissalo: Vielenorts. Auch in niederschlagsarmen Jahren begegnet man dem Pilz bei den Farnbeständen des Naturreservats, in der feuchten Mulde am Wege westlich davon und unter den Eichen im Struthiopteris-Hain, in günstigen
Jahren wiederum auf sämtlichen üppigeren Hainflächen und besonders reichlich in den Eichenhainen westlich vom Naturreservat. Das optimale Auftreten ist auf den September entfallen, und z.B. am 16. IX. 1960 übertraf der Pilz mit seinen Hunderten von Fruchtkörpern an Reichlichkeit alle anderen Pilze auf dem im allgemeinen nur mit blosser Laubstreu bedeckten Boden des Haines.

Lemu, Nyynäinen: Am 4. IX. 1960 reichlich zusammen mit Lactarius quietus auf einem Ackerhügel unter ein paar grossen Eichen.

Taivassalo, Ketarsalmi: Ein einziger Fruchtkörper unter einer einsamen grossen Eiche am Rande einer Sandgrube.

In Schweden dürfte der Pilz im Verbreitungsgebiet der Eiche ziemlich häufig zu finden sein. NATHORST-WINDAHL (1956) bezeichnet ihn in Südwestschweden als ziemlich häufig, und nach INGELSTRÖM (1940) ist er auch in der Umgebung von Stockholm keineswegs selten. In Dänemark ist die Art nach Ferdinandsen \& Winge (1943) hier und da zu finden.

Zusammen mit Lactarius quietus Fr. dürfte die Art zu den bedingungslosesten Begleitern der Eiche in Finnland gehören.

Im TUR 30 Proben.

Karstens (op.c.) Standortsbezeichnung »locis arenosis» trifft jedenfalls in bezug auf Ruissalo, den besten Standort des Pilzes im Gebiet, nicht das Richtige. Der Pilz wächst vor allem in blosser Hainerde oder in der nackten Laubstreu und meidet grasbewachsene Flächen und noch mehr die Zwergstrauchvegetation. In schattigen Hainen ist der lückige Aufbau der Untervegetation naturbedingt, er kann aber, wie an den Wegrändern, auch durch den Menschen hervorgerufen sein. Auch der Standort in Lemu, Nyynäinen, war wahrscheinlich infolge der Betretung durch das Vieh nackt oder fast nackt. Der nackte Grabenrand im Struthiopteris-Hain von Ruissalo ist gleichfalls früher vom Pilz bewachsen gewesen. In den Sammlungen des Stockholmer Reichsmuseums befindet sich eine von Lundell am am 24. IX. 1948 gesammelte Probe mit dem Vermerk: »On bare soil and among fallen leaves under oak and beach close to road». Dies passt ausgezeichnet auch auf die hiesigen Standorte des Pilzes. Einmal fand ich die Art reichlich auch in einem sehr morschen Eichenstock, und von ähnlichem Standort liegt die Art im Stockholmer Museum auch aus Gotland vor.

Um eine so südlich betonte Art es sich auch handelt, sind die Fruchtkörper des Pilzes nicht frostempfindlich. Auch überhaupt dürften die Wärmeansprüche der wärmeliebenden Arten auf die Induktions- und Entwicklungsphase des Fruchtkörpers selbst konzentriert sein. Diesen Pilz kann man oft noch im Oktober antreffen, und die spätesten Proben im TUR sind vom 16. X. (1960) und 26. X. (1955), als es schon kalte Perioden gegeben hatte. Im Jahre 1961 wurde der Pilz noch am 5. November angetroffen, dieser Herbst war aber bis dahin ganz ohne Fröste gewesen.

\section{Lactarius quietus $\mathrm{Fr}$.}

Wird zum erstenmal in Finnland von Karsten (1879) namentlich aus Ruissalo erwähnt, später von EkLUND (1944) aus Korppoo, von Tuomikoski (1959) aus Bromarv und Espoo und von v. SaHulMANN (1960) aus Tammisaari. Thesleff (1920) 
nennt den Pilz auch aus Viipuri im östlichen Abschnitt der finnischen Eichenzone. Alle Funde dürften aus der unmittelbaren Nähe von Eichen stammen.

Diese Art gehört zu den am gleichmässigsten verbreiteten und zugleich reichlichsten Lactarien von Ruissalo und wächst dort, ausser in den üppigsten Hainen, auch in zwergstrauchreichen Eichenwäldern von heidewaldartigem Charakter und im Umkreis von einsamen Eichen im Nadelwald. Im Stadtgebiet von Turku ausserdem in Katariinanlaakso, Muhkuri und Pansio (häufig und auch reichlich), Metsäkylä (jedjährlich unter einsamer Eiche im Nadelwald), im übrigen Untersuchungsgebiet in Taivassalo, Ketarsalmi (16. X. 1960); Lemu, Nyynäinen (i.J. 1960 noch am 4. Oktober verschiedenorts reichlich); Nousiainen, Linnamäki (karger Felsabhang mit Eichen); Kakskerta, Kulho; Raisio, Perno; Kaarina, Karpanmäki; Piikkiö, Tuorla; Parainen, Attu und Lofsdal.

Ist einer der typischsten obligatorischen Begleiter der Eiche in Finnland und ist wohl im ganzen hiesigen Verbreitungsgebiet dieses Baumes zu finden Vorläufig ist aber der Pilz nicht z.B. bei den grossen Eichen auf der Insel Kirkkosaari in Köyliö und merkwürdigerweise auch nicht in Vaisakko in Halikko gefunden worden, trotzdem es sich doch dort anscheinend um einen höchst typischen Standort gerade für diese Art handeln dürte. Man hat aber zu berücksichtigen, dass der Pilz in seinem Auftreten eine recht deutliche Periodizität erkennen lässt, die längere Beobachtungszeiten voraussetzt.

In Skandinavien ist das Vorkommen des Pilzes gleichfalls von der Eiche abhängig, und demzufolge gehört die Art in Gegenden, wo es reichlich Eichen gibt, neben Lactarius torminosus (Schaeff. ex Fr.) Gray und L. necator (Bull. em. Pers. ex Fr.) Karst. zu den häufigsten Pilzen (Nathorst-WINDAHL 1956, p. 323). In Dänemark gemein (FERDINANDSEN \& WINGE 1943), in Norwegen dagegen sehr selten (Blytt 1905, p. 96): »Im Eichenwald bei Christiania».

Im TUR 21 Proben.

Lactarius piperatus Scop. ex Fr. sensu Neuhoff 1956

Obwohl diese systematisch schwierige Art (vgl. Neuhoff 1956, p. 88-89), die in der finnischen Literatur und auch in den Museen kollektiv gefasst worden ist, wahrscheinlich nicht kategorisch an die Eichenzone gebunden ist, liegt der Schwerpunkt ihrer Verbreitung in Finnland dennoch unbedingt in diesem Gebiet. Sie wird (zusammenfassende Úbersicht bei Tuomrkoski 1953, p. 19) aus Korppoo, Merimasku, Turku, Bromarv, Tvärminne, Sipoo Viipuri und Tammela erwähnt; dazu kommen Hjortö auf Ahvenanmaa sowie Lohja und Lammi (v. Schulmann 1960). Nach Mag.phil. T. Räsänen (briefl.) kommt die (Kollektiv-) Art vielenorts in der Umgebung von Kuopio vor.

Die Funde aus Tammela, Lammi und Kuopio erweisen, dass die Art kein obligatorischer $\mathbf{M y}$ korrhizenbildner bei Eichen ist (vgl. LoBA Nov 1960 p. 129). Es ist möglich, dass das nachstehende Fundortsverzeichnis möglicherweise auch die im folgenden $\mathrm{zu}$ besprechende Art $L$. glaucescens Grossl. enthält. Ich habe die im Verzeichnis mitgeteilten Funde der vorliegenden Art zugezählt, wenn sich das Fleisch (des Stieles) nicht grünt. In der Menge befinden sich aber Exemplare, deren Milchsaft sich mit $\mathrm{KOH}$ gelb färbt (Ruissalo, Ajatinniemi, 31. VII. 1961); beim Hauptteil tritt jedoch bei Einwirkung von $\mathrm{KOH}$ keine Farbänderung des Milchsaftes ein. Alle sich deutlich grünenden Exemplare wurden als $L$. glaucescens gedeutet. In diesen Fällen färbt sich der Milchsaft offenbar immer gelb.

Die Sporengrösse betrug in der Probe aus Metsäkylä (Herbarmaterial, 296 Messungen) $6.41 \pm 0.21$ $\times 5.11 \pm 0.28 \mu$. Dieser Wert ist viel kleiner als der von NeUHOFF (1956, p. 87) angegebene $8-9.5 \times$ $5.5-7 \mu$, dagegen nähert er sich schon sehr dem von Ricken (1915) mitgeteilten $6-7 \times 6 \mu$. Der Unterschied gegenüber den Werten von NEUHOFF kann nicht einzig darauf beruhen, dass sich seine Messungen auf frisches Material gründen, wobei die unentwickelten Stadien nicht den Mittelwert herabdrücken, denn der maximale Wert beträgt im finnischen Material nur 8,5. \%.

Nachstehend Fundorte:

Turku: Ruissalo, sehr häufig und reichlich besonders im Naturreservat und im Eichenhain westlich davon, dazu an mehreren anderen Stellen auf der Insel, ausserdem in Katariinanlaakso, Muhkuri und Metsäkylä.

Úbriges Untersuchungsgebiet: Lemu, Nyynäinen; Mynämäki, Kasurila; Kakskerta, Kulho; Rymättylä Kepuinen; Kaarina, Karpanmäki; Piikkiö, Tuorla; Parainen, Lofsdal; Halikko, Vaisakko.

Nur an zwei Stellen habe ich den Pilz nicht im Eichenwald angetroffen. In Metsäkylä war der Standort ein Kiefern-Fichtenwald und in Mynämäki ein Kiefern-Birkenmischwald vom MyrtillusTyp. Kennzeichnende Begleitarten des Pilzes sind Lactarius vellereus, L. quietus, L. mitissimus, Tricholoma sulphureum und T. album. Es liegen aus Finnland auch andere Beobachtungen über das Vorkommen der Art ausserhalb des Eichenwaldes vor. So meldet Thesleff (1919) den Pilz aus Fichtenwald, und in der Tat ist die Art in ihrem Hauptyerbreitungsgebiet offenbar in keiner Weise an eine bestimmte Holzartenzusammensetzung gebunden. Nach NEUHOFF (op.c., p. 87) wächst der Pilz vorwiegend im EichenHainbuchmischwald, doch auch im Birken-Fichtenwald, im Rotbuchenwald und ebenso, wenn auch seltener, in Fichten- und Kiefernwäldern, meist hordenweise.

In Schweden und Dänemark ist die Art offenbar häufiger als in Finnland (FERDINANDSEN \& WINGE 1943, Lange 1941, Nathorst-Windahl 1956). Als häufig gilt der Pilz auch südlich des Finnischen Meerbusens (WITKowski 1934, p. 166). In Ungarn ist die Art einer der wichtigsten Pilze der (Eichen-) Wälder und steht in gewissen Waldtypen unter den »Gewicht-Dominanten» an erster Stelle (BoHus \& BABOs 1960, p. 13).

Die Sammlungen von TUR enthalten 15 Proben dieses Pilzes.

\section{Lactarius glaucescens Grossl.}

Diese Art ist offenbar oft mit $L$. piperatus verwechselt worden. Erst Tuomikosk i HMF sammelte 1952 an zwei Stellen in Bromarv den Pilz unter dem Namen L. glaucescens und 1953 auch noch in Espoo, Bodom, an Orten, von wo auch zahlreiche andere charakteristische Pilze der Eichenzone vorliegen. Von Schulmann (1960) erwähnt den Pilz aus Bromarv, Framnäs.

Ich bin dem Pilz 1961 reichlich in Katariinanlaakso und an zwei Stellen in Ruissalo begegnet. 
Besonders die kräftige Verfärbung der durchgeschnittenen Stielbasis, die Kürze des Stieles und die starke und rasche Gelbfärbung des Milchsaftes mit $\mathrm{KOH}$ sind besonders gute Merkmale. Die bei leichter Beschädigung der Lamellen hervorsickernden Milchtropfen können zu kleinen Kügelchen trocknen, die im Verlauf von einigen Stunden eine deutlich graue Tönung annehmen, aber sich auch dann mit $\mathrm{KOH}$ sofort wieder gelb färben. Der Pilz erreicht gewöhnlich nicht die Grösse des L. piperatus. Trotzdem es sich um eine klare und leicht kenntliche Art handelt, gibt es jedoch im Formenkreis piperatus - glaucescens eine schwierig definierbare Form, und offenbar gerade auf dieses Problem weist auch Neuhoff (1956, p. 88-89) hin. Er sagt sich nämlich einen Pilz angetroffen zu haben, der sonst durchaus dem L. glaucescens gleicht, dessen Fleisch sich aber nicht grünt. Auch ich habe in Ruissalo ähnliche Pilze gefunden, deren Milchsaft sich mit $\mathrm{KOH}$ deutlich verfärbte, während das Fleisch des Stieles gar nicht grün wurde.

Die Lamellen stehen bei $L$. glaucescens verschieden dicht, im allgemeinen aber kaum weitläufiger als bei $L$. piperatus, wie NeUHoff (op.c.) angibt. Die Hutoberfläche ist im allgemeinen bräunlicher als bei der letztgenannten Art und zeigt bei einigen Proben (auch getrockneten) kleine rundliche »Blössen», ganz wie Spuren von Regentropfen.

Bei Einsicht der Sammlungsbelege im TUR bin ich zu der Ưberzeugung gekommen, dass dort die Art schon früher aus Katariinanlaakso (Nikoskelainen, 1958), dem Gelände von Pääskyvuori in Turku (Studentenexkursion, 1960) sowie wahrscheinlich auch aus Lemu, Nyynäinen (1960) vorgelegen hat. Dabei ist der Pilz durchgehends entweder in Eichenwäldern (Katariinanlaakso, Ruissalo, Nyynäinen) oder in Haselgebüschen (Pääskyvuori) aufgetreten. Tuomikoski fand ihn in Espoo im Haselhain und in Bromarv, Framnäs unter Linden.

Der Art ist im Norden offenbar nicht gebührende Beachtung geschenkt worden, und möglicherweise haben die Unklarheiten in der Deutung der Fries'schen Namen (vgl. Neuhof op.c.) es bewirkt, dass es nicht leicht ist, sich einen Begriff von der Verbreitung und der Ökologie dieses Pilzes zu bilden. Beide sind allgemein denen des $L$. piperatus gleichgestellt worden.

Die einzigen sicheren Funde der Art in Schweden stammen aus Bohuslän und Halland, wo der Pilz 1958 in der Nähe von Hasel, Espe und Birke und im Buchenwald gefunden wurde (vgl. ANDERsson 1958). In Mitteleuropa gehört zum Standort des Pilzes allgemein die Eiche, ebenso wird durchgehends auch die »thermophile» Natur der Art hervorgehoben (NeuHofF op.c., p. 90).

Lactarius glaucescens gehört offenbar zu den Pilzen der Eichenzone in Finnland.

\section{Lactarius azonites Bull, ex Gmel.}

KARSten (1889, p. 120) erwähnt aus Ruissalo einen Pilz unter dem Namen Lactarius acris (Bolt.) Fr. $\mathrm{Da}$ aber die Merkmale, die er angibt, besser auf L. azonites Bull. ex Gmel. passen und der echte L. acris im ganzen Norden unbekannt ist, äussert TuomIKoskI (1953, p. 12) die Ansicht, dass Karstens Pilz, der übrigens heutigentags wohlbehalten in den Sammlungen des HMF vorhanden ist, offenbar ein L. azonites ist. Dieses Taxon wird auch von FREY (1944, p. 14) unter dem Namen $L$. fuliginosus Fr. f. albipes Lange aus Saltvik auf Ahvenanmaa erwähnt.
Tuomroski (op.c.) sammelte die Art in Bromarv, Framnäs. Ich bin der Ansicht, dass L. fuliginosus und L. azonites bei uns auch an Museumsbelegen nach der Oberflächenstruktur der Sporen auch dann voneinander trennbar sind, wenn die Farbe des Stieles keine einwandfreie Trennung ermöglicht. L. pterosporus habe ich nie angetroffen. Auch dann, wenn die Oberflächenerhebungen der Sporen hoch sind, bilden sie ein deutliches Netzmuster.

Im Untersuchungsgebiet trlangt der Pilz seine grösste Reichlichkeit in Ruissalo. Seine besten Standorte sind hier der mit Eichen bewachsene Hügelabhang $\mathrm{S}$ von der Choraeus-Quelle und der mit Eichen und Haselsträuchern bestandene Südabhang der Landzunge Ajatinniemi. Sonst sind meistens nur vereinzelte Fruchtkörper angetroffen worden. Die besten Vorkommnisse vertreten nicht den frischesten Haintyp von Ruissalo, und darum begegnet man $L$. azonites nicht oft zusammen mit $L$. serifluus am gleichen Standort. Ersterer liebt die wärmeren und etwas trockeneren Abhänge, letzterer wiederum die frischen schattigen laubstreureichen Haine. Demnach gibt es auf den sonnigen Grasheiden am Südabhang von Katariinanlaakso wohl reichlich $L$. azonites, aber überhaupt nicht $L$. serifluus. Begleitpilze sind hier Amanita pantherina, Boletus edulis ssp. reticulatus, Clitopilus prunulus und Russula pseudointegra, die hier beide als typische Bewohner von offenen und hellen Eichenabhängen zu betrachten sind.

Drittens wurde die Art im Eichenwald von Saari in Mietoinen gefunden, und zwar unter einsamer Eiche am Wege, an der Böschung des Strassengrabens, an ähnlichem Ort wie auch in Katariinanlaakso.

Das maximale Auftreten dürfte im allgemeinen früher als bei L. serifluus, wohl schon Ende August, einfallen. Im TUR liegen 14 Proben aus der Zeit von 17. VIII.-14. IX. vor. Eine Ausnahme bildet der Fund von Mietoinen, mit dem Datum 19. X. (1960)!

Ich habe den Pilz stets nur in unmittelbarer Nähe von Eichen gefunden. Da dieses Verhältnis zur Eiche auch der allgemeinen Auffassung entspricht, sofern es sich um $L$. azonites u.a. im Sinne von NeuHoff (1956, p. 188) handelt, muss die Möglichkeit in Betracht gezogen werden, dass die von v. Sahulmann (1960) unter diesem Namen aus Lammi und Parikkala erwähnten Pilze irgendeiner anderen naheverwandten Art angehören. Ich habe selbst in Utsjoki eine in diesen Artenkreis gehörende Form mit hellem Stiel und sich gleichfalls rötendem Fleisch angetroffen, die aber im ganzen brauner wirkt und im Vergleich zu L. azonites einen längeren Stiel hat. In allen diesen Fällen kann es sich m.E. unmöglich um den südfinnischen $L$. azonites handeln. Trotzdem die Originaldiagnose bei FrIes (1821) für eine Farbvariation des Stieles nicht Raum lässt, wäre es nicht mit der biologischen Denkweise vereinbar, die Sache so zu deuten, dass hierbei also eine Farbvariation überhaupt ausgeschlossen ist (vgl. Neuhoff op.c.). Da die erwähnten Formen mit hellem Stiel neben den normalen vorkommen, muss jene Farbvariation des Stieles wahrscheinlich tatsächlich bei derjenigen Art vorkommen, die FRIES seinerzeit $L$. fuliginosus benannte, trotzdem ihm nur Stücke mit dunklem Stiel vorgelegen hatten.

Lactarius azonites zeigt in Europa offenbar eine stark südliche Verbreitung. NeuHoff (op.c.) bezeichnet die Art erst in Südwestdeutschland, Frankreich und in der Schweiz als häufig. Nach Pearson (1950, p. 
94) ist der unter dem Namen L. fuliginosus stehende Pilz in England häufig. Für den Norden sind die Angaben - in erster Linie wegen der nomenklatorischen Wirrnis - einigermassen unsicher (vgl. Neuhoff 1956, p. 189). Auch in Finnland vertritt die Art das aller südlichste Element, und ihre Verbreitung ist hier demnach auf den klimatisch unbedingt günstigsten Teil des Landes beschränkt.

Lactarius zonarius (Bull. ex. Fr.) Fr. Karsten (1879, p. 182) erwähnt den Pilz aus Turku. Dazu findet sich bei TUомıковкі (1953, p. 24) die Erwähnung: "Zwei Proben in HMF von W. Nyberg aus U. Porvoo gesammelt und von dem Sammler als unsicher bezeichnet, zeigten viersporige Basidien (L. insulsus).»

Ich habe die Art nur in Turku Ruissalo, im Eichenhain am Rande des anschliessenden Abies balsamea -Bestandes sowie in Kakskerta, Kulho, 29. VIII. 1962 auf blosser Erde im Eichenhain unter dem Steilfelsen am Südabhang der Anhöhe Linnavuori gefunden. Die Proben entsprechen der Beschreibung bei Neunoff (1956, p. 118-119): »Hut ockerblass, strohgelb - - - gezont», die treffender ist als die bei KARSTEN (1. c.) »orangegul eller gulaktig» (»orangegelb oder gelblich»). Dem Stiel fehlen die typischen 》auf weissem Grunde hellgelb gefärbten Gruben» des L. insulsus, auch rötet sich das Fleisch des Fusses nie. Die zu viert in den Basidien vorkommenden Sporen sind $7.15 \times 6.40 \mu$ gross, was noch nicht gegenüber L. insulsus [mit gleichfalls vier Sporen in der Basidien] entscheidet.

Die Art ist in Skandinavien selten und südlich, ist aber offenbar kollektiv gefasst worden. Der von LANGE (1940, p. 37) aus Dänemark erwähnte und öfters gesammelte Pilz gehört augenscheinlich hierher. NAhthorst-windahl (1956, p. 323) erwähnt nur L. insulsus (sensu Neuhoff) als Begleiter der Eiche, nicht aber L. zonarius. Da BlytT (1905, p. 94) den Pilz hier und da aus den Nadelwäldern Südnorwegens erwähnt, hat man es offensichtlich mit einer ganz anderen Art zu tun. Nach Neuhoff (op. c.., p. 119 findet man den Pilz »in Eichen-Hainbuchwald wohl nur auf kalkhaltigem oder wenigstens neutralem Boden».

Lactarius flexuosus Fr. var. roseozonatus v. Post

KARSTEN (1889, p. 120) erwähnt aus Ahvenanmaa, Jomala die Art Lactarius roseozonatus Post. Da $L$. trivialis (Fr.) Fr. und $L$. flexuosus Fr, in seinem Untersuchungsgebiet allgemein vorkommen, ist dieser Pilz von den genannten Arten offenbar deutlich verschieden gewesen, da er ihn als besondere Art aufführt. Ich habe am Rande des einzigen Quercus-Struthiopteris-Haines von Ruissalo unter Eiche und Schwarzerle einen Pilz gefunden, der offenbar diesem Taxon zuzuzählen ist. Er ist unleugbar in der Natur sofort von $L$. flexuosus unterscheidbar mit seinem im Vergleich zum Grau des L. flexuosus bräunlicheren Hut und der verhältnismässig kräftigen rötlichen Zonation des letzteren. Der Stiel ist mit dem finnischen L. flexuosus verglichen am Grunde stärker gelb. Der Pilz fühlt sich auch nicht ebenso fest an. Der Standort in Ruissalo, ein frischer Hainboden, ist weniger typisch für L. flexuosus, der hierzulande im allgemeinen auf Pfaden in deutlich kulturbeeinflusster Umgebung und auf harten Grasflächen zu finden ist.

Es ist möglich, dass sich der Name an sich ursprünglich gar nicht auf diese Art bezieht (NEUHofF
1956). Auf jeden Fall existiert aber eine derartige Form des L. flexuosus.

LANGE (1940, p. 38) spricht von einer besonderen Art, L. roseozonatus (Fr.) Bat., die in Dänemark jedoch nur einmal angetroffen worden sein soll. Seine Abbildung des Pilzes auf Taf. 172 (B) ist etwas rötlicher als der Pilz von Ruissalo.

\section{Lactarius mitissimus Fr.}

Nach der Auffassung von Tuomikoski (1953) gehört unser kleiner orangeroter Lactarius gerade zu dieser Art. Er wirkt auch recht einheitlich, und L. aurantiacus Fr., der aus Finnland früher gemeldet wurde (z.B. RautavaARA 1947), dürfte im allgemeinen hierher zu zählen sein.

Der Pilz ähnelt sehr der Abbildung bei Bresadola (1927, Taf. 392), und die von Neuhoff (1956, p. 72) mitgeteilten Merkmale, der beinahe milde Geschmack des Milchsaftes (allerdings mit einigermassen bitterem Nachgeschmack), die Gleichfarbigkeit von Hut und Stiel und die flach ausgebreitete Form des Hutes, passen gut. Die Sporen (gemessen an getrocknetem Material) sind jedoch kleiner (Ruissalo, 100 Messungen: $6.67 \pm 0.06 \times 5.35 \pm 0.04 \mu$; Turku, Metsäkylä, 202 Messungen: $6.61 \pm 0.07 \times 5.16$ $\pm 0.03 \mu$; Lemu, Nyynäinen, 100 Messungen: 7.07 $\pm 0.25 \times 6.10 \pm 0.06 \mu)$ als die von NeuHoff angegebene Grösse $8-9.5 \times 6.5-7.5 \mu$.

Die Art ist nach Tuomikoski (op.c.) als südlich und als verhältnismässig selten zu betrachten. TuoMIKoskI erwähnt 17 Fundorte, die sich stark auf Südwest- und Südfinnland häufen. Die Art ist aus irgendeinem Grunde nicht recht beachtet worden. FrEY (1944 a) weist anlässlich seines Fundes auf Ahvenanmaa auf die Seltenheit des Pilzes hin und meint ihn als erster in Finnland gefunden zu haben, weil ja KARsten (1889, p. 124, nicht aber 1881, p. 12) seinen Fund aus Turku mit Fragezeichen versehen hat.

Später ist der Pilz u.a. aus Parikkala und sogar noch aus Lapinlahti erwähnt worden (v. SchulMANN 1957). Dass aber die Art hier dennoch zur Sprache genommen wird, beruht darauf, dass sie innerhalb der Eichenzone um Turku häufig vorkommt und z.B. in Yläne und Tammela anscheinend völlig fehlt, was wiederum auf eine sehr schroffe Grenze in der Verbreitung gegen das Inland hindeutet. Ich gebe nachstehend eine Ǔbersicht über die Funde im Untersuchungsgebiet. Im TUR liegen 30 Proben, einem Teil der Angaben liegen lediglich die Aufzeichnungen im Felde zugrunde.

Turku: In Ruissalo zumal im östlichen Haingebiet vielenorts, besonders häufig in den Hainen bei der Choraeus-Quelle sowie in dem angepflanzten Abies balsamea-Bestand, wo man den Pilz noch bis spät in den Herbst hinein (z.B. 5. XI. 1961) antreffen kann In der Nähe von Eichen (in Eichen- und Haselhainen) in Katariinanlaakso, Muhkuri, Metsäkylä, Pansio, Kurala, Pääskyvuori und Takakirves; an andersartigen Standorten dazu noch auf der sog. Patterinmäki-Anhöhe S von Itäharju (reiner Kiefernwald), Pahaniemi (Fichten-Kiefernmischwald) und Metsäkylä nebst Piispanristi (reiner Fichtenwald).

Úbriges Untersuchungsgebiet: Taivassalo, Ketarsalmi (Eichenwald); Lemu, Ohensaari (desgl.); Askainen, Lempisaari (Eichenwald und Hain mit eingestreuten Eichen); Nousiainen, Linnamäki ; Masku, Kankainen (Fichtenwald); Rymättylä, Kepuinen (Eichen- und Haselhain); Parainen, Lofsdal, Attu 
und Peksor (Eichenstandorte); Korppoo, Lohm (unter Eichen); Kuraklintti (in Haselgebüsch); Lieto, Kunnanmäki und Vanhalinna (Fichtenwald mit einigen Eichen); Raisio, Perno; Kakskerta, Kulho; Kaarina, Karpanmäki; Piikkiö, Tuorla und Jauhosaari (Fichtenwald mit Eichen); Halikko, Pihko; Uskela, Tupuri; Paimio, Hääsvuori (unter einzelnen Eichen).

Als Hauptstandorte des Pilzes in der TurkuGegend haben sich also die Eichenhaine und die hainartigen Fichtenwälder erwiesen. Oft findet man hier als Begleiter der Art auch andere typische Pilze der Eichen-Haselhaine, wie etwa Lactarius pyrogalus, L. piperatus (sensu Neuhoff 1956), L. quietus und L. vellereus. In Mitteleuropa gilt als optimaler Standort ein üppiger 40-60jähriger Fichtenwald (NEUHOFF 1956, p. 173; vgl. auch Tuомıкоsкi 1953), während der nahverwandte $L$. aurantiacus Fr. vor allem im »Laubwald auf schwerem Boden» zu finden ist. Dies könnte vielleicht den Anlass geben, die ganze Art einmal noch taxonomisch vorzunehmen, nicht zumindest weil ja auch im nördlichsten Finnland, z.B. in Utsjoki, ein sehr verwandtes Taxon vorkommt (vgl. KaLLIO 1960), allerdings in einer vom südlichen Pilz deutlich abweichenden Form mit klar gelb sich färbendem Milchsaft.

\section{Gantharellaceae}

Craterellus sinuosus (Fr.) Fr.

Im Schrifttum wird dieser Pilz aus Finnland nicht erwähnt.

Die Funde im Untersuchungsggebiet sind die folgenden.

Ruissalo, in den besten Hainabschnitten der Insel, besonders in dem frischen Eichenhain auf der Westseite des Naturreservats sowie im Eichenbestand am Nordabhang der Anhöhe nördlich davon reichlich und in allen Jahren mit Ausnahme der trockensten (wie etwa 1955) und kältesten (1962); Katariinanlaakso, nur im Teilgebiet 9 von Nikoskelainen (1955), in der Laubstreu unter Eichen am Fusse des Felsens. Der Standort ist wegen des vom Felsen herabrieselnden Wassers einigermassen frischer als seine nächste Umgebung; Muhkuri, in reicher Laubstreu im Eichen-Haselhain des Nordabhangs.

Mietoinen, Eichenwald von Saari, reichlich in einem kleinen Dickicht von jungen Eichen zusammen mit reichlicher Leotia lubrica Fr., auch eine Art des reichen Hainbodens (vgl. NANNFELdT 1943, p. 45).

Piikkiö, Tuorla, am Abhang mit Eiche und Hasel am Rande von Kuninkaanniitty, gleichfalls zusammen mit Leotia lubrica Fr. in dichten Gruppen auf fast blosser Streu, wie oft auch in Ruissalo; Uskela, Veitakkala, im Eichen-Haselhain in der blossen Streu auf unterliegendem Fels, an sehr ähnlichem Standort wie in Katariinanlaakso; Uskela, Tupuri, unter Haselsträuchern im Eichenwald am Fusse eines Felsens; Halikko, unter Eiche am Grabenrand des vom Gehöft Vuorentaa zur Hauptstrasse führenden Weges.

Die Art ist morphologisch nicht ganz einheitlich. Auch beim gruppenweisen Auftreten gleicht ein Teil der Exemplare mit ihrem ziemlich geraden Hutrand mehr der typischen Hauptform, die anderen wieder- um müssten offenbar eher derjenigen Art zugezählt werden, die FrIEs unter dem Namen Craterellus crispus aus Schweden beschrieben hat. Nach LUNDELL (Fungi exs. suec., Nr. 2670 und briefl.; vgl. auch BRESADOLA 1927) ist jedoch C. crispus wohl vornehmlich als eine systematisch minderwertigere Form zu betrachten, und darauf deutet auch die gleitende Skala des obenerwähnten Merkmals in ein und demselben Schwarm hin, der recht wahrscheinlich wohl zugleich auch einen einheitlichen Klon repräsentiert. In Finnland scheint vor allem jene crispus-Form gut vertreten zu sein, einem durchaus typischen Fruchtkörper mit geradem Hutrand und sehr schwach entwickelten Hymeniumadern begegnet man seltener; die besten solchen Proben stammen aus Ruissalo.

Die Art scheint, auch kollektiv gefasst, in Finnland nur in Eichenbeständen, mit Vorliebe an etwas frischen Stellen mit dichter Vegetation (sehr gern auch Haselgesträuch) und reichlicher Streu vorzukommen. Die obenerwähnte, von Ridelius gesammelte schwedische Probe $\mathrm{Nr} .2670$ trägt eine sehr charakterisierende Standortsbezeichnung »Under hazel in oak wood, in the transition zone between the bare soil under the bushes and the surrounding grass-grown soil», und die Probe Nr, 1779: »Under oaks, hazel etc.» Dr. Seth Lundell hat die Artbestimmung an einer ihm zugesandten Probe aus Ruissalo bestätigt, und er betont (briefl.) die schwache Ausbildung des crispus-Zuges bei dem Exemplar. In Mitteleuropa ist die Art ausdrücklich ein Bewohner der Haine (HaAs 1933, p. 130-131).

Für die Sporengrösse wurden nach je 100 Messungen folgende Werte gefunden: Ruissalo $8.21 \pm$ $0.17 \times 5.09 \pm 0.03 \mu$, Katariinanlaakso $8.44 \pm 0.20$ $\times 5.8 \pm 0.07 \mu$.

Craterellus cornucopioides (L. ex Fr.) Pers.

$\mathrm{Zu}$ den höchst typischen Pilzen der Eichenwälder im Untersuchungsgebiet gehört auch Craterellus cornucopioides (L. ex Fr.) Pers., der in fast allen untersuchten Eichenwaldungen angetroffen wurde. In Ruissalo ist er besonders häufig und um so reichlicher, je üppiger der Hainstandort. Die besten Wuchsstätten des Pilzes auf der Insel sind darum das Naturreservat und das Haingebiet westlich davon. In Katariinanlaakso und Muhkuri im Stadtgebiet von Turku findet man den Pilz weniger, was mit der trockeneren Natur der dortigen Standorte zusammenhängt. Úbriges Untersuchungsgebiet: Mietoinen, Saari; Taivassalo, Ketarsalmi; Lemu, Nyynäinen; Rymättylä, Kepuinen; Kaarina, Karpanmäki; Piikkiö, Tuorla; Parainen, Attu; Halikko, Vaisakko und Pihko; Perniö, Teijo; Pohja, Fiskars.

In Mitteleuropa findet man den Pilz in üppigen Hainen (z.B. Neuhoff 1956). In Finnland ist er aber nicht auf die Eichenhaine und auch überhaupt nicht auf die Haine beschränkt. Ich habe ihn in Yläne, Elijärvi, in Kiefernwald mit dünnem Humus auf Rapakiviunterlage, desgleichen an ähnlicher Stelle in St. Honkilahti gesammelt. Dazu wächst er an einigen der besten Hainstandorte in Yläne, so im Kirchdorf am Rande des Tupamäki-Hains (vgl. Kallio 1954). Nach v. Schulmann (1960) gibt es den Pilz noch in Elimäki und Lammi, nach $H$. SÅLtiN (mündl.) an mehreren Stellen in Lappi T.1. Schliesslich wird er noch aus Kuopio angegeben (Sienitietoja 1961, n:o 4 und Mag.phil. Torvo RÄSÄNEN briefl.). 
Craterellus cinereus Fr. ex Pers.

Das hiesige mykologische Schrifttum kennt die Art nicht. Sie ist offenbar in gewissem Grade auch in Skandinavien missgedeutet worden, und darum sind die auf sie bezüglichen Verbreitungsangaben im vorliegenden als einigermassen unsicher zu werten. Unter anderem Craterellus sinuosus ist fälschlich mit diesem Namen benannt worden.

Im Untersuchungsgebiet kenne ich den Pilz nur von drei Stellen, nämlich aus dem üppigen Eichenhain westlich vom Naturreservat in Ruissalo, von einstweilen nicht näher bezeichneter Stelle in Katariinanlaakso (die Probe stammt von einer Studentenexkursion i.J. 1961) sowie drittens aus Perniö, Ylikylä.

Dr. Seth Lundell in Uppsala hat mir in grösstem Entgegenkommen schwedisches Vergleichsmaterial zugestellt. Dieses erweist, dass es sich tatsächlich um die hier in Rede stehende Art handelt. Die Probe von Katariinanlaakso entspricht durchaus der Form bei Bresadola (1927, Taf. 480). In Ruissalo wuchs der Pilz zusammen mit C. cornucopioides. Ein unfehlbares und deutliches Erkennungsmerkmal in solchen Fällen sind die ziemlich gut entwickelten Hymeniumleisten.

In Schweden ist der Pilz gleichfalls selten. INGELSTRÖм (1940) gibt ihn aus Park- und Hainvegetation an, FERDINANDSEN \& Winge (1943) bezeichneten ihn in Dänemark als nicht häufig. Nach RrakeN (1915) in Mitteleuropa selten in Hainen. Weiter östlich dürfte die Häufigkeit zunehmen (vgl. BoHus \& BABOs 1960).

\section{Gasteromycetes}

Cyathus striatus Pers.

Die hiesigen Fundorte deuten auf eine südliche Verbreitung hin. Schon Karsten (1889) erwähnt den Pilz aus Vähäheikkilä und Ruissalo in Turku und aus Helsinki. Malmström (1933, p. 69) sammelte ihn in der Nähe von Helsinki und STENLID (1947) in A. Lemland. Ich selbst habe die Art vielmals in Ruissalo angetroffen, wo man aber den Pilz besonders in Anhäufungen von Eichenzweigstreu sogar sehr reichlich finden kann. Doch auch in Yläne stiess ich 1960 und 1962 beim See Elijärvi im Himbeergesträuch auf den Pilz, der trotz seiner eventuellen südlichen Verbreitung also doch nicht einzig an die Eichenzone gebunden ist.

In Schweden ziemlich allgemein bis Uppsala (Thore Fries 1921, p. 49). In Norwegen weist die Art eine Küstenverbreitung auf (EakBlad 1955, p. 78).

\section{Lycoperdon echinatum Pers.}

Gehört zu den auffälligsten und am leichtesten kenntlichen Arten der Gattung, und es müssten demgemäss von di esem Pilz mehr Angaben vorliegen als von anderen seltenen Lycoperdon-Arten. Der Schwerpunkt der nordischen Verbreitung liegt in Skandinavien. Nach ANDERsson (1941, p. 404) überschreitet der Pilz nirgends den Limes norrlandicus. Er ist auch vorwiegend als ein Buchenwaldpilz betrachtet worden (vgl. T. Fries 1921), es gibt aber Proben auch von Eichenhügeln.

Im HMF liegt unter diesem Namen eine Probe aus dem Hesperia-Park in Helsinki (1958, Malmström). Das Exemplar ist aber ganz zu jung, um eine Art- bestimmung zu erlauben. Thesleff (1919, p. 52) erwähnt die Art aus der Umgegend von Viipuri, wo der Pilz nach seiner Auffassung nicht einmal selten ist. Von Sahulmann nennt Funde aus Parainen, Karkkila und Lammi.

Ich habe die Art in Turku in Ruissalo und Katariinanlaakso angetroffen. Im Teilgebiet 9 (NıкоsKeLAINEN 1955) von Katariinanlaakso war der Pilz im Jahre 1960 sogar reichlich zumal im Steinicht unter den Eichen des südexponierten Haines am Fusse des hier vorkommenden Felsens zu finden. In Ruissalo fand ich den Pilz in demselben Jahre nur einmal.

Nach Wrikowski (1934, p. 172) begegnet man dem Pilz schon in Estland »in fast allen Wäldern der Umgebung von Tartu, nicht selten». Da die Art anderseits in Norwegen gänzlich fehlt (EckBLAD 1955, p. 43), gleicht er den Phanerogamenarten mit südöstlich-kontinentaler Allgemeinverbreitung in Nordeuropa.

\section{Scleroderma aurantium Pers.}

Karsten (1889, p. 16) erwähnt Scleroderma aurantium Pers. als ein Synonym zu S. verrucosum Bull. und bezeichnet den Pilz als sehr selten in Laub- und Nadelwäldern auf Sandboden (EH. Tampere; V. Ruissalo). Auch Thesleff (1919, sub nom. S. vulgare $\mathrm{Fr}$.), der den Pilz auf sandigem Wege unter Linden in seinem Untersuchungsgebiet fand, hält die Art für äusserst selten. MALmström (1933-34) erwähnt den Pilz aus Helsinki, EkLund (1944, p. 216) aus Korppoo. Im Verzeichnis von v. SarulMANn (1960) liegt die Hauptform aus Pohja (Fiskari) und var. spadiceum Schff. aus Parainen vor. TuomIKoskr (1959) hält die Art für selten und offenbar südlich. Palmgren (1920, p. 105) nennt noch drei Stellen in St: Kankaanpää, Peipohja und Ulvila.

In Südwestfinnland besonders im Gebiet der Eiche verhältnismässig häufig an etwas trockenen Stellen an den Abhängen der Eichenhügel, an Ackerrändern und zumal in Ruissalo in stark vermorschten Eichenstümpfen. Fundorte in TUR: Turku, Ruissalo (reichlich), Katariinanlaakso (ebenso) und Muhkuri, im übrigen Untersuchungsgebiet in Kaarina, Karpanmäki; Piikkiö, Tuorla; Parainen, Peksor; Mynämäki, Kallavuori; Halikko, Viurila und Pihko.

In Schweden allgemein im Süden bis Uppsala, aber nicht mehr nördlicher (FRIES 1921, p. 53).

In Norwegen hat der Pilz gleichfalls eine südliche Verbreitung (HøEG 1944, p. 65-70; vgl. auch EaKBLAD 1955).

\section{Helvellaceae}

Die Gattung Helvella enthält mindestens zwei in Finnland südliche Arten, die hier gleichfalls noch besprochen werden mögen, nämlich $H$. crispa und H. elastica.

\section{Helvella crispa}

EKLUND (1943) nennt den Pilz aus Korppoo »am grossen Graben» und HagkmaN (1946) aus feuchtem Polytrichum-Bestand unter wassertriefendem Fels in Tvärminne.

Im TUR befindet sich eine Probe aus Kulho (Eichenhain von Linnavuori), eine aus Park von Kupittaa in Turku. Die Art wurde 18. IX. 1962 recht reichlich in Parainen, Ålö, Piukkala in frischem 
Fichten-Birkenmischwald mit Hainpflanzen, u.a. Helleborine latifolia, angetroffen. Auf der Insel Peksor nahe bei vorigem Fundort wuchs der Pilz unter Eichen. Eine Probe wurde von Laila Hakala in Kuopio gesammelt.

Diese leicht kenntliche Art muss in Finnland selten und vielleicht auch periodisch sein (vgl. Hackman 1946). Der Fund aus Kuopio zeigt, dass der Pilz wider Vermutung nicht besonders südlich ist (vgl. RautavaAra 1947). Eher mag Helvella crispa eine Art der Hainzentren sein.

In Mitteleuropa dürfte die Art nicht selten sein und besiedelt namentlich die Haine (BRESINSKY \& Zeitlmayr 1960; vgl. auch Pirk 1944, der den Pilz für eine Differentialart des Asperuletosums im Bereich des Querceti-Carpinetums hält). In Schweden ist die Art südlich und nach NANNFELDT (1952, p. 205) besonders unter Eichen und Buchen zu finden.

Helvella elastica Bull.

Gilt in Finnland als selten (Tиомгкоsкx 1959).
Stenlid (1947) erwähnt den Pilz von Ahvenanmaa.

Ich habe die Art an folgenden Orten gefunden: Turku (Ruissalo, nähere Standortsangabe fehlt; Katariinanlaakso, Ackerrand am Fusse eines Abhangs mit Eichen; Metsäkylä, Fichtenwald, in der Nadelstreu des Waldrandes); Kaarina (Karpanmäki, Eichenhain); Piikkiö (Tuorla, üppiger Südabhang mit Fichten, Haselsträuchern und Eichen); Parainen (Kirjala, Abhang mit Fichten; Attu, Fichten-Laubmischwald). Dazu gibt es im TUR eine Probe von Ilkka Kukkonen aus Korppoo, Lohm und von $H$. Såltin aus Pohja, Fiskari.

Der Pilz ist also im Gebiet nicht so sehr selten. Er ist hier nicht von der Eiche abhängig, sondern sein Vorkommen ohne Unterschied im Fichtenwald und Hain ist lediglich ein Ausdruck für bestimmte Ansprüche in bezug auf die Frische des Standorts. In Mitteleuropa gilt die Art vorwiegend als ein Hainpilz und wird aus Ungarn als eine recht wichtige Komponente der Flora gewisser Eichenwaldtypen erwähnt (BoHus \& BABos 1960).

\section{BLICK AUF DIE VERBREITUNGSFRAGEN ALS GEOBOTANISCHES UND ÖKOLOGISCHES PROBLEM}

\section{Einige geobotanische Grosszüge der Verbreitung der Makromyceten}

Die im vorhergehenden genauer besprochenen Pilze vertreten einen südlichen Artenbestand, der in dieser Richtung seines Areals die äusserste Grenze seiner Verbreitung in der Eichenzone erreicht oder jedenfalls innerhalb derselben reicher als nordostwärts nach dem Inland hin ist.

Das angehäufte Material vermag dagegen nicht mit genügender Gewissheit solche Arten anzugeben, für die dieses Gebiet wiederum die südwestliche Grenze ihrer allgemeinen Verbreitung bildet. Vielleicht könnte Lactarius repraesentaneus Britz. als ein Beispiel für diese Gruppe in Frage kommen. Diese nördliche und die Gebirge bewohnende Art (vgl. Singer 1954) ist in Mitteleuropa mit Ausnahme der Gebirge überall selten (Neunoff 1956). Aus Dänemark erwähnen weder NEuHoff (op. c.) noch Lange (1940) den Pilz, wohl aber Möller (1946). In Südschweden ist der Pilz ziemlich selten (NATHORST-WINDAHL 1956; vgl. auch ANDERSSON 1958).

In Finnland is $L$. repraesentaneus offenbar überall, auch in Lappland, gemein (Tuomikoski 1952; Kallio 1959). In Yläne bin ich dem Pilz vielenorts begegnet, namentlich in Birkenwäldern, in frischen Fichtenwäldern mit eingestreuten Birken und u.a. im Birkengebüsch am Verlandungsufer des Sees Elijärvi. Von Schulmann (1960) erwähnt die Art von Ahvenanmaa und aus Parainen, Karkkila, Elimäki, Lammi und Parikkala. Bei EkLund (1943, Korppoo) und STenlid (1947, Ahvenanmaa) dürfte L. repraesentaneus im Material von Lactarius scrobiculatus enthalten sein. Ich habe zwar den Pilz in Turku u.a. im Gelände von Pääskyvuori angetroffen, bei meinen Eichenwaldstudien bin ich ihm aber nich begegnet, und darum betrachte ich die Art namentlich an Eichenstandorten - als selten im Gebiet.

Eingehendere quantitative Untersuchungen würden vielleicht die relative Abnahme von Lactarius trivialis (Fr.) Fr. nach Südwesten hin z.B. im Vergleich zu Yläne erweisen, wo diese Art einen der ersten Plätze unter den Waldpilzen zusammen mit u.a. Laccaria laccata (Scop. ex Fr.) Berk. \& Br. sowie gewissen Russula- und Cortinarius-Arten einnimmt. In Ruissalo spielt die Art, namentlich in den Eichenhainen, eine sehr bescheidene Rolle.

Ein Vergleich der Pilzfloren des südwestlichen und südöstlichen Abschnitts der Eichenzone Finnlands - dazu bietet sich durch die Untersuchung von Thesleff (1919) aus der Gegend von Viipuri die Möglichkeit lässt einige Unterschiede hervortreten.

Von den neun namentlich in der Eichenzone gefundenen südlichen Boleten des südwestfinnischen Eichengebietes werden aus dem Osten nur zwei erwähnt, nämlich Gyroporus cyanescens und Xerocomus chrysenteron, von sonstigen südlichen Arten (mit weiter Verbreitung) noch $X$. badius und Suillus granulatus, die beide dort nach Thesleff grosse Seltenheiten sind.

Fistulina hepatica fehlt im östlichen Eichengebiet und ist aus der Provinz Uusimaa nur einmal aus Helsinki angegeben. In die Gruppe der in Richtung Helsinki fehlenden Arten gehören u.a. Polyporus frondosus und Boletus edulis ssp. reticulatus.

Bezeichnet man als südwestlich diejenigen 
Arten, die nicht im östlichen Eichengebiet angetroffen worden sind, wären als solche zu den ebenerwähnten Arten noch die folgenden hinzuzufügen:

\section{Hygrocybe punicea \\ Laccaria amethystina \\ Tricholoma irinum \\ Oudemansiella radicata \\ Marasmius prasiosmus \\ Mycena inclinata \\ Amanita spissa \\ A. citrina}

Rhodophyllus lividus

Russula pseudointegra

R. cyanoxantha

Lactarius azonites

L. zonarius

L. serifluus

Craterellus sinuosus

C. cinereus
Aus dem südöstlichen Eichengebiet werden jedoch auch einige südliche Arten erwähnt (TheslefF op. c.), die im südwestlichsten Finnland vorkommen, auch wenn sie im obigen Verzeichnis fehlen, und zwar Calocybe georgii und Lactarius controversus, letzterer u.a. aus Turku (Karsten 1889, p. 119).

Entsprechen nun die im vorhergehenden mitgeteilten Verbreitungsbilder der Wirklichkeit, so ist die rezente Verbreitung der besprochenen Arten ein Erweis dafür, dass die Ausbreitung der Pilze nach einer bestimmten Richtung hin wie bei den Phanerogamen nur allmählich erfolgt (vgl. HinTIKKA 1931, p. 11-12), sowie dass die Entstehung von Exklaven durch Fernausbreitung auch bei ihnen als Ausbreitungsfaktor lediglich sekundäre Bedeutung besitzt, auch trotzdem Beispiele jenes Typs der Ausbreitung auch aus Finnland angeführt werden können (z.B. Mutinus caninus; vgl. MäKIneN 1964) und Lepiota acutesquamosa (TUR) in Kuopio.

Auch bei vielen von Südwestfinnland bis Viipuri verbreiteten Arten nimmt die Häufigkeit gegen den Osten hin ab. Die in Turku und dem vorgelagerten Schärenhof sowie offenbar auch auf Ahvenanmaa häufigen Arten Tricholoma sulphureum und T. columbetta sind im Untersuchungsgebiet von TheslefF sehr selten.

Von den oben im speziellen Teil besprochenen Pilzen wirkt auf Grund der z. Z. vorliegenden Angaben nur Lycoperdon echinatum südöstlich, ist doch die Art (siehe oben S. 67) sowohl in der Viipuri-Gegend als auch in Estland ziemlich häufig, aber in Südwestfinnland selten. Ihre Seltenheit in diesem von finnischen Mykologen am gründlichsten durchsuchten Gebiet muss echt sein, handelt es sich doch um einen auffallenden und leicht kenntlichen Pilz. In Südschweden gibt es ihn

wieder, nicht aber mehr in Norwegen, m.a. W., das Verbreitungsbild würde recht gut dem Auftreten vieler südöstlich-kontinentalen Phanerogamen in Nordeuropa entsprechen (vgl. Hultén 1950; KALELA 1961).

Die im vorgehenden mitgeteilten Verzeichnisse enthalten mehrere Seltenheiten, an sich durchaus natürlich, befindet man sich doch in einem Grenzegebiet des Vorkommens dieser Arten. Anderseits gibt es aber da auch sowohl in bezug auf Masse und Frequenz als auch die jährliche Dauer des Auftretens nicht wenig bedeutungsvolle Arten. Lactarius quietus und $L$. serifluus sind mitunter die dominierenden Pilze der Haine von Ruissalo, Amanita citrina, A. pantherina und Rhodophyllus lividus können in manchen Herbsten in Katariinanlaakso alle anderen Arten an Menge übertreffen, und Tricholoma sulphureum ist auch in ungünstigen Pilzjahren an den verschiedenen Untersuchungspunkten am sichersten zu finden.

Die Verbreitung der Pilze als geobotanisches Problem ist eng mit der Verbreitung bestimmter Phanerogamengesellschaften verknüpft. Ein Beweis dafür ist die Anwendung der Pilze als gute Differentialarten in der Phytozönologie (vgl. Leischner-Siska 1939; Slipp \& Snell 1944; Parker-Rhodes 1955).

Da ein Vergleich der Waldtypen und anderer Pflanzenverbände unserer Eichenzone mit den mitteleuropäischen bisher nicht mit der erforderlichen Genauigkeit durchgeführt worden ist, gestaltet sich ein entsprechender Vergleich der Pilzfloren notgedrungen nur orientierend. Der Begriff »Eichenwald» ist schon an und für sich vieldeutig - in Finnland z.B. kann er sich von einer fast schon felskiefernwaldartigen Vegatation bis zu den üppigsten Hainen erstrecken, wie man sie im Naturreservat von Ruissalo findet. Dennoch mag ein solcher, auch wenn nur Beispielsweiser Vergleich geeignet sein können, einige Aufschlüsse über die geobotanische Natur der Pilzflora unserer Eichenregion zu geben.

Neuhoff (1956, p. 26) teilt für das mitteleuropäische Querceto-Carpinetum folgendes Pilzverzeichnis mit, das er für besonders bezeichnend hält.

Amanita phalloides

A. rubescens

Collybia radicata

C. platyphylla
Tricholoma columbetta Marasmius confluens M. prasiosmus $M$. peronatus 
Inocybe geophylla

I. umbrina

Inoloma bolare

Stropharia aeruginosa

Stropharia squamosa

Russula delica

$R$. cyanoxantha

$R$. sororia.

Von Lactarien, die er besonders untersucht hat, nennt er die folgenden:

$\begin{array}{ll}\text { Lactarius quietus } & \text { Lactarius piperatus } \\ \text { L. chrysorrheus } & \text { L. pyrogalus } \\ \text { L. subdulcis } & \text { L. glyciosmus } \\ \text { L. blennius } & \text { L. pubescens } \\ \text { L. violaceus } & \text { L. torminosus } \\ \text { L. vellereus } & \end{array}$

Von den 35 Arten dieses Verzeichnisses sind mindestens 26 auch in meinem Untersuchungsgebiet, und zwar in Katariinanlaakso, zu finden. In Utsjoki sind nur noch 10 Arten gefunden worden, nämlich Marasmius confluens, M. peronatus, Inocybe geophylla, (Russula delica), Stropharia aeruginosa, S. squamosa, Boletus edulis, Lactarius glyciosmus, L. pubescens und $L$. torminosus.

Den typischen Makromycetenbestand des im Vergleich zum vorigen dürftigeren mitteleuropäischen Eichen- und Birkenhains (Betula verrucosa) auf saurem Boden bilden folgende Arten (NeuHoff op. c., p. 25); Amanita fulva, A. citrina, A. spissa, A. pantherina, Collybia maculata, Inocybe lacera, Rozites caperata, Dermocybe anomala, Russula ochroleuca, Boletus felleus, B. calopus, Xerocomus badius und Lactarius rufus sowie dazu noch die eigentlichen eichengebundenen Pilze. Von den genannten 13 Arten ist nur eine (Boletus calopus) in Katariinanlaakso fremd, ist aber nach KARSTEN (1859, p. 16, sub nom. B. pachypus Fr.) in dem nahe gelegenen Piispanristi gefunden worden. Dieses Pilzverzeichnis zeigt eine zumindest ebenso grosse Übereinstimmung zwischen den Eichenpilzfloren von Mitteleuropa und Katariinanlaakso, wie sie auch der Phanerogamenbestand aufweist.

Über die Mykoflora des üppigsten frischen Querceto-Carpinetums auf neutralem Boden heisst es bei Neunoff (l.c. : »In der Pilzflora ist Craterellus cornucopioides der Massenpilz; häufig sind auch Otidea onotica, Clavaria cristata, Tricholoma sulphureum, Mycena pura, Paxillus involutus, Rhodophyllus nidorosus, Inocybe petiginosa, Phlegmacium nemorensis, Russula cyanoxantha; von selteneren Arten seien Otidea cochleata, Rhodophyllus lividus, Russula farinipes,
$R$. pseudointegra, R. violeipes, Boletus pulverulentus genannt.»

Im Untersuchungsgebiet gibt es derart üppige Haine mit neutralem oder schwach alkalischem Boden überhaupt nicht, und dennoch ist auch von diesen Pilzen mehr als die Hälfte auch in Ruissalo $\mathrm{zu}$ finden, ja selbst ein paar der als Seltenheiten bezeichneten.

Einige Umstände mögen aus dem verfügbaren Material erfasst werden können. Die Pilze zeichnen sich mehr als die Phanerogamen durch eine weitumspannende Verbreitung aus - sind doch viele der gemeinen Pilze Finnlands zugleich auch Kosmopoliten. »Verbreitungsgruppen» gibt es also bei den Pilzen weniger als bei den Phanerogamen, und die Verbreitungsareale sind offenbar grosszügiger insofern, als sie den geobotanischen Grossgrenzen folgen und gelegentlich verbindend zwischen zwei Gebieten auftreten können, die in bezug auf die Phanerogamen nur wenig Gemeinsames aufzuweisen haben. Als ein europäisches Beispiel mögen noch die Pflanzenlisten von BoHus \& BABOs (1960) aus Ungarn erwähnt werden. Unter den Phanerogamen der dortigen Eichenwälder stösst man nur auf wenige auch in Finnland vorkommende Arten, unter den Pilzen gibt es ihrer viele. So ist von den vierzehn charakteristischen Phanerogamen des Melica Quercus cerris - Q.petraea -Waldes (op.c., p. 7) nur Viola riviniana auch in unseren Wäldern zu finden, von den 90 Pilzen (op.c., Tab. 3) dagegen nicht minder als reichlich die Hälfte einzig in der Nahumgebung von Turku (Katariinanlaakso, Ruissalo).

Für Finnland wiederum sei folgendes Beispiel angeführt, die wahllos herausgegriffene Liste einer einzigen Pilzexkursion nach Katariinanlaakso (Teilgebiet 9, Nikoskelainen 1955) am 14. IX. 1960. Sie enthält 22 Arten, die sich nach heutiger Auffassung auf die verschiedenen Verbreitungsgruppen auf die Weise verteilen, dass 13 bis hinauf nach Lappland verbreitet sind ( $\mathrm{L}$ im Verzeichnis), bei 7 die Nordgrenze irgendwo weit im Süden, offenbar innerhalb der Eichenzone liegt (E) und nur bei zweien (N) die Grenze im Bereich der eigentlichen Nadelwaldregion verbleiben dürfte.
L Tricholoma saponaceum
$\mathrm{L}$ Clitocybe odora
E Amanita pantherina
L A. muscaria
$\mathrm{N} A$. rubescens
$\mathrm{L} A$. vaginata
N Lepiota cristata
L Cystoderma granulosum
L Clitopilus prunulus

E Rhodophyllus lividus

L Boletus edulis ssp. edulis

E Boletus edulis ssp. reticulatus

E B. miniatoporus

$\mathrm{E}$ Xerocomus chrysenteron

L X. subtomentosus

L Leccinum scabrum

L Russula delica 
L Lactarius fuliginosus

E L. azonites

[L L. mitissimus coll (?)

L L. turpis

L L. deliciosus

Diese Einheitlichkeit im grossen, namentlich in betreff der Natur der nördlichen Nadelwaldregion, spiegelt sich wohl auch ganz allgemein aus dem auf die Flora und die Vegetation bezüglichen Schrifttum wider, und das Ziehen von deutlichen Grenzen im Kerngebiet der Waldregion selbst ist auch hinsichtlich der Phanerogamen schwerer. In Finnland haben nur die beiden geobotanischen Grenzen der Nadelwaldregion gegen die im Laufe der Forschung zu verschiedenen Zeiten durchgeführten Grenzrevisionen standzuhalten vermocht. Es muss aber betont werden, dass man äusserst vorsichtig sein muss, wenn man in diesem noch frühen Stadium der Kenntnis der Verbreitung der Makromyceten Grosslinien der Verbreitung zu ziehen versucht.

Wenn man z.B. in Lappland eine Pilzart findet, die nach den Belegen in den Museen für südlich (z.B. RAUTAVAARA 1947) gehalten worden ist, hat man sich zweierlei Möglichkeiten zu denken. Die Art kann entweder durch ganz Finnland oder nur im südlichsten und nördlichsten Teil des Landes verbreitet sein. Als wahrscheinliches Beispiel des ersteren möge Marasmius fulvobulbillosus Rob. Fries (Xeromphalina cauticinalis (With. ex Fr.) Kühner \& Maire) dienen. Dieser Pilz ist nach den Museumsbelegen und auch nach Angaben im Schrifttum (V. Hintikka 1957) ein südfinnischer Pilz. Nachdem er nun aber i.J. 1960 auch am Raessijoki in Utsjoki gefunden wurde, ist es schwer zu sagen, ob man es mit einer in Finnland durch die ganze Nadelwaldregion verbreitete oder von den Süd- und Nordküsten gegen das Inland vorstossende Art mit einheitlicher süd-nördlicher Verbreitung in Skandinavien zu tun hat. Da nun aber der Pilz in Südfinnland noch in Tammela (KARsten), Yläne und Lappi T.1. deutlich häufig zu finden ist und auch in Kuopio gesammelt worden ist (TUR), kommt mir die erstere Alternative wahrscheinlicher vor. In dem Falle bringen Untersuchungen in Mittel- und/oder Nordfinnland die Lösung.

Ungefähr in dieselbe Kategorie würde auch noch z.B. Tricholoma terreum fallen, die als südlich gegolten hat, aber in manchen Jahren (z.B. 1959) auf den Heideböden von Utsjoki reichlich $\mathrm{zu}$ finden ist (gleiches gilt auch
Camarophyllus bicolor, Russula foetens, Tricholoma album und Spathularia flavida). Noch kann Polyporus squamosus erwähnt werden, in Südfinnland ein Pilz der »südlichen» Laubbäume meistens in den Parken, der aber auf Salix an 3 Stellen in Utsjoki (TUR) und auch in Finnmarken (Sivertsen 1961) gesammelt worden ist. Erst später ist es möglich zu entscheiden, ob es sich hier um eine solche Kategorie der Verbreitung handelt, wie sie z.B. Arabis hirsuta und Sedum annuum unter den Phanerogamen aufweisen, die einerseits im südlichsten Finnland und anderseits im nördlichsten Lappland oder/und im norwegischen Finnmarken verbreitet sind, oder lediglich um die Forschungsgeschichte und vielleicht auch um ein taxonomisches Problem.

Es sind Auffassungen geäussert worden (z.B. LeIschner-Siska 1939), dass mit einer reichen Phanerogamenflora in vielen Vegetationstypen eine Armut der Pilzflora einhergeht, sowie dass es in den Hainen wenig Pilze gibt. Dies trifft für die jetzt untersuchten Eichenhaine nicht zu. Im Gegenteil ergibt sich z.B. in Katariinanlaakso eine positive Korrelation der Artenzahlen. Auch in Polen ist Wojewoda (1961) zu dem eindeutigen Ergebnis gekommen, dass die Makromycetenflora des Pineto-Vaccinietum myrtilli mit ihren 71 Arten viel ärmer als die des an Phanerogamen reichen Fagetum carpaticum (131 Arten) ist.

Vom Standpunkt der Verbreitung der Pilze handelt es sich offenbar um vielerlei Gruppen mit verschiedenen ökologischen Ansprüchen, die eine Korrelation mit der Eichenzone in hiesigem Sinne aufweisen. Diese Zone spiegelt bei uns einen bestimmten klimatischen Allgemeinzug wider, dessen erschöpfende Analysierung offenbar vorläufig nicht gelungen ist (vgl. jedoch Jalas 1950, 1957). Ihm folgen geographisch solche Pilze, die anscheinend in keinem Verhältnis zu einem bestimmten Pflanzenverein (Waldtyp) stehen. Gute Beispiele von solchen Pilzen mögen Amanita pantherina und A. citrina sein, denen beiden man sowohl in Nadel- als Laubwäldern, in Hainhumus und auf Sandheiden begegnen kann, sowie möglicherweise auch Gyroporus cyanescens (vgl. Stordal 1955). Eine zweite Gruppe umfasst Arten, die gewissermassen von einer bestimmten Phanerogamenart oder Pflanzengesellschaft der Eichenzone abhängig sind. Diese Korrelation kann sich 
indessen auch auf falsche Deutung zurückführen. Man kann es hier eventuell lediglich mit gleichlautenden Ansprüchen verschiedener Organismen in bezug auf die Unterlage und die mikroklimatischen Faktoren zu tun haben.

Die Laubstreu der Eiche oder irgendeiner anderen typischen Pflanze der Eichenzone bildet für manche Arten eine dermassen notwendige Lebensbedingung, dass sie wenigstens in hiesigen Verhältnissen sicher die Verbreitung des in Frage stehenden Pilzes mit bestimmt. Marasmius prasiosmus Fr. bietet wohl das klarste Beispiel eines von der Eichenlaubstreu abhängigen Pilzes. Bei diesen wie auch bei den unmittelbar von der Eiche abhängigen Mykorrhizenpilzen (z.B. Lactarius quietus, $L$. serifluus und Tricholoma lascivum) oder den Parasiten und Spezialsaprophyten dieses Baumes (z.B. Fistulina hepatica, Mycena inclinata, Daedalea quercina, Fomes robustus und Polyporus sulphureus) handelt es sich auch darum, in welchem Masse die Klimaansprüche des Pilzes und des betreffenden Baumes sich decken oder also inwieweit der Pilz seinem Wirt bis zu dessen äusserster Arealgrenze folgt. In Finnland fehlen gewisse mitteleuropäische Parasitenpilze, deren »Wirte» dagegen wohl in der hiesigen Eichenzone vorkommen. So ist hier z.B. Scleroderma aurantium in der Eichenzone häufig, aber stets ohne den auf diesem Pilz schmarotzenden Xercomus parasiticus der in Finnland überhaupt nicht gefunden worden ist, trotzdem er noch in Südschweden vorkommt (vgl. ANDERsson 1939).

Bei einigen Pilzen der Eichenzone lässt sich wenigstens in gewissem Sinne ein Biotopwechsel gegenüber Mitteleuropa feststellen. So scheinen u.a. Amanita citrina, A. pantherina (und auch A. spissa), im Süden viel stärker nadelwaldorientiert zu sein als in Finnland, wo der Schwerpunkt ihrer Reichlichkeit jedenfalls im Untersuchungsgebiet deutlich in den Hainen liegt. $\mathrm{Zu}$ derselben Gruppe wäre noch Lactarius mitissimus zu zählen. Hierbei vermittelt aber offenbar das Begriffspaar Laubwald - Nadelwald nicht das richtige Bild, wenn es gilt, die Ökologie der genannten Arten zu charakterisieren.

Das Auftreten der Eiche ist auch in Finnland einigermassen auch vom Felsgrund abhängig. Die besten Eichen-Haselhaine, denen man am Fusse der Felsen begegnet, sind gewöhnlich im Vergleich zum hiesigen
Durchschnittswaldboden einigermassen weniger sauer, oft im Anschluss an Amhibolit. An den besten Pilzstandorten von Ruissalo und Katariinanlaakso in Turku und Karpanmäki in Kaarina nähert sich die Bodenazidität (Humus) im allgemeinen dem Wert von $\mathrm{pH}$ 6. Untersucht man das Verhalten gewisser mitteleuropäischer, auch in Finnland vorkommender Pilze zum pH des Bodens, erhält man jedoch leicht die Auffassung, dass es sich offenbar gar nicht so viel um das $\mathrm{pH}$ an sich handelt, sondern um irgendeinen anderen ökologischen Faktor, der mit der Bodenazidität an verschiedenen Stellen etwas verschieden korreliert ist. Russula delica und Lactarius uvidus können nach BREZINSKY \& ZEITLMAYR (1960) als Indikatoren für Bodenkalk betrachtet werden. In Finnland besiedelt letzterer normalerweise die sehr sauren Moorränder, und auch Russula delica kann keineswegs für einen Kalkindikator gehalten werden, obwohl die Art auch zu den Pilzen der besten Haine im Untersuchungsgebiet gehört. Ebenso besitzt Inocybe geophylla Kummer, die im Verzeichnis von Brezinsky \& ZeitLMAYR gleichfalls noch erwähnt ist, in Finnland keine Bedeutung als Kalkindikator. Anderseits ist zu bemerken, dass die in Bayern als »Säureindikatoren» auftretenden Arten Amanita pantherina, A. spissa und Russula vesca in Finnland eher eine unterdurchschnittliche Azidität der Waldböden an den Tag zu legen scheinen.

Bei manchen Arten dürfte die Korrelation zwischen Auftreten der Pilze und Boden-pH recht nachdrücklich hervortreten. Die in Südwestfinnland seltene Peziza acetabulum L. ist hier in Kalksteinspalten gesammelt worden (vgl. Mäkinen 1964), und noch in Grönland konstatiert man bei der Art diesen selben Anspruch auf Alkalinität des Substrats (LANGE 1957, p. 74). Aus demselben Grunde sind die Möglichkeiten des Vorkommens von Boletus satanas Lenz in Finnland wohl höchstens auf den Bereich des Silurkalkes im südwestlichsten Schärenhof, der Regio insularis von EkLund (1934), beschränkt.

Die geringe Azidität des besten Standorts in Katariinanlaakso ( $\mathrm{pH}$ über 6) dürfte nicht nur über die diesbezüglichen Ansprüche vieler von hier genannten Phanerogamen, sondern etwas auch über die der Pilze besagen. Nach Neuhoff (1956, p. 27) können von den in Katariinanlaakso antreffbaren Pilzen Tricholoma sulphureum, Russula cyanoxantha, $R$. 
delica, R. pseudointegra, Xerocomus chrysenteron, Rhodophyllus lividus, Lactarius azonites und $L$. pyrogalus als Pilze des alkalischen bis neutralen Eichenhains betrachtet werden. Auch noch Craterellus cornucopioides Pers. wäre bei reichlichem Auftreten als Vertreter eben eines solchen Hains mit neutraler Bodenreaktion anzusehen.

Zwischen dem Auftreten vieler südlichen Phanerogamen und der Topographie des Geländes besteht hier im Grenzgebiet ihrer Verbreitung eine gewisse Korrelation, die in erster Linie als klimatisch bedingt gedeutet worden ist. Die deutlich hemeroben Grasheideflecke des südwestlichsten Finnlands bilden somit für den südwestlichen und südlich-kontinentalen Artenbestand einen geeigneten Standort, dessen Mikroklima die Mindestansprüche der in Rede stehenden Arten erfüllt. Die unmittelbare mikroklimatische Abhängigkeit der Pilzverbreitung ist bisher nicht näher geklärt. Die Häufung bestimmter, nicht gegenseitig gebundener südlicher Pilze, die u.a. in ihrer Beziehung zu der Holzart sowie zum Waldtyp verschiedene Elemente vertreten, auf eine beschränkte Fläche, wie etwa in Katariinanlaakso und weniger typisch auch an allen anderen untersuchten Punkten des Untersuchungsgebietes, deutet vor allem darauf hin, dass es sich eben um die Erfüllung der ökologischen Mindestansprüche gerade auf diesen beschränkten Flächen handelt.

Die Phanerogamen von Katariinanlaakso (die wichtigsten Arten der Grasheiden wurden eingangs auf S. 33 schon genannt) gehören dem südlichen Florenelement an (Jalas 1950; Nikoskelainen 1955; Kalela 1961). Man stellt fest, dass es ihrer hier auf einer Fläche von nur einigen Aren mindestens 14 gibt. Dadurch ist diese Grasheide wohl einzig in ihrer Art auf dem ganzen finnischen Festland.

Als ebenso einzigartig kann sie auch hinsichtlich ihrer Pilzflora betrachtet werden, wie es allein schon die Namen Gyroporus castaneus, Boletus edulis ssp. reticulatus, B. erythropus, B. luridus, Leccinum griseum, Xerocomus chrysenteron, Rhodophyllus lividus, Amanita pantherina, Russula cyanoxantha. $R$. pseudointegra, Lactarius azonites, $L$. quietus, $L$. piperatus, $L$. glaucescens, Tricholoma lascivum, T. columbetta, T. sulphureum, Craterellus crispus und Lycoperdon echinatum besagen.

Weil die Bedeutung der Fruchtkörper- bildung für die Ausbreitung und Erhaltung der Pilze in vielem noch unklar ist, kann hier die Frage nicht diskutiert werden, welches von beiden: das Gedeihen der Hyphen im Boden oder vor allem die Fruchtkörperbildung von einem bestimmten mikroklimatischen Faktor ausschlaggebend beeinflusst wird. Man weiss auf jeden Fall, dass sowohl die Entstehung als auch die Grössenausbildung des Fruchtkörpers weitgehend von der Bodentemperatur anhängig ist. Viele in Finnland vorkommende (südliche) Arten sind selbst in Mitteleuropa »kälteempfindlich» (vgl. Frieriah 1937) und infolgedessen nur in warmen Jahren antreffbar. Die Günstigkeit des Standorts spiegelt sich somit auch darin wider, wie regelmässig eine Art zu fruchten imstande ist. In dem günstigen Pilzjahr 1959 wurde im Botanischen Garten der Universität in Ruissalo Rhodophyllus lividus in verschiedenen Teilen (auch am Nordostabhang) des in der Mitte des Gartens gelegenen kleinen Eichenhügels angetroffen, sonst ist der Pilz nur am Südwestabhang zu finden gewesen.

Es ist zu bemerken, dass die Fruchtkörper der südlichen Arten an sich und auch ihre Entwicklung offenbar gar nicht kälteempfindlicher als die vieler unserer weitverbreiteten Arten sind. So findet man Lactarius serifluus in Ruissalo wohl am reichlichsten im späten Herbst, oft nach Frösten, $\mathrm{Ma}$ rasmius prasiosmus ist ein wahrhafter Oktoberpilz, dem man noch in der zweiten Hälfte dieses Monats begegnen kann, und auch Rhodophyllus lividus kann noch nach Frostperioden zu finden sein. Es möge aber festgestellt werden, dass hierzulande die Fruchtkörper vieler südlichen Arten ebenso gross und selbst grösser als in Mitteleuropa werden (siehe Rhodophyllus lividus, Oudemansiella radicata, Xerula longipes). Es kann also eine allgemeine Grössenabnahme nach der Peripherie des Vorkommens hin nicht beobachtet werden.

Alles, was wir heute von der Verbreitung der Grosspilze wissen, gründet sich ausschliesslich auf die Beobachtung der Fruchtkörper, an die mutmassliche Verbreitung des Hyphenstadiums ist nur indirekt heranzukommen. Ein vereinzeltes Beispiel: Lactarius quietus Fr. findet man an der Wurzel einer einsamstehenden verhältnismässig jungen Eiche im Nadelwald, so z.B. in Turku Metsäkylä und in Nousiainen, Linnamäki. Als 
Arbeitshypothese kann aber angenommen werden, dass es Arten, deren Fruchtkörperbildung von der Eiche abhängig ist, im Bereich der Eichenzone vielleicht in viel weiterem Ausmass als lediglich unter den Eichen selbst gibt, während sie ausserhalb der Zone nicht vorkommen.

Ähnliches kann man überhaupt in den Grenzgebieten der Artverbreitung finden. So gibt es z.B. in Utsjoki, das schon ausserhalb des Gebietes der zusammenhängenden Kiefernwälder liegt, vereinzelte Kiefern hier und da durch das ganze (weite) Kirchspiel. Gewöhnlich handelt es sich um junge Bäume aus den 1930er Jahren oder selbst noch aus späterer
Zeit, und die Entfernung vom Wald kann mehrere Kilometer betragen. Dennoch kann man unter diesen spontan entstandenen Kieferchen Suillus luteus finden, der in seiner Fruchtkörperbildung ausnahmslos von der Kiefer abhängig ist. Es ist möglich, dass dieser Pilz in Lappland weit und breit ausserhalb des Areals der Kiefer vorkommt, aber erst durch eine irgendwann zufällig aufkeimende Kiefer zur Fruchtkörperbildung stimuliert wird. Die Lösung jener geomykologischen Fragen setzt eingehende Untersuchungen in den Grenzgebieten und Pflanzversuche voraus, um zu ermitteln, wo der Boden Hyphen einer bestimmten Pilzart enthält, wo wieder nicht. Diese Ermittlungen könnten dann einerseits mit klimatischen und anderseits z.B. mit waldgeschichtlichen Klarstellungen verknüpft werden.

\section{LITERATUR}

Andersson, O., 1939: Notiser om intressanta storsvampar 5. - Bot. Notiser 1939, 819-825.

- 1940: Notiser om intressanta storsvampar 7. - Ibid. 1940, 406-412.

- 1941: Notiser om intressanta storsvampar 10. - Ibid. 1941, 393 - 403.

- 1943: Studier över Boletaceer. - Bot. Notiser 1943, 185-202.

- 1956: Three rare or little known Bolets in Sweden. - Friesia 5, 180-189.

Andersson, S. O., 1958: Svampfynd från sydvästra Sverige. - Friesia 6, 40-45.

Auer, A., 1937: Muhkurin kasvisto. - Silva Fennica $41,1-36$.

BJøRNEKAER, K., 1938: Undersøgelser over nogle danske poresvampes biologi med saerligt hensyn till deres sporefaeldning. - Friesia $2 ; 2,1-24$.

Blytr, A., 1905: Norges Hymenomyceter. - Vidensk. Selsk. Skrifter I. Math.-naturv. KI. 1904, 6. Christiania.

Boнus, M. and M. BaBos., 1960: Coenology of terricolous macroscopic fungi of deciduous forests. Contributions to our knowledge of their behaviour in Hungary. - Bot. Jahrb. $80: 1,1-100$.

Bresadola, G., 1927-1933: Iconographia Mycologica.

Bresinsky, A. \& L., Zeitlmayr, 1960: Die Pilze "Kapuziner-Hölzls» und des "Nymphenburger Schlossparkes». - Ber. Bayer. Ges. $33,11-19$.

Buar, R., 1952: Die Blätterpilze des nordwestlichen Sachsens. - Leipzig.

Bughwald, N. F. \& H. A. Jørgensen, 1948: Er der nogen sammenhaeng mellem klimaet og forrekomsten af frugtlegemer hos Polyporus dryadeus (Pers.) Fr.? Friesia 3: 5, 381-387,

BärLUND, Ulla, 1948: Några svampfynd från Hailuoto-Karlö och Uleåborg. - Memor. Soc. F. Fl. Fenn. 24, 55-56.

Bülow, K., 1956: Ornamentation of spores of Russula laurocerasi Melzer and Russula Bot. Notiser 1889, 131-142.
BüLow, w., 1889: Bidrag till Skånes svampflora. Bot. Notiser 1889, 131-142.

Coker, W. Ch. \& A. H. Benss, 1943: The Boletaceae of North Carolina. - Univ. of North Carolina Press.

Eckblad, F.-E., 1955: The Gasteromycetes of Norway. - Nytt Mag. for Botanikk 4, 19-85.

- 1960: Notes on some larger Basidiomycetes and their distribution in Norway. - Ibid. 8, 179-188.

EKLUND, O., 1934: Eine pflanzengeographische Neueinteilung Südwest-Finnlands. -- Memor. Soc. F. Fl. Fenn. 10, 272-288.

-- 1943 a: Boletus satanas Lenz., für Finnland neu. - Ibid. 18, 2.

- 1943 b: Zur Pilzflora des Schärenarchipels SW-Finnlands. - Ibid. 18, 2-20.

- 1944: Weitere Beiträge zur Pilzflora des Schärenarchipels SW-Finnlands. - Ibid. 19, $212-216$.

Ferdinandsen, G. \& O. Winge, 1943: Mykologisk ekskursionsflora. - København.

Frey, R., 1944: Tvenne vid lärkträdet bundna hattsvampar. - Memor. Soc. F. Fl. Fenn. 19, 8-9.

- 1944 a: Några anteckningar om basidsvampfloran på Åland. - Ibid. 19, 9-16.

Friedrich, K., 1936: Zur õkologie der höheren Pilze. - Ber. d. Dtsch. Bot. Ges. 54, 386-393.

- 1937: Zur õkologie der höheren Pilze. II. Ibid. 55, 419- 426 .

FrIes, E., 1849: Summa vegetabilium Scandinaviae. Uppsala. Sectio posterior.

FrIES, T. G. E., 1921: Sveriges Gasteromyceter. Arkiv för Bot. 17:9,1-62.

HaAs, H., 1933: Die bodenbewohnenden Grosspilze in den Waldformationen einiger Gebiete von Württenberg. - Bei h.z. Bot. Centralblatt 50, $35-134$.

Hagkman, W., 1946: Helvella crispa Scop. funnen i Tvärminne (N.) - Memor. Soc. F. Fl. Fenn. $22,2-3$.

HrNtikka, E. V. K., 1957: Über die finnischen Arten und Varieteten der Gattung Xer- 
omphalina Kühner \& Maire. - Karstenia $4,5-9$.

Hrntikka, T., J., 1931 : Sienimaantieteellisestä (mykogeograafisesta) tutkimuksesta varsinkin Suomessa, 49 S. Helsinki.

- 1933: Úber die Verbreitung von Phallus impudicus L. in Finnland.- Friesia 1, 88-90.

- 1950: P. A. Karstenin elämäntyöstä. - Karstenia $4,5-9$.

Holmberg, U., 1961: Intressanta svampar i Kristianstadstrakten. - Bot. Notiser, 114, 241244.

Hult, R., 1896: Vedväxternas utbredning i Finland. - Geogr. För. Finl. Vetensk. Medd. 1-63.

Hultén, E., 1950: Atlas över växternas utbredning i norden. - Stockholm.

Høeg, O. A., 1944: Om Scleroderma aurantium Pers. og Boletus parasiticus Fr. i Norge. Blyttia 2, 65-70.

InGELström, E., 1940: Svampflora. - Stockholm.

JAHnsson, LEA, 1929: Ruissalon saaren tammialueiden aluskasvillisuudesta. - Turun Ylioppilas $1,170-204$.

Jalas, J., 1950: Zur Kausalanalyse der Verbreitung einiger nordischen Os- und Sandpflanzen. Annales Bot. Soc. 》Vanamo» 24: 1.

- 1955: Hemerobe und hemerochore Pflanzenarten, ein terminologischer Reformversuch. - Acta Soc. F. Fl. Fenn. 72;11.

- 1957: Die geobotanische Nordostgrenze der sog. Eichenzone Südwestfinnlands. - Ann. Bot. Soc. »Vanamo» 29: 5, 1-32.

Jørstad, I., 1948: Storsopper på fruktträd og baerbuskar i Norge. - Friesia 3, 352-376.

KAlelA, A., 1961: Suomen eteläinen kasvistoaines. - Oma Maa 9, 426-450.

Kallio, P., 1953: Lakkisieniä Ruissalon luonnonsuojelualueelta kuivuussyksynä 1951. - Karstenia 2, 48-49.

- 1960: Utsjoen sienistä. - Luonnon Tutkija $64,38-45$.

KaRLVALL, F., 1949: Anteckningar om skivsvampar i Västsverige. - Bot. Notiser 1949, 403-413.

Karste n, P. A., 1859 : Sydvestra Finlands Polyporeer. - Akad. afhandl. Helsinki.

- 1867: Enumeratio Fungorum et Myxomycetum in Lapponia orientali aestate 1861 lectorum. - Not. Sällsk. F. Fl. Fenn. förhandl. $7,193-224$.

- 1868: Agaricini in paroecia Tammela crescentes. - Ibid. 9, 333-347.

- 1876: Mycologia Fennica III. Basidiomycetes. - Bidr. till känned. Finl. Natur och Folk 25 .

- 1879: Rysslands, Finlands och den Skandinaviska Halföns hattsvampar. - Ibid. 32.

- 1881: Hymenomycetes Fennici. - Acta Soc. F. Fl. Fenn. 2:1, 1-40.

- 1883: Symbolae ad Mycologicam Fennicam IX-XI. - Medd. Soc. F. Fl. Fenn. 9, 3971.

- 1889: Kritisk öfversikt af Finlands basidsvampar. - Bidr. Känned. af Finl. Natur och Folk. 48.

Kreisel, H., 1961: Die phytopathogenen Grosspilze Deutschlands. - Jena.

KÜHneR, R. \& H. Romagnesi, 1953: Flore analytique des champignons supérieurs. - Paris.

LaIne, U., 1955: Haisusienen (Phallus impudicus
(L.) Pers. viimeaikaisesta esiintymisestä Varsinais-Suomen pohjoisosissa. - Luonnon Tutkija $59,8-11$.

- 1960: Perniön pitäjän putkilokasviston pääpiirteet. - Turun Ylioppilas 7, 9-81.

LANge, J. E., 1935-1940: Flora Agaricina Danica I-V. - Copenhagen.

LANGe, M., 1946: Mykologiske indtryk fra Lapland. - Friesia 3, 161-170.

- 1957: Macromycetes III, ecological and plant geographical studies. - Meddel. Grönland 148,2

LAURILA, M., 1939: Basidiomycetes novi rarioresque in Fennia collecti. - Ann. Bot. Soc. „Vanamo» $10: 4$.

Leisghner-Siska, Eifride, 1939: Zur Soziologie und Ókologie der höheren Pilze. - Beih. zum Bot. Centralblatt 59, Abt. B, 359-429.

Lind, J., 1913: Danish fungi as represented in the herbarium of. E. Rostrup. - Copenhagen 1913.

Lindgren, L., 1954: Ruissalon putkilokasvisto. Turun Ylioppilas 3, 145-181.

Lobanow, N. N., 1960: Mykotrophie der Holzpflanzen. - Berlin.

Lundell, S., 1932: Bidrag till Uppsalatraktens Hymenomycetflora I. Vårdsätra naturpark. - K. Sv. Vetensk. Akad. Skr. i Naturskyddsärenden $22,1-33$.

Lundell, S. \& J. A. NAnnfeldt, 1934-1961: Fungi Exsiccati Suecici, praesertim Upsalienses. - Uppsala.

Luther, H., 1947: Beobachtungen über Phallus impudicus (L.) Pers. in Finnland. - Memor. Soc. F. Fl. Fenn. 23, 45-59.

Malmström, N., 1933: Om några fynd av sällsyntare buksvampar i Finnland. - Memor. Soc. F. Fl. Fenn. 9, 68-69.

- 1934: Senhöstens hattsvampar i frost och blida. - Ibid. 9, 69-91.

- 1943 a : Boletus luridus Schaeff. från Åland. Ibid. $18,68-70$.

- 1943 a: Boletus pulverulentus Opat. och B. castaneus, nya för Finland. — Ibid. 18, 7073.

- 1943 b: Fynd av Boletus cyanescens Bull. och Gyrodon lividus Sacc. ex Bull. - Ibid. 18, $73-77$.

- 1943 c: Agaricider, för landet nya o.a. från södra Finland. - Ibid. 18, 77-83.

Michael, E. \& B. Hennig, 1958-1960: Handbuch für Pilzfreunde, I und II. - Jena.

MÄkinen, Y., 1964: im Druck (Karstenia VI).

Mäkinen, Y. \& Nirna Tarén, 1960: Piikkiön Harvaluodon ja Jauhosaaren kasvistosta. - Turun Ylioppilas 7, 93-128.

Möller, F. H., 1946: Sjaeldenere svampefund fra Randersegnen i 1945. - Friesia3: 3, $171-173$

- 1956: Two little known Danish Mushrooms. - Friesia 5, 312-316.

NANNFELDT, J. A., 1959: The mycofloristical exploration of Scandinavia, especially Sweden.

- Friesia 6, 167-213.

- 1943: The Geoglossaceae of Sweden. - Arkiv f. Bot. 30 A4, $1-67$.

- 1952: Fungi. - In: Vilda växter i Norden, 190-333. Stockholm.

Nathorst-Windahl, T., 1949: Amärkningvärda 
fynd av hymenomyceter i Bohuslän, Västergötland och Dalsland. - Botaniska Notiser 1949, 201--212.

- 1956: Zur Verbreitung der Agaricales in den Wäldern des südwestlichen Schwedens. Friesia 5, 319-324.

Neuhoff,W., 1956: Die Milchlinge (Lactarii). Die Pilze Mitteleuropas Bd II b.

Nikoskelainen, Ritva, 1955: Katariinanlaakson ja sen lähiympäristön putkilokasvisto. - Turun Ylioppilas 4, 229-248.

Norrlin, J. E., 1910: Kasvisto ja Kasvillisuus. Suomen Kartasto.

Nyberg, W., 1934: Några i Borgå och dess omnejd funna sällsyntare svamparter. - Memor. Soc. F. Fl. Fenn. 10, 20-23.

- 1944: Fynd av några mera sällsynta svamparter. - Ibid. 19, 16-18.

- 1946: Iakttagelser år 1945 om svampfloran i Grankulla och på några andra orter i Nyland, - Ibid. 22, 46-52.

- 1950: Två sällsynta svampar, Armillaria imperialis Fr. och Craterellus clavatus (Pers.) Fr.

Overholts, L. O., 19.53: The Polyporaceae of the United States, Alaska and Canada. - Ann. Arbor. Univ. Michigan Press. London.

Palmgren, R., 1920: Tryffelimäinen sieni, Sclerodermá vulgaris L., Suomessa. - Luonnon Ystävä 1920, 105-106.

PArker-Rhodes, A. F., 1955: The Basidiomycetes of Skogholm Island XII. Correlations with the chief plant associations. - New Phytol. 54, $259-273$.

Parmasto, E., 1956: Tähtsamate Eesti NSV torikuliste määraja. - Juhend alamate taimede Uurimiseks IV, Abiks loodusevaatelijale Nr. 26.

Pearson, A. A., 1950: British Boleti. - The Naturalist.

- 1950 b: The genus Lactarius. - Ibid.

- $1950 \mathrm{c}$ : The genus Russula. - Ibid.

Pilát, A., 1954: Pilze (mit farbigen Tafeln nach Aquarellen von Ušák). Amsterdam.

Pilát, A. \& Nannfeldt, J. A., 1954: Notulae ad cognitionem Hymenomycetum Lapponiae Tornensis (Sueciae). - Friesia 5, 6-38.

PIR K, W., 1944: Zur Soziologie der Pilze in QuercetoCarpinetums. - Rundbrief d. Zentralstelle für Vegetationskartierung. Stolzenau/Weser.

Ramsвоттом, J., 19.54: Mushrooms \& Toadstools. A study of the activities of fungi. - The Naturalist. Lıondon.

Rautavaara, T., 1947: Suomen sienisato. Tutkimuksia sen laadusta, suuruudesta, käytöstä ja arvosta. Porvoo-Helsinki.

Ricken, A., 1915: Die Blätterpilze (Agaricaceae). Leipzig.

Romell, L., 1911: Hymenomycetes of Lappland. Ark. för Bot. 11:3.

Schaeffer, J., 1952: Russula-Monographie. - Bad Heilbrunn.

von Sahulmann, O., 1960: Zur Kenntnis der Basisiomyceten Finnlands. - Karstenia 5, 5-99.
Singer, R., 1949: The Agaricales in modern taxonomy. - Lilloa, Revista de Botanica 22.

- 1954: The cryptogamic flora of the Arctic, Fungi, - Bot. Rev., 20, 451-462.

- 1962: The Agaricales in modern taxonomy. 2nd edition.

Sivertsen, S., 1961: Funn av Polyporus squamosus og P. melanopus i det nordligaste Norge. Friesia 6, 381-382.

Slipp, A. \& W. H. Snell, 1944: Taxonomic-ecologic studies of the Boletaceae in northern Idaho and adjacent Washington. - Lloydia $7: 1,1-66$.

Stenlid, G., 1947: Några anteckningar om Ålands svampflora. - Memor. Soc. F. Fl. Fenn. $23,82-90$.

Stordal, J., 1952: Larger Fungi from Hallingdal, southern Norway. - Blyttia 10, 114-120.

- 1953: Notater om storsopp i Våle, Vestfold. - Friesia IV, 267-295.

- 1955: Utbredelsen av noen Boletus-arter i Norge. - Blyttia 1955, 71-78.

- 1956: Distribution of Tricholoma gambosum (Fr.) Gill. and Boletus granulatus L. ex Fr. in Norway. - Friesia V, 409-416.

Størmer, P., 1931: Polyporus umbellatus (Pers.) Fr. og Boletus appendiculatus Schaeff. funnet i Norge. - Nyt Mag f. Naturvidensk., Oslo.

Svensson, H., 1940: Anteckningar om Karlstadstraktens skivlingflora. I. - Medd. fr. Värml. Natursk. Förening 13, 1-40.

- Anteckningar om Karlstadstraktens skivlingflora. II. - Ibid. 15, 1-28.

TAPANA, R., 1958: Tammi (Quercus robur L.) Lounais-Suomen mantereella. - Turun Ylioppilas 5, 29-66.

Thesleff, A., 1895: Om förekomsten af Phallus impudicus i Finland. - Medd. Soc. F. Fl. Fenn. 21, 85-86.

- 1919: Studier öfver basidsvampfloran i sydöstra Finland med hänsyn till dess sammansättning, fysiognomi, fenologi och ekologi. Bidrag till känned. om Finlands natur och folk 79: 1 .

Tuомгкоsкi, R., 1943: Sortavalan seudun sienimaailmaa. - Luonnon Ystävä 47, 178-179.

- 1950: Meikäläisistä Krombholzia-alasuvun tateista. - Luonnon Tutkija 1950:4 115-120.

- 1953: Die Lactarius-Arten Finnlands. Karstenia 2, 9-25.

- 1959: Sienet värikuvina. - Porvoo-Helsinki.

- 1961: Havaintoja Inarin metsien lakkisienistä. - Sienitietoja 4, 2-4.

Veselý, R., 1934: Amanita - In: Atlas des chamgipnons de l'Europe von Ch. Kavina und A. Pilát. Praha.

Witkowskr, N., 1934: Uber die höheren Pilze der Umgegend von Tartu. - Veröffentl. Phytopathol. Versuchsstation d. Univ. Tartu.

Wojedowa, W., 1961: Observations mycologiques des individus du Fagetum carpaticum et du Pineto-Vaccinietum myrtillii dans les environs de Rabzyn. - Fragmenta floristica et geobotanica Inst. Bot. Akad. Sci. Poloniae publ. Ann. 6: 4, 725-768. 